NBER WORKING PAPER SERIES

\title{
THE EFFECT OF EDUCATION ON ADULT HEALTH AND MORTALITY: EVIDENCE FROM BRITAIN
}

\author{
Damon Clark \\ Heather Royer \\ Working Paper 16013 \\ http://www.nber.org/papers/w16013
}

\author{
NATIONAL BUREAU OF ECONOMIC RESEARCH \\ 1050 Massachusetts Avenue \\ Cambridge, MA 02138
}

May 2010

For useful comments, we thank Josh Angrist, Kelly Bedard, David Card, Olivier Deschenes, John DiNardo, Michael Grossman, Mireille Jacobson, Nico Lacetera, Justin McCrary, Jonah Rockoff, Justin Sydnor, Ty Wilde and numerous seminar participants. Paul Clark, Megan Henderson and Matt Masten provided excellent research assistance. The views expressed herein are those of the authors and do not necessarily reflect the views of the National Bureau of Economic Research.

NBER working papers are circulated for discussion and comment purposes. They have not been peerreviewed or been subject to the review by the NBER Board of Directors that accompanies official NBER publications.

(C) 2010 by Damon Clark and Heather Royer. All rights reserved. Short sections of text, not to exceed two paragraphs, may be quoted without explicit permission provided that full credit, including $\odot$ notice, is given to the source. 
The Effect of Education on Adult Health and Mortality: Evidence from Britain

Damon Clark and Heather Royer

NBER Working Paper No. 16013

May 2010

JEL No. I10,I20,J10

\begin{abstract}
$\underline{\text { ABSTRACT }}$
There is a strong, positive and well-documented correlation between education and health outcomes. There is much less evidence on the extent to which this correlation reflects the causal effect of education on health - the parameter of interest for policy. In this paper we attempt to overcome the difficulties associated with estimating the causal effect of education on health. Our approach exploits two changes to British compulsory schooling laws that generated sharp differences in educational attainment among individuals born just months apart. Using regression discontinuity methods, we confirm that the cohorts just affected by these changes completed significantly more education than slightly older cohorts subject to the old laws. However, we find little evidence that this additional education improved health outcomes or changed health behaviors. We argue that it is hard to attribute these findings to the content of the additional education or the wider circumstances that the affected cohorts faced (e.g., universal health insurance). As such, our results suggest caution as to the likely health returns to educational interventions focused on increasing educational attainment among those at risk of dropping out of high school, a target of recent health policy efforts.
\end{abstract}

\author{
Damon Clark \\ Industrial Relations Section \\ Princeton University \\ Firestone Library A-16-J-2 \\ Princeton, NJ 08544 \\ and NBER \\ damonc@princeton.edu \\ Heather Royer \\ Department of Economics \\ University of California, Santa Barbara \\ 2127 North Hall \\ Santa Barbara, CA 93106 \\ and NBER \\ royer@econ.ucsb.edu
}




\section{Introduction}

There is a well-established yet striking correlation between health and education. ${ }^{1}$ Across sexes, races and time, more-educated people enjoy better health than less-educated people. ${ }^{2}$ Even at lower levels of education, these correlations are strong. For example, in the US, the fraction of adults with 11 years of education reporting fair or poor health in 2006 was 25.6 percent. Among those with exactly a high school degree, the analogous figure was 14.4 percent. $^{3}$ As shown by Banks et al. (2006) and Cutler \& Lleras-Muney (2007), similar patterns can be found in the UK. Not surprisingly, these statistics inspire strong views about the relationship between education and health. Typical of these is Michael Grossman's claim that "years of formal schooling completed is the most important correlate of good health" (Grossman, 2005, pg. 32).

From an education perspective, the strength of this relationship suggests that health could be one of the most important sources of non-monetary returns to education. ${ }^{4}$ As such, traditional cost-benefit analyses that ignore health could understate the attractiveness of educational investments. From a health perspective, the relationship suggests that education could be a powerful tool for improving health, especially given the ambiguity in the returns to additional health care spending (Weinstein \& Skinner, 2010). Health policy-makers have taken note of this correlation. For example, the U.S. national health objectives include targets for high school completion rates (Healthy People 2010) and the British government has cited potential health benefits as a reason why the compulsory schooling age might be raised to 18 (Seager, 2009). These policies will, however, only be effective if education causes individuals to be healthier. Yet the causal nature of the education-health relationship is not well-established, particularly in view of the strong associations between education and other characteristics such as ability (Griliches, 1977) and discount rates (Fuchs, 1982). As such, the causal effect of education on health may be smaller than the partial correlation between education and health.

Quasi-experiments represent a promising approach to identifying the causal effects of education

\footnotetext{
${ }^{1}$ See Adams et al. (2003) and references cited therein for a good summary of this literature.

${ }^{2}$ The correlational studies look at many different dimensions of the health-education gradient - over time (Pappas et al., 1993), over the life cycle (Beckett, 2000; Lynch, 2003), across sexes (Christenson \& Johnson, 1995; McDonough et al., 1999), and across races (Williams \& Collins, 1995). The first seminal study of this relationship was that of Kitagawa \& Hauser (1968).

${ }^{3}$ We base these calculations on data from the 2006 National Health Interview Survey.

${ }^{4}$ See Oreopoulos \& Salvanes (2009) for further discussion of this point.
} 
on health. A strand of the recent education-health literature employs this approach. As summarized by Cutler \& Lleras-Muney (2006) and Grossman (2004), the consensus from this quasiexperimental literature is that education improves health. ${ }^{5}$ Among these studies, Lleras-Muney (2005) is prominent. She uses instrumental variables methods to exploit state-level changes in compulsory schooling policies and child labor laws across the United States during the first half of the 20th century. Her results suggest that the mortality effects of education are large. She estimates that an extra year of schooling reduces 10-year mortality rates (i.e., the probability of dying between successive decennial censuses) by over 30 percent. ${ }^{6}$ Yet these policy changes affected cohorts for whom educational attainment was already rising and mortality was already falling. This implies that the validity of these estimates depends on the correct specification of these concurrent trends. Mazumder (2007) shows that estimated education impacts are highly sensitive to the specification of these trends. A regression discontinuity design could, potentially, mitigate these concerns by exploiting sharp changes in educational attainment. Lleras-Muney (2005) supplements her main analysis with such an approach but acknowledges that the samples are too small to draw firm conclusions. Albouy \& Lequien (2009) use regression discontinuity methods to examine the mortality effects of two compulsory schooling changes in France, but their analysis is hampered by small sample sizes and the imprecision of the "first stage" estimates falling into the realm of weak instruments.

This paper presents new evidence on the education-health relationship using a 1947 change and a 1972 change to British compulsory school laws. The 1947 change meant that children born before April 1, 1933 (who turned 14 before 1 April 1947) could leave school when they turned 14, whereas children born after this date could not leave until they turned 15. The 1972 change extended the compulsory schooling age further: children born after September 1, 1957 could not leave until they turned 16.

There are two main reasons why the changes to British compulsory schooling laws can provide valuable new evidence on the relationship between education and health. First, as stressed by Oreopoulos (2006), since many students in Britain leave school at the earliest opportunity, these

\footnotetext{
${ }^{5}$ These papers include Adams (2002); Arendt (2005); Arkes (2003); Berger \& Leigh (1989); Deschenes (2009); de Walque (2007); Grimard \& Parent (2007); Kenkel et al. (2006); Lleras-Muney (2005).

${ }^{6}$ Lleras-Muney (2005) calculates mortality rates using population counts from the 1960-1980 Censuses of cohorts born between 1901 and 1925. Her main specifications imply that an extra year of education reduces 10-year mortality rates between 3 and 4 percentage points off of a mean base mortality rate of 10 percent.
} 
changes affected a large portion of the population, particularly in comparison to U.S. compulsory school law changes. The first change in Britain kept around one half of the affected cohorts in school for an extra year; the second change kept around one quarter of the affected cohorts in school for an extra year. In comparison, the U.S. policy changes affected roughly 5 percent of the relevant cohort (Lleras-Muney, 2002; Goldin \& Katz, 2009). Estimates based on these British law changes are, therefore, likely to generate estimates closer to an average treatment effect (Oreopoulos, 2006). Second, because these law changes induced such sharp changes in educational attainment, regression discontinuity methods can pinpoint the effects of education on health. These methods rest on a relatively mild assumption: that individuals' proximate in date of birth would otherwise have had similar health outcomes. This assumption seems plausible and, furthermore, is testable, at least in terms of observable characteristics.

Although this is not the first paper to use regression discontinuity methods to assess the health impacts of these changes - Oreopoulos (2006) supplemented his study of the earnings impacts of the 1947 change with an analysis of their impact on self-reported health - we extend the existing research in several ways. First, we assess the mortality impacts of these compulsory schooling changes, as well as their impacts on self-reported health, weight and blood pressure, and on health behaviors such as smoking, drinking and exercise. Second, we assess the impacts of both the 1947 and 1972 changes. Our use of multiple outcomes and both school leaving changes ensures that our estimates are not particular to one outcome at one point in time. Third, we assess the impacts of these changes using data at the month-of-birth level; Oreopoulos (2006) uses year-of-birth comparisons. Since the compulsory schooling changes were introduced mid-year (April 1st 1947 and September 1st 1972), this assigns the appropriate treatment to each cohort and ensures that our estimates are based on the weakest possible identification assumptions - a comparison of cohorts born a month apart. ${ }^{7}$ Although estimates of the earnings impacts of these changes appear invariant to whether the analysis is done at the year- or month-of-birth level, we find that for some health outcomes, year-of-birth contrasts could yield quite misleading estimates.

\footnotetext{
${ }^{7}$ Since we began work on this project, Jurges et al. (2009) have used month-of-birth contrasts to estimate the impacts of the 1947 and 1972 compulsory schooling changes on self-related health and two biomarkers (blood fibrinogen and C-reactive protein levels). Consistent with our estimates of the impacts of these changes on other outcomes available from the HSE nurse visits (e.g., blood pressure), they find no evidence for causal impacts on these outcomes. They find some evidence for a causal effect on women's self-rated health, although these estimates are imprecise. In one part of our analysis, we use census data based on much larger samples to show that the compulsory schooling changes had very small effects on the self-reported health of both men and women.
} 
Our analysis confirms that these compulsory school law changes led to sharp increases in completed years of education. We also confirm that the 1947 change increased the earnings of affected men (estimates for women are imprecise, as are estimates of the earnings impacts of the 1972 change). Despite these effects on education and earnings, we estimate that the 1947 change had no significant impact on mortality between the ages of 45 and 69 and we can rule out reduced-form mortality reductions larger than 0.08 percentage points (off a base of 18.4\%). We estimate that the 1972 change had only small effects on mortality between the ages 20 and 44 and we can rule out reducedform mortality reductions larger than 0.34 percentage points (off a base of $2.4 \%$ ). We also estimate that both changes had, at best, small impacts on a wide range of health outcomes and health behaviors. These findings contrast with the positive effects on self-reported health found by Oreopoulos (2006). Our results also contrast with Silles (2009), who uses both compulsory schooling changes in an instrumental variables approach to understand the effects of schooling on self-reported health.

There are no obvious explanations for the small health effects that we find. It is hard to attribute them to the presence of universal health insurance in Britain, since there are pronounced socioeconomic differences in both access to care and quality of care in Britain (the Black Report (of Health \& Security, 1980), the Whitehead Report (Whitehead, 1987), and the Acheson Report (Acheson et al., 1998)). It is hard to attribute them to the quality of the additional years of education induced by these changes, since for men at least, the 1947 change has a statistically significant impact on earnings. It is hard to attribute them to the wider circumstances facing cohorts affected by these compulsory schooling changes. The 1947 change followed a period of rapid social change (e.g., the Great Depression and Second World War) but the 1972 change did not. One could argue that these changes did not improve health because they did not affect the teenage peer group of affected cohorts, but they should have changed their adult peer groups via their impacts on labor market outcomes.

The alternative explanation is that these types of education intervention have a small causal impact on health, one that our regression discontinuity design is uniquely able to isolate. This suggests that despite other benefits (Oreopoulos \& Salvanes, 2009), these types of education policies may be an ineffective means of achieving health goals. For the US, this implies that the educational objectives of Healthy People 2010, which include a high school completion goal of 90 percent, may be less effective than hoped. For England and Wales, this implies that plans to increase further the compulsory school leaving age in England and Wales may not have the health benefits that have 
been claimed for them.

\section{The Relationship Between Education and Health}

In this section we discuss the mechanisms that might generate a causal relationship between education and health. This sets the scene for our empirical analysis and informs the discussion of our estimates. These mechanisms can be categorized into the direct and indirect effects of education on health. Note that we restrict attention to the relationship between education and own health. There is a large related literature on the impact of education on infant health (e.g., Currie \& Moretti (2003); McCrary \& Royer (2006)), but that is not the focus of this paper.

Education might have a direct effect on health and health behaviors via its influence on productive and allocative efficiency (Grossman, 2005). That is, education may impart direct knowledge about health and health behaviors, thereby shifting the health production function. In addition, education could change the allocation of health inputs.

The proposed indirect effects are broad. The most frequently-mentioned is the effect of education on labor market opportunities - higher rates of employment and increased earnings (Card, 1999). The labor market returns could influence health by increasing the affordability of healthimproving goods (e.g., gym membership), by increasing access to medical care (via increased income or employer-based health insurance) or by reducing income volatility and hence stress. There are many other indirect mechanisms through which the education-health link could run. For example, more-educated people could work in safer environments (Cutler \& Lleras-Muney, 2006), they could be more patient and hence more likely to engage in healthier behaviors (Fuchs, 1982; Becker \& Mulligan, 1997), they could have a higher rank in society (Rose \& Marmot, 1981) or they could be exposed to healthier peers (Duncan et al., 2005; Gaviria \& Raphael, 2001; Powell et al., 2005; Trogdon et al., 2008). Note that empirical evidence distinguishing the relative importance of these mechanisms is limited, due partly to a lack of data and partly to the identification problems associated with estimating the causal effect of education on these various mechanisms. ${ }^{8}$

\footnotetext{
${ }^{8}$ Using US data, Cutler \& Lleras-Muney (2006) provide a thorough analysis of the cross-sectional relationship between education, health and these intervening mechanisms. Although they acknowledge that it is hard to draw firm conclusions, they speculate that efficiency effects are especially important, perhaps even more important than income effects. In support of that conclusion, Lleras-Muney (2005) estimates a strong relationship between education and mortality even after controlling for income. In an analysis of British data, Cutler \& Lleras-Muney (2007) find that the British gradient weakens (by between 9 and 35 percent) when cognitive ability is controlled and when measures of social integration are controlled (by around 10 percent). To the extent that there exists a causal relationship between education and health in Britain, this suggests that some of it might run through cognitive ability and social integration.
} 
This discussion has three important implications for quasi-experimental studies of the relationship between education and health. First, since the health effects of education might operate through several channels (e.g., effects on tastes versus effects on earnings), a quasi-experimental manipulation of education might affect health even if it does not affect earnings. Second, since the health effects of these channels may be different, different sources of education variation (e.g., variation generated by compulsory schooling laws versus variation generated by college-related policies) could impact different channels and thus, have different health effects. Third, since the health effects of these channels could be both positive or negative, a zero effect of education on health could reflect positive effects operating through some channels and negative effects operating through others. A channel through which education might have negative effects on health is income. That is because education is known to increase income and because, as found by Snyder \& Evans (2006), income might have a negative effect on mortality.

With these implications in mind, we view the quasi-experimental variation exploited in our study as particularly informative. First, since we identify the effects of two compulsory schooling changes, and since these changes affected a large share of the population, our estimates might be a useful guide to the effects of future policy interventions of this type. Second, because we can examine the effects of this variation through several channels (e.g., health behaviors), we can, for example, assess whether the net impacts of education reflect positive effects operating through some channels and negative effects operating through others. This contrasts with the prior literature, which tends to focus on a limited set of outcomes.

\section{Compulsory Schooling in Britain}

The laws governing the length of compulsory education in Britain are national. This is an important contrast to U.S. compulsory school laws, which are state-regulated. The British compulsory schooling laws specify the maximum age by which children must start school and the minimum age at which children can leave school. The maximum age by which children must start school is currently five. ${ }^{9}$ We focus on variation in the minimum age at which children can leave school. We study a 1947 change that increased the compulsory school leaving age from fourteen to fifteen

\footnotetext{
${ }^{9}$ As discussed by Woodhead (1989), there has been a recent trend for students to start school before five, with practice varying across local authorities. Crawford et al. (2007) provide a thorough analysis of the impacts of British school start policies.
} 
and a 1972 change that increased it from fifteen to sixteen. The first of these changes meant that students could not leave school until part way through grade nine. The second meant they could not leave school until part way through grade ten.

Both the 1947 and 1972 changes were the products of long political campaigns. Under the slogan of "Secondary Education for All" and on the grounds that fourteen year olds were too young to work, various groups campaigned for the change from 14 to 15 throughout the 1920s and 1930s. Most commentators agree that the law would have been changed in the 1930s had war not broken out (Timmins, 1996). As the war drew to a close, the 1944 Education Act was passed. This Act raised the minimum school leaving age from 14 to 15 and a Ministerial order later in 1944 specified that it would be raised on 1 April 1947. This gave school districts over two years to prepare for the change. The 1944 Act also gave the Minister of Education the power to raise the age to 16, when conditions allowed. The Minister did this in March 1972 (Statutory Instrument No. 444) and the age was raised to 16 on 1 September 1972. Some opposed the 1947 change on the grounds that it would compromise the war recovery effort by diverting resources to schools and decreasing the supply of juvenile labor. Supporters countered that this would be offset by the higher quality of labor supplied. ${ }^{10}$ The 1972 change was less controversial.

Figure 1 illustrates the impacts of these changes in the context of the wider trends in educational attainment in Britain. ${ }^{11}$ This figure shows the fraction of men with completed years of education in each of four categories: nine years or less, ten years or less, eleven years or less and no university degree. ${ }^{12}$ This figure presents data at the quarter-of-birth level using Health Survey of England data, described in more detail below. The 1947 change reduced the fraction that completed nine years or less by roughly one half; the 1972 change decreased the fraction that completed ten years by roughly one quarter. As shown below, finer month-of-birth comparisons and regression-based analyses point to similar conclusions.

In some respects, the two changes were similar. Both were secured by an extensive program of school building and the key elements of the school system did not change between 1947 and 1972 .

\footnotetext{
${ }^{10}$ O'Keefe (1975) summarizes the debate surrounding the reform.

${ }^{11}$ Deaton \& Paxson (1999) use this cross-cohort variation in schooling to understand the relationship between schooling and mortality in Britain. They estimate that an additional year of schooling reduces the odds of mortality by 2 percent.

${ }^{12}$ The parallel figure for women looks similar. We analyze the health effects of these changes on both men and women.
} 
In particular, students attended primary school until fifth grade, after which they were tracked (via a primary school test) into different types of secondary school: "grammar schools" for the most able (roughly 20\%); "modern schools" for the remainder. ${ }^{13,14}$ The law changes most likely affected students in the modern schools.

In other respects, the character of the two changes was different. First, while the 1972 change increased the fraction of cohorts that received formal qualifications, it is less clear what the extra year of education generated by the 1947 change entailed. ${ }^{15}$ Ministry of Education reports and commentary from the time suggest that schools used the extra year to introduce some students to more advanced material and help other students master more basic material. ${ }^{16}$ Whatever the extra year entailed, estimates of the labor market returns to this extra year suggest it was highly valued by the labor market: Harmon \& Walker (1995); Oreopoulos (2006); Devereux \& Hart (2008) all find statistically significant returns for men; only Devereux \& Hart (2008) fail to find statistically significant returns for women. Our own analysis confirms that the 1947 compulsory schooling change had a statistically significant impact on the earnings of affected men (see Appendix C for analysis; estimates for women are less precise). The 1972 compulsory schooling change was less powerful, hence the results are less clear.

Second, the circumstances facing the cohorts affected by these two changes were very different. The cohorts affected by the 1947 change were born during the Great Depression and had their education disrupted by war. ${ }^{17}$ Although the men affected by the change were too young to fight

\footnotetext{
${ }^{13}$ We define these grades using U.S. labels. In Britain, grades nine and ten are referred to as "year ten" and "year eleven." This is because the U.S. kindergarten year is "year one" in Britain.

${ }^{14}$ These proportions varied by local schools authority. In 1947, some authorities had yet to make secondary schools (either modern or grammar) available to all students. Instead, students attended all-age schools that were expanded to accommodate the students affected by the 1947 compulsory schooling change. By 1972, some local authorities had replaced this system with one in which all children attended the same "comprehensive" secondary school.

${ }^{15}$ By the 1970s, high schools in England offered a series of two-year courses that ran through grades nine and ten and required students to sit formal examinations at the end of grade ten ("O" levels and Certificate of Secondary Education). Hence, by compelling students to stay in school until part way through grade ten, the 1972 change gave students an incentive to complete these courses.

${ }^{16}$ According to a 1947 Ministry of Education report, "the main value...of the lengthened school course lies in the fact that the schools will now be able to do more effectively in four years what they previously had to do in three. Even more important, it gives the schools a better chance of exercising a permanent influence for good on those who pass through them" (HSMO, 1948) p.13. Based on various school district reports of the implementation of the new law, a leader commented in the Times Educational Supplement on 5 April 1947 that "Teacher supply, accommodation and curricula are not reckoned by those directly responsible to be the insuperable problems they seem to some despondent outside observers." (p.156)

${ }^{17}$ Evacuation of school-aged children (aged 5 to 15) went into effect in September 1939. School children from "evacuation" areas thought at risk were sent to "reception" areas; "neutral" areas were not affected. Around 40\% of school children in London were evacuated; figures for other evacuation areas are smaller. Some of these children were away for up to two years, although many returned sooner and all attended school in the reception areas (Titmuss, 1950).
} 
in the Second World War, they were required to serve two years of military service from ages 18 to $20{ }^{18}$ Both men and women were affected by rationing, introduced in 1940 and removed in 1954 (Zweiniger-Bargielowska, 2000). This ensured that modest quantities of certain foodstuffs (mainly sugar, dairy products and meat) were shared equally among the population. ${ }^{19}$ These circumstances likely do not threaten the internal validity of our 1947 estimates as exposure to these events was similar for cohorts born on either side of the 1 April 1933 cutoff. These circumstances might however affect external validity. For this reason, the contrast with the 1972 change, which occurred during less eventful times, is especially useful.

\section{Empirical Strategy}

The sharp changes in educational attainment generated by these changes to compulsory schooling laws provide us with an excellent opportunity to analyze the health effects of education. Our analysis proceeds in three steps. First, we estimate the education effects of these compulsory law changes. Second, we estimate the mortality effects of these changes. Third, we estimate the health effects of these changes and use the changes to estimate the health effects of additional years of completed education. In the remainder of this section, we discuss these steps in more detail.

\section{A The Impacts of the Compulsory Schooling Changes on Education}

We use a standard regression discontinuity framework (Lee \& Lemieux, 2009; Imbens \& Lemieux, 2008) to estimate the effects of the compulsory law changes on educational attainment, our "first stage" relationship. Specifically, we estimate the following equation separately for each law change:

$$
E_{i c t}=\gamma_{0}+\gamma_{1} D_{i c}+f\left(R_{i c}\right)+X_{i c t}^{\prime} \gamma_{2}+u_{i c t}
$$

where the dependent variable is a measure of educational attainment for individual i in birth cohort c at time t, $D$ is a dummy variable indicating whether an individual belongs to a postchange cohort, $R$ is an individual's birth cohort (measured in months) relative to the relevant cutoff (April 1933 for the 1947 change, September 1957 for the 1972 change) and $X$ includes predetermined characteristics such as the year of the survey. The function $f($.$) captures the underlying$

\footnotetext{
${ }^{18}$ See Scott (1993) for details of post-war conscription policies and Buonnono (2006) for an analysis of the labor market impacts of military service based on its phasing out in 1960.

${ }^{19}$ Many have argued that rationing may have improved the nutritional content of the typical diet (Prynne et al., 2007).
} 
relationship between birth cohort and educational attainment. The inclusion of the vector $X$ can, potentially, reduce the residual variation in the outcome, thereby improving the precision of the estimates. Its inclusion should not, however, affect our estimates of $\gamma_{1}$, since for individuals born near the cutoff (i.e., April 1933 or September 1957), the elements of $X$ should be uncorrelated with being born on one side of the cutoff or the other. The term $u$ is the error term representing unobservable factors affecting educational attainment. The parameter of ultimate interest is $\gamma_{1}$, the effect of the law changes on completed education.

There are two ways to estimate the parameter $\gamma_{1}$. First, one can choose a parametric function for $f$ (e.g., a quadratic polynomial in $R$ ) and use all of the available data to estimate the equation above via ordinary least squares (Lee \& Card, 2008), typically referred to as the global polynomial approach. Second, one can specify $f($.$) to be a linear function of R$ (fully interacted with $D$ such that the cohort trends can have different slopes on either side of the threshold) and estimate the equation over a narrower range of data, typically referred to as the local linear approach. As discussed by Lee \& Lemieux (2009); Imbens \& Lemieux (2008), this approach can be viewed as generating estimates that are more local to the threshold. It will be especially useful if a parametric function estimated over all of the data cannot adequately capture the relationship between birth cohort and completed education. We adopt the local linear approach and choose the bandwidth using the cross-validation procedure suggested by Imbens \& Lemieux (2008). We also test the sensitivity of estimates to the chosen bandwidths. ${ }^{20}$ In unreported results, we find that the global polynomial approach produces similar estimates.

\section{B The Impacts of the Compulsory Schooling Changes on Mortality}

We use two methods to exploit the regression discontinuity approach and analyze the mortality effects of these changes. First, we use the panel nature of the data (i.e., we observe birth cohorts over time) to perform a hazard analysis (Efron, 1988). This is the approach adopted by Sullivan \& von Wachter (2007) and Lee \& McCrary (2009). Second, we use a "cross-sectional" approach like that used to estimate the education effects of these changes, where the dependent variable is the fraction of a cohort that died within a certain age interval. For comparability with the previous literature, we also report estimates from cross-sectional models in which the dependent variable is

\footnotetext{
${ }^{20}$ For space considerations, we do not report estimates using alternative bandwidths.
} 
a ten-year mortality rate.

The hazard approach makes efficient use of the panel nature of the data. Under this approach, we estimate the following panel logit model of the probability of dying at time $t$ conditional on being alive at time $\mathrm{t}-1:^{21}$

$$
P\left(Y_{i c t}=1 \mid D_{i c}, X_{i c t}\right)=F\left(\theta_{1} D_{i c}+X_{i c t}^{\prime} \theta_{2}\right)
$$

where $Y$ equals 1 if individual $\mathrm{i}$ in cohort $\mathrm{c}$ is dead in period $\mathrm{t}$ and 0 otherwise, $F$ is the logit cumulative distribution function, and the vector $X$ includes age in months and a polynomial in the running variable $R .^{22}$ Each person i contributes $\mathrm{n}$ observations to this regression where $\mathrm{n}$ is the number of time periods from 1970 to 2007 during which person i is alive. We use likelihood ratio tests to determine the appropriate degree of the polynomial in $R$. These tests compare the likelihood function for the least restrictive model (i.e., the model that includes fixed effects for each value of $R$ ) with that for the imposed polynomial model. Instead of reporting estimates of $\theta_{1}$, we report log odds ratios, effectively comparing the mortality risk of a person in the just-affected cohort with that of a person in the just-unaffected cohort.

The cross-sectional approach involves estimation of reduced-form equations of the following form:

$$
F_{c}^{x, y}=\alpha_{0}+\alpha_{1} D_{c}+g\left(R_{c}\right)+X_{c}^{\prime} \alpha_{2}+v_{c t}
$$

where $F$ is the fraction of birth cohort c that dies between ages $x$ and $y$, where the denominator of this fraction is the size of the cohort at birth. Again, the function $g($.$) is a fully-interacted linear$ polynomial in $\mathrm{R}$ designed to control for cohort-level trends. The other variables in equation (3) are defined as before and $v$ is an error term. For data reasons discussed below, $\mathrm{R}$ is measured in quarters for the 1947 change and in months for the 1972 change. We measure mortality at the cohort level rather than at the individual level because the mortality data include no individuallevel covariates aside from sex. Since the covariates should be uncorrelated with $D$, their inclusion might improve the precision of our estimates but would have little effect on their magnitude. We

\footnotetext{
${ }^{21} \mathrm{t}$ denotes month for both the 1947 and 1972 reforms.

${ }^{22}$ Effectively one can estimate, as we do, this regression using cohort-level grouped data, but we present it as an individual-level regression equation for exposition reasons.
} 
examine the effects for different ages (i.e., for different values of $x$ and $y$ ) as the effects of education on health could vary across the age distribution.

\section{The Impacts of Education on Other Health Outcomes}

We use a standard "fuzzy" regression discontinuity framework to estimate the impacts of the additional education induced by the compulsory law changes on other measures of health and health behaviors. In particular, we treat equation (1) as a first-stage equation and add an outcome equation describing the relationship between these outcomes and education:

$$
H_{i c t}=\beta_{0}+\beta_{1} E_{i c}+h\left(R_{i c}\right)+X_{i c t}^{\prime} \beta_{2}+w_{i c t}
$$

where $H$ is a health outcome (e.g., self-reported health) for individual i belonging to cohort c at time t. In this equation, the relationship between the dependent variable and birth cohort is captured by the function $h($.$) , which we again specify to be a fully-interacted linear function of R.$ The parameter $\beta_{1}$ is the effect of an additional year of education. The error term $w$ will include omitted determinants of these outcomes (e.g., family background). Since these are likely correlated with education, least squares estimation of this equation would generate inconsistent estimates of $\beta_{1}$. This motivates our regression discontinuity approach.

We combine equations (1) and (4) and estimate $\beta_{1}$ via two-stage least squares, using $D_{i c}$ as the excluded instrument. As recommended by Imbens \& Lemieux (2008), we use the bandwidths suggested by a cross-validation procedure applied to the reduced-form relationship between the health outcomes and the law changes. Since our first-stage estimates are robust to the choice of bandwidth, this procedure generates estimates similar to those obtained by taking the ratio of the reduced-form to the first-stage estimates, where the separate estimates are based on separate bandwidths and where standard errors are calculated using the delta method.

We interpret this estimate as a local average treatment effect, the effect of the additional education for those who would not have received this education in the absence of the law changes (Imbens \& Angrist, 1994). Since these law changes appear to keep students in education for only one additional year, we interpret these estimates as the effects of an extra year of education for students compelled to stay an extra year. These effects may be very different from the effects of an additional year of education at other parts of the education distribution. They may also be very 
different from the effects of an additional year of education for students that would have remained in school regardless of the law changes. As argued by Oreopoulos (2006), however, since these changes affected large fractions of the relevant birth cohorts, these estimates may be close to the average causal effect of this extra year.

\section{Identification}

The key assumption underlying these procedures is that the conditional expectations of the potential outcomes (completed education, mortality, self-reported health) with respect to birth cohort are smooth through the $\mathrm{R}=0$ threshold. In this case, we can attribute any discontinuities at these thresholds to the causal effects of the school-leaving changes. Although we cannot test this assumption directly, an implication is that there should be no discontinuities in pre-determined outcomes. In this context, birth outcomes are the most relevant pre-determined outcomes for which we have data. We tested for discontinuities in cohort size, sex ratios, infant health (as measured by fraction stillborn) and illegitimacy rates. Our estimates, not reported to conserve space, suggest no such discontinuities. This is, perhaps, unsurprising, since these laws were changed after the affected children were born, limiting the scope for behavior that would generate discontinuities in these types of pre-determined outcomes.

\section{Data}

\section{A Mortality analyses}

To estimate the mortality effects of the compulsory schooling law changes, we use mortality data obtained from the Office for National Statistics. These data include counts of deaths among all residents of England and Wales by month of birth, month of death, and sex for the years 1970 to 2007. As a separate dataset, we also have counts of deaths by general cause (circulatory, pulmonary, and non-circulatory, non-pulmonary) for the years 1970 to 2004 by quarter of birth, year of death, and sex.

For the hazard analyses, we estimate all regressions at the month-of-birth level. Such analysis requires a count of the population at risk of dying in each time period. For the 1947 reform, our hazard analysis begins in 1970. We infer the population size by birth cohort in 1970 by taking the population by birth cohort in the 1991 Census (the earliest available) and subtracting the deaths occurring between 1970 and 1991 by birth cohort; we infer the size of the population at later periods 
by subtracting the deaths occurring between 1970 and these later periods. For the 1972 reform, our hazard analysis begins in 1972, such that the youngest cohort in the hazard analysis is observed from age 16 onwards. $^{23}$ We infer population size in 1972 in a parallel fashion.

For the cross-sectional analyses, the dependent variable is the fraction of a birth cohort that died between certain ages. The numerators in these fractions come from the mortality data. Birth counts from the Office of National Statistics are the denominators. For the cohorts affected by the 1947 change, we have birth counts by quarter of birth and, we estimate equation (3) at the quarter-of-birth level. For the cohorts affected by the 1972 change, we have birth counts by month of birth and we estimate equation (3) at the month-of-birth level.

The biggest limitation of these mortality data is that they start in 1970. Our analysis of the 1947 change will, therefore, miss mortality between 1947 and 1970 - roughly when these cohorts were aged 15 to 40. While this is not ideal, there are three reasons why we believe that this limitation does not lessen the value of our analysis. First, this problem does not affect our analysis of the 1972 change. That is, for the cohorts affected by the 1972 compulsory school change, we can observe mortality from 1972 onwards. Second, this problem is common to other analyses of the mortality effects of education (e.g., Albouy \& Lequien (2009); Deschenes (2009); Lleras-Muney (2005)). This is because most quasi-experimental studies focus on interventions that occurred many years ago (to analyze mortality at later ages) and because mortality data are usually available only for more recent years. Third, we can test for selective mortality before 1970. We do this in three ways. First, we estimate effects on survival until 1970. Second, we estimate effects on survival until age 45 , the youngest age at which we use the cross-sectional analysis to consider the mortality effects of the 1947 reform. Third, we estimate effects on survival until 1991. While this will identify a combination of pre- and post-1970 mortality effects, survival to 1991 is easily measured using birth counts and 1991 Census data. To measure survival to 1970 we use birth counts, 1991 Census data and deaths recorded between 1970 and 1991.

None of these approaches provide strong grounds for supposing there was differential mortality prior to 1970. For example, for men, even after controlling for trends in age, the effect of the reform on the probability of survival to 1970 is small (0.013 off of a base survival probability of 0.82 ) and statistically insignificant (standard error 0.001). The estimated effect on the probability

\footnotetext{
${ }^{23}$ Our results are similar if the hazard analysis starts in 1970.
} 
of survival to age 45 is similar, as are the corresponding estimates for women. ${ }^{24}$ Estimates of the effects of the reform on survival until 1991 are consistent with small or no effects on either pre- or post-1970 mortality. Again, for men, after controlling for trends in age, the effect of the reform on the probability of survival to 1991 is small and statistically insignificant (a 0.01 effect off of a base probability of 0.78 , standard error 0.0098). Again, the estimate is similar for women. ${ }^{25}$

A second limitation of the mortality data is that they include deaths of people that died in England and Wales, not people that were born in England and Wales. The data will then exclude people born in England and Wales who died elsewhere and will include people born elsewhere who died in England and Wales. The first source of migration bias will likely bias us toward finding a protective health effect of education. In other words, by ignoring migration we might overstate the causal effects of education on health. This is because existing research suggests that more-educated individuals are more mobile (Malamud \& Wozniak, 2006). In Appendix D we examine and discuss the effects of the reform on migration patterns to the United States. As expected, our estimates suggest that post-reform cohorts were, if anything, more likely to migrate to the United States. The second source of migration bias, the inclusion of immigrants in our mortality counts, is likely less troublesome. While immigration to Britain may have responded to the compulsory schooling changes (e.g., because of the temporary decline in labor supply), we would expect immigrants to be composed of roughly equal numbers of people born on either side of the relevant birth cohort thresholds. Consistent with this hypothesis, we find no discontinuities in the probability of observing immigrants born in particular months. ${ }^{26}$ These two limitations are inherent in any mortality analyses.

A third limitation of these mortality counts is that they do not contain any education information. Hence, while we can use them to estimate the effects of these law changes on education, we cannot use them to estimate the effects of education on mortality. Since we find very small mortality effects of these laws, this is not a major concern, particularly in view of the large first-stage effects that we estimate. ${ }^{27}$

\footnotetext{
${ }^{24}$ For men, the effect on the probability of survival until age 45 is 0.013 (base probability 0.80 , standard error 0.010). For women, the effect on the probability of survival until 1970 is 0.012 (base probability 0.84 , standard error 0.011 ) and the effect on the probability of survival to age 45 is 0.011 (base probability 0.83 , standard error 0.010 ).

${ }^{25}$ The estimate is 0.01 , off of a base probability of 0.73 (standard error 0.0096).

${ }^{26}$ These estimates (not reported) are based on pooled Health Survey of England data.

${ }^{27}$ Note that even if the mortality data had education information, mortality effects of education could bias estimates of the effects of education on mortality. In particular, our first-stage estimates would be based on a selected sample - the population of those not dying. In order to calculate valid instrumental variables estimates of the effect of education on mortality, one needs to estimate the first-stage regressions before cohorts have experienced any
} 
Finally, since the month of birth information provided on the death certificate is reported by a relative of the deceased, it may be measured with error. Any such error would bias our mortality estimates towards zero. For at least two reasons, we do not think this type of error drives our findings. First, while measurement error in date of birth is likely largest for people that die when they are very old, the oldest people in our analysis are 69 . Second, the mortality estimates that we obtain using administrative mortality data are comparable to the estimates that we obtain using Census data and measuring deaths using reductions in cohort size. Since Census information on month of birth is self-reported, it should be free of this type of measurement error.

\section{B First-stage analyses}

We use Health Survey of England (HSE) data to estimate our first-stage and instrumental variables regressions. Begun in 1991, the HSE is an annual survey that combines a questionnaire-based component with objective information (such as measured blood pressure) obtained from a nurse visit. We pool all waves of these data from 1991 through 2004 to give us large samples of roughly 20,000 adults born in a 15-year interval around each compulsory school law change. In addition to basic demographic information such as gender and age, these questionnaires include all of the variables needed to estimate equation (1): month of birth, year of birth and age left full-time education. Age left full-time education is not the same as completed years of education, but for our purposes we can view these as equivalent (see Appendix B for a discussion of this point).

Because we estimate these models using data obtained over the period 1991-2004, any mortality effects of these laws could, potentially, bias these first-stage estimates. This concern applies to our estimates of both the 1947 and 1972 compulsory school changes. Since our mortality analysis suggests that these changes had, at best, small mortality effects, we would not expect any educationbased selection into the HSE data. Indeed, we find that the fraction of the birth cohort observed in the HSE is smooth through the April 11933 and the September 11957 thresholds (not reported).

\section{Health analyses}

The HSE is our main source of health data. Since the HSE contains both health measures and measures of completed education, we can also use it to provide instrumental variables estimates of calculations. They do not affect our analysis as we find no effects of education on mortality. 
the effects of education on these health measures. To gain more precision, we also use health survey data from the General Household Survey (GHS) and the 1991 and 2001 U.K. Censuses. The GHS, also used by Oreopoulos (2006), is an annual survey of over 13,000 households in Great Britain that includes information on demographics (including month of birth from 1986 to 1996), household composition, employment, education and health. The Censuses cover the entire population of England and Wales hence these generate very precise estimates. The Censuses include standard questions on self-reported health and illness prevalence, but no questions on completed education (or wages). As such, we cannot use them to generate instrumental variables estimates of the health effects of education.

\section{Results}

We report our results in three subsections. These correspond to the three steps of our empirical strategy, described above. We begin with the effects of the compulsory schooling law changes on educational attainment. We then report our estimates of the effects of the law changes on mortality. Finally, we report our estimates of the effects of the additional education induced by the law changes on other measures of health and health behaviors.

\section{A The Impacts of the Compulsory Schooling Changes on Education}

To examine the effect of the law changes on educational attainment, we begin by graphing the relationship between birth cohort and the probability of completing less than nine and less than ten years of education (Figure 2). All panels of this graph present averages by month of birth. The vertical bars denote the appropriate birth cohort cutoff for the relevant compulsory schooling change. Superimposed onto these graphs are the fitted linear trends and estimated discontinuities obtained from estimation of equation (1) without covariates.

The 1947 change reduced the fraction of individuals completing nine or fewer years of education by around 0.5 . The 1972 change decreased the fraction completing ten or fewer years of education by around 0.25 . Table 1 quantifies these relationships. The Table reports two estimates of equation (1) for each dependent variable. The first estimate is that displayed in Figure 2, obtained from estimation of equation (1) without covariates. The second estimate comes from a model that regression-adjusts for month-of-birth dummies, year- and month-of-survey dummies and a thirdorder polynomial in age. We would not expect educational outcomes to display an age profile 
(conditional on month of birth) because for most respondents, completed education should be fixed from the early twenties onwards. Nevertheless, the age profile adjustment potentially removes idiosyncratic noise. It is more important to remove the age profile when analyzing health outcomes.

There are three main points to note about these estimates. First, the effects of the law changes are precisely estimated. ${ }^{28}$ The t-statistics for the years of education regressions are in excess of six for the 1947 change and five for the 1972 change. For the dichotomous outcomes, the t-statistics are even higher. The magnitudes of the t-statistics suggest that these changes are powerful instruments for educational attainment. Despite his use of year-of-birth comparisons, the first-stage estimates of Oreopoulos (2006) for the 1947 change are similar. Oreopoulos (2006) does not examine the effects of the second reform. Second, as expected, regression-adjustment for age and survey year/month does not affect the point estimates. Third, the law changes generated only weak spillovers to higher levels of educational attainment: the 1947 change generated a small increase in the fraction of girls that completed ten or fewer years of education but had little impact on the corresponding fraction for boys; the 1972 change had no effects on the fractions completing eleven or fewer years, although these estimates are less precise. To a first approximation therefore, one can view these law changes as forcing students that would previously have left at the earliest opportunity to stay in school for one more year.

One final point concerning Figure 2 and Table 1 relates to compliance. A small fraction of those subject to the new laws appear to complete less education than these new laws required. For the 1972 law change, this is particularly marked among those born in June, July, and August. We discuss the sources and implications of this pattern in Appendix B. To summarize, we conclude that the pattern should have little impact on our estimates since it is quite regular and hence can be controlled for via the inclusion of post-change month-of-birth controls.

More generally, our estimates are specific to the population of "compliers," those whose educational attainment was affected by these law changes (Imbens \& Angrist, 1994). As noted by Oreopoulos (2006), while the compliers make up only a fraction of the affected cohorts (0.5 in 1947 , 0.25 in 1972), this fraction is large relative to other analyses based on compulsory school laws. For example, Lleras-Muney (2005) estimates that U.S. compulsory schooling changes enacted at the

\footnotetext{
${ }^{28}$ In estimates discussed later, we are able to combine the HSE estimates with those from the GHS to estimate an even tighter first stage.
} 
beginning of the 20th century affected less than five percent of the relevant cohorts.

\section{B The Impacts of the Compulsory Schooling Changes on Mortality}

Having shown that the compulsory school law changes affected educational attainment, we turn to their impact on mortality. We begin with an analysis of the impact of the 1947 change. We then analyze the impact of the 1972 change.

\section{i Evidence from the 1947 change}

We begin our mortality analysis by reporting estimates based on the hazard approach described earlier. In our logit specification we include the post-change dummy $D$, a full set of age-in-months dummies and a fully-interacted linear polynomial in month of birth. ${ }^{29,30}$ Likelihood ratio tests suggest that a linear polynomial is sufficient, since tests of this model against one that includes month-of-birth dummies (i.e., a completely flexible model) yield p-values exceeding 0.05.

In the first column of estimates in Table 2, we report the log-odds ratios for the post-change dummy by sex. A log-odds ratio exceeding one suggests that post-reform cohorts have higher mortality risk; a ratio below one suggests that post-reform cohorts are at lower risk of dying. ${ }^{31}$ The estimates for men imply that the 1947 change led to a 1.1 percent increase in the likelihood of dying in every month of the 1970-2007 period. The estimates for women imply that the 1947 change led to a 0.4 percent increase in the likelihood of dying.

Although these positive effects are counterintuitive, they are statistically insignificant for women and only marginally significant for men (at the 5 percent level). More importantly, they are also very small. Indeed, in the graphical display of our cross-sectional analysis, discussed below, we do not observe a discontinuity in mortality starting with the 1933 quarter 2 birth cohort for males or females. We therefore interpret the positive, statistically-significant effect for males as a consequence of a type I error. An alternative explanation is that the additional earnings generated by the additional education increased engagement in unhealthy behaviors such as alcohol consumption.

We turn next to the estimates of the probability of dying between certain ages, following the

\footnotetext{
${ }^{29} \mathrm{~A}$ cross-validation procedure for choosing the appropriate bandwidth for this type of non-linear model has not yet been developed. We therefore use the bandwidth suggested by our analysis of the probability of death between ages 45 and 69. Our estimates exhibit little variation across different bandwidths.

${ }^{30}$ When we estimate the pooled regression, we also include a male dummy variable in the logit specification.

${ }^{31}$ Furthermore, we interpret the size of the estimates as percents. A log-odds ratio of 1.038 would suggest that relative to individuals born immediately prior to April 1, 1933, individuals born immediately following April 1, 1933 had a 3.8 percent higher likelihood of dying in each month of the 1970-2007 period.
} 
approach outlined by equation (3). This approach is, arguably, more transparent than the hazard analysis, since these estimates can be represented graphically. We start with a crude mortality measure: the probability of dying between age 45 and 69, displayed in Figure $3 .{ }^{32,33}$ The graph shows the expected negative relationship between these probabilities and birth cohort, but there is no apparent discontinuity in this outcome for the cohorts born in quarter 2 of 1933 and later. In fact, the associated point estimates are again positive, although small and generally not statistically significant. These estimates are consistent with the hazard estimates, neither of which provide any evidence that the compulsory schooling change reduced mortality.

To examine this relationship further, Figure 4 plots death rates over 5-year age intervals. Due to space constraints, we present figures for men and women together. Later, we provide separate estimates by sex. Again, the graphs suggest that there was no systematic reduction in death rates for the cohorts born after 1933 quarter 2 .

The remainder of Table 2 presents regression discontinuity estimates by sex and age group. In the presence of a mortality-reducing effect of education, we would expect these estimates to be negative. There is only one negative estimate. Most of these estimates are small and statistically insignificant. For instance, the 95 percent confidence interval for the overall death rate for ages 45 to 69 spans from -0.80 (a 0.4 percent decline) to 7.98 (a 4.35 percent rise).

Since only 20 percent of the relevant cohort died between the ages of 45 and 69 , an obvious question is whether the cohorts are old enough for us to detect sizable effects. There are two reasons why we think they are. First, Lleras-Muney (2005) finds that the mortality-reducing effects of education are largest between the ages of 35 and 64. Second, a simulation exercise (described in Appendix E) suggests that our methods would detect relatively small effects. For example, if a year of education improved life expectancy by 1.5 years, an effect consistent with Lleras-Muney (2005), we would expect to observe effects on mortality rates among the 45-69 age group of around -20. An effect of this size is much larger than the effects reported in Table 2.

Education may have different effects on mortality associated with different diseases. For example, Cutler et al. (2006) find that the education gradient in health is steeper for knowledge-intensive,

\footnotetext{
${ }^{32}$ The earliest age we observe the 1947 cohort is age 33 in 1970 , and the latest age is 74 , but since we also use several younger and older cohorts in the analysis, we look at mortality between 45 and 69 .

${ }^{33}$ In addition to a fully-interacted linear trend in the running variable, these regressions include quarter-of-birth controls (i.e., quarter 1, quarter 2, and quarter 3 dummies) designed to capture any seasonality in this outcome. Our estimates are qualitatively similar whether or not these are included.
} 
technology-intensive diseases (e.g., diabetes). To explore whether our aggregated analysis obscures effects on particular types of diseases, Figure 5 considers the probability of dying between ages 45 and 64 from three different disease classes: respiratory, circulatory and deaths from other causes. Table 3 presents the corresponding point estimates. ${ }^{34}$ For all these classes of death, there is no discrete downward shift beginning with the 1933 quarter 2 cohort.

Overall, we find that the additional education induced by the 1947 compulsory school law change had little impact on mortality. Yet on this evidence alone, we would be cautious about drawing more general conclusions about the relationship between education and mortality. That is because these effects may be specific to one cohort, and this cohort experienced the Great Depression and the Second World War, factors potentially affecting the life trajectories of its members. We therefore turn next to the 1972 change in compulsory schooling laws.

\section{ii Evidence from the 1972 change}

The 1972 change generates another education quasi-experiment that can be used to identify the causal effect of education on health. Since this change occurred during less turbulent times, we can use it to assess the generalizability of the 1947 estimates. The caveat is that there are other reasons, besides these wider circumstances, why the two quasi-experiments might yield different estimates. First, the later change affected educational attainment at a slightly higher point in the education distribution. The effects of education on health could be non-linear. ${ }^{35}$ Second, we observe the cohorts affected by the 1972 change at different ages than those affected by the 1947 change. This is relevant if the health effects of education vary over the life-cycle. Nevertheless, since both changes extended the period of compulsory schooling, we might expect their effects to work through similar channels and to have broadly similar impacts.

The first column of Table 4 reports estimates based on the hazard approach. For men, we are able to rule out effects of -0.002 percent at the 5 percent significance level. Even after dividing these reduced-from estimates by the first-stage estimates, the effects are quite small. In contrast, for

\footnotetext{
${ }^{34}$ Since our data by cause are only available through 2004 , we can only look at general-cause deaths up to age 64 . The most common circulatory diseases resulting in death are heart disease and stroke. The most common pulmonary diseases resulting in death are pneumonia (nearly a half of all cases), cancers and chronic obstructive pulmonary disease (which includes chronic bronchitis and emphysema).

${ }^{35}$ For the United States, Cutler \& Lleras-Muney (2006) note that for education levels below 10 years of schooling, some outcomes (e.g., mortality) appear to be linearly related to years of schooling while others do not. For education beyond 10 years of schooling, the health returns to education appear to be constant.
} 
women, the effects are consistent with health-improving effects of education and are on the verge of statistical significance at the 5 percent level. These effects imply a much larger effect for women than for men but, for both sexes, are substantially smaller than the estimates of Lleras-Muney (2005).

Turning to the cross-sectional approach, Figure 6 plots 20-44 year old mortality rates by birth cohort. Relative to Figures 3-5, there are more data points in these graphs. That is because for these later cohorts, we have birth cohort sizes by month of birth and hence can analyze the effects of the 1972 change at the month-of-birth level. This is ideal, since unlike the 1947 change (introduced on 1 April), the 1972 change (introduced on 1 September) cuts across a birth quarter. The graph provides little evidence for any discontinuity in mortality rates beginning with the September 1957 cohort.

The remainder of Table 4 provides regression discontinuity estimates of these mortality effects by age group; Figure 7 provides the corresponding graphs. For men, the effects are generally positive. For women, the absence of any effects on the probability of dying between ages 20 and 44 appears to mask the possibility of some negative effects on the probability of dying at younger ages, but only one of these estimates is statistically significant. These effects are consistent with the hazard estimates. The estimates are small in percentage point terms as the probability of dying between 20 and 44 is low (roughly 2 to 3 percent of the relevant cohorts die between these ages), but in percent terms, some of the effects are modest. For example, our estimate of the effect of the 1972 change on the probability of dying between ages 20 and 24 is consistent with that predicted by a 1.5 year increase in life expectancy. Against that, we estimate smaller effects at slightly older ages and no or positive effects beyond age 35. Overall, these mortality estimates for the 1972 change suggest little or no effects.

\section{The Impacts of Education on Other Health Outcomes}

Since we find little evidence of any mortality impacts of these laws, an analysis of their impacts on various survivor outcomes should be free of mortality-driven sample selection biases. We consider two types of outcomes: measures of health, including both subjective and objective measures, and measures of health behaviors, including self-reports of smoking, drinking, diet and exercise. Some of these health measures are strong predictors of mortality (Idler \& Benyamini, 1997), and some of these health behaviors (e.g., smoking) are known causes of morbidity and mortality. 


\section{i Evidence from the 1947 change}

We begin our analysis by reporting estimates of the impacts of the 1947 law change on measures of health. We then turn to measures of health behavior.

\section{Health measures}

Using pooled HSE data (all waves from 1991 to 2004), panel A of Table 5a presents least squares estimates of the effects of education on various self-reported health measures. To ensure these are based on a sample comparable to the one for whom the reforms had the biggest effect, we use individuals that are born in the United Kingdom, are born within 60 months of the cutoff and leave full-time education at or before age sixteen. We began by estimating separate models for men and women but did not reject the hypothesis that effects were the same for men and women. We therefore chose to pool the data and include a male dummy. ${ }^{36}$

The least squares estimates (the column labeled "OLS") suggest that an additional year of education reduces the probability of being in fair or worse health by roughly nine percentage points, ${ }^{37}$ reduces the probability of reporting a longstanding illness by three percentage points ${ }^{38}$ and reduces the probability of reporting reduced activity by two percentage points. The least squares effects are, respectively, $25 \%, 5 \%$ and $10 \%$ of the pre-change means.

The regression discontinuity estimates of the reduced-form effects of the compulsory schooling change on these outcomes (the column labeled "RF w/o X") are small. For example, the estimated effect on self-reporting being in fair or worse health is -0.008. The estimated effects on self-reporting having a long-standing illness and self-reporting reduced activity both take the wrong sign, but are close to zero. Figure 8 gives a graphical representation of the reduced-form estimates for "fair or worse health". Moving from the left to the right of these graphs, we see that health outcomes become more favorable across cohorts. This is because these cohorts have benefited from secular improvements in health (e.g., technological progress) and because they are younger when interviewed. We do not however see a marked change in health outcomes among those just affected by

\footnotetext{
${ }^{36} \mathrm{By}$ pooling we generate larger cell sizes and more precise estimates of the impacts of the ROSLAs. It is worth bearing in mind that while sample sizes in the HSE are relatively large (around 300 individuals per month of birth cohort), they are tiny in comparison to those underlying the mortality analyses, which effectively contain the entire population hence are around 100 times larger.

${ }^{37}$ The precise question is "How is your health in general? Would you say it was...".

${ }^{38}$ The question is "Do you have any long-standing illness, disability or infirmity. By long-standing I mean anything that has troubled you over a period of time or is likely to trouble you over a period of time."
} 
the compulsory schooling changes.

Turning back to panel A of Table 5a, we see that regression adjustment for pre-determined covariates has little effect on the reduced-form estimates (the column labeled "RF"). These covariates include a flexible function of age, designed to remove the age profile in these outcomes. In the final column we present instrumental variables estimates of the effect of an additional year of education on these outcomes (column labeled "IV"). These estimates are statistically indistinguishable from zero, although only the estimate for "fair or bad health" is precise enough to reject the least squares estimates. ${ }^{39}$ Overall, while the least squares estimates suggest large health effects of education, the instrumental variables estimates suggest that the additional education induced by the 1947 change did not improve health, at least as measured by these self-reported outcomes.

Objective health measures may be more precise indicators of underlying health status. The HSE contains some of these, obtained from a nurse visit to consenting respondents. In panel B of Table 5 a we report estimates of the effects of education on the probability of being obese (Body Mass Index $(\mathrm{BMI})>30)$ ), the probability of being overweight $(\mathrm{BMI}>25)$, the incidence of hypertension and blood pressure. ${ }^{40}$ The least squares estimates suggest that education has beneficial effects on these outcomes, although effect sizes are generally smaller than they were for self-reported health. ${ }^{41}$ The reduced-form and instrumental variables estimates again suggest no obvious relationship between education and these outcomes. In particular, none of the instrumental variables estimates are statistically significant and these frequently take the "wrong" sign.

\section{Health behaviors}

While the above analysis suggests that the additional education generated by the 1947 compulsory school law change did not affect health as measured when these cohorts were in their sixties, it may generate health effects at older ages. For that reason, it is interesting to assess whether this additional education affected health behaviors, since these might manifest themselves as poorer later-life health and higher later-life mortality rates.

Starting with smoking, we classify respondents into three mutually exclusive and exhaustive

\footnotetext{
${ }^{39}$ Here we treat the least squares estimates as a fixed quantity instead of a random variable. That is, we are not conducting a Hausman test.

${ }^{40}$ We base our blood pressure measure on diastolic blood pressure, but our results are similar when using systolic blood pressure.

${ }^{41}$ These findings are consistent with the analysis of Johnston et al. (2009), who also find smaller least squares estimates for objective measures of health.
} 
categories - "currently smoking", "started smoking, stopped smoking" and "never smoked" - and consider impacts on "currently smoking" and "ever smoked". The first is probably most informative, since a large fraction of the affected cohorts report ever smoking. ${ }^{42}$ The "currently smoking" question relates only to cigarettes while the "ever smoked" question includes pipes and cigars. Table $5 \mathrm{~b}$ reports estimates of the impacts of education on these outcomes. For "currently smoking" the least squares estimates are very large: an extra year of education appears to reduce the probability of smoking by five percentage points, around one quarter of the pre-change mean. For "ever smoked", the least squares estimate is smaller (an extra year reduces this probability by three percentage points), although still statistically significant. ${ }^{43}$

For both smoking measures, the reduced-form estimates are small and statistically indistinguishable from zero. Figure 8 presents the associated graph for the reduced-form impact on "currently smoking". For both smoking measures the instrumental variables estimates are also statistically insignificant. The confidence interval associated with the "currently smoking" IV estimate almost excludes the least squares estimate.

Looking further down Table 5b, the least squares estimates suggest that education is associated with healthy behaviors such as eating fruit and vegetables, taking vitamins and getting exercise. The least squares estimate does however suggest that education is associated with higher alcohol consumption. Again, the reduced-form estimates typically cannot be distinguished from zero and the instrumental variables estimates are less precise. As discussed below, we pursue various strategies to try to obtain more precise instrumental variables estimates of the effects of education on these various outcomes.

At this point, it is worth noting that if the effects of drinking on health were large enough, and if the reform had positive effects on drinking, these might explain why the reform had small effects on health overall. The evidence suggests, however, that the health impacts of drinking are moderate. For example, Sturm (2002), using a cross-sectional approach, concludes that the health risks of problem drinking are half those of smokers.

\section{Extensions}

\footnotetext{
${ }^{42}$ This might be because the "ever smoking" definition includes pipe and cigar smoking.

${ }^{43}$ Others have argued that education might increase the probability of using soft drugs (Cutler \& Lleras-Muney, 2006). Such an effect could be one reason why the least squares estimate is smaller for "started smoking" than "currently smoke".
} 
We pursue three approaches to generate more precise instrumental variables estimates of the effects of education on health. First, since several variables appearing in the HSE also appear the General Household Survey (GHS), we pool data from the GHS and HSE. Second, we follow an approach used by Katz et al. (2007) and estimate education impacts on summary measures of health and health behaviors. Third, to assess robustness more generally, we estimate the health impacts of the additional education generated by the 1972 change (in the next section).

The pooled GHS-HSE estimates are reported in Appendix Table A1a. As expected, these are more precise than those based solely on the HSE. Nevertheless, the point estimates are similar. The least squares estimates suggest strong correlations between education and self-reported health and health behaviors. The instrumental variables estimates suggest that omitted variables likely drive these correlations. For all but two of the six outcomes reported (currently drink and currently smoke), the IV estimates can rule out effects the size of the OLS estimates.

We report summary estimates based on the approach of Katz et al. (2007) in Appendix Table A1b. For example, we estimate education impacts on a summary measure of self-reported health based on the individual items "health bad," "long-standing illness" and "reduced activity." A simple way of estimating effects on this summary measure would be to take a simple average of the effects on the individual items. There are two differences between this simple approach and the approach taken by Katz et al. (2007) and followed here. First, to ensure they are comparable, the individual items are standardized (via the sample standard deviation in the items) before they are averaged. Second, to enable the appropriate calculation of the variance of this summary measure, the individual item effects are estimated in a seemingly unrelated regression (SUR) system. This generates the same point estimates as would be generated if the individual effects were estimated separately but ensures that the individual sampling variances account for the covariance across the individual estimates. The sampling variance of the summary measure is then a function of the sampling variances of the individual items obtained via SUR estimation. Under the null hypothesis that the standardized summary measure is zero, the standard t-statistic can be computed as the standardized summary estimate divided by the square root of this adjusted sampling variance.

For the summary measures of self-reported health, objectively-reported health and smoking, the least squares estimates are large and the instrumental variables estimates are small and statistically 
indistinguishable from zero. We can rule out effects the size of the OLS estimates for the selfreported health measures. For the summary measure of food consumption and exercise, both the least squares and instrumental variables estimates are small and positive, but both are imprecise and neither are statistically distinguishable from zero at the five percent level.

\section{ii Evidence from the 1972 change}

The health impacts of the 1972 change are presented in Tables $6 \mathrm{a}$ and $6 \mathrm{~b}$. The results for health outcomes (Table 6a) are broadly consistent with those obtained for the 1947 change (Table 5a). Indeed, since the population affected by the 1947 change is approximately 25 years older than the population affected by the 1972 change when interviewed for the Health Survey of England (between 1991 and 2004), it is remarkable how close are the two sets of estimates. For example, the least squares estimate of the effect of education of the probability of self-reporting being in fair or bad health is around nine percentage points for those affected by the 1947 change and around seven percentage points for those affected by the 1972 change. All of the other least squares estimates take the same sign across the two sets of estimates and are often close in magnitude. While the reduced-form and instrumental variables estimates are less close in magnitude, and while the signs often differ between the two samples, nearly all estimates are statistically insignificant in both samples. For no outcome could a statistical test reject the hypothesis that the instrumental variables estimates are the same across the two samples. However, the estimates are measured with less precision for the 1972 cohort.

The results for health behaviors (Table 6b) are also consistent with those obtained for the 1947 analysis (Table 5b). The main exception is the least squares estimate of the impact of education on currently smoking (much larger in the 1972 sample), but the sample means are also higher in this sample. The more important point is that across both samples, the instrumental variables estimates suggest that the additional education induced by both laws had smaller impacts on the probability of smoking than suggested by the OLS relationships. The same conclusion can be drawn for the other outcomes presented in Tables $5 \mathrm{~b}$ and $6 \mathrm{~b}$.

Similar to Appendix Tables A1a and A1b, Appendix Tables A2a and 2b present pooled analyses (i.e., using both the GHS and the HSE) and summary estimates of the health effects of the 1972 change. Again, pooling datasets generates larger samples and, typically, more precise estimates. For example, the confidence interval around the pooled estimate of the effect of an additional year 
of education on the probability of being in fair or bad health now excludes the least squares estimate. Similarly, the summary estimates are often statistically indistinguishable from zero, even though some of the individual estimates are significant.

\section{iii Summary and Evidence from Census Data}

Taken together, these estimates paint a relatively consistent picture. The least squares estimates suggest that education has large effects on both health and health behaviors. None of the instrumental variables estimates point to a strong and persistent effect of education on health.

The caveat here is that these instrumental variables estimates are not always precise, even after we have pooled HSE and GHS data and even after we have estimated impacts on summary outcomes. As a result, while the weight of this evidence suggests that the additional education induced by these compulsory schooling changes does not affect health, one can find individual estimates that are statistically significant (e.g., for the "eat vegetables daily" outcome for the 1947 change, for the "reduced activity" outcome for the 1972 change) or find estimates that suggest the effects of the 1947 and 1972 changes work in opposite directions (e.g., the "obese" and "overweight" outcomes). The estimates are even less precise when estimated separately by sex. We combined data for men and women to improve precision and because, for most outcomes, we could not reject that the male and female coefficients were the same. ${ }^{44}$

We would like to generate more precise estimates and we would like to generate precise estimates for men and women separately. We pursue two additional strategies with these goals in mind. First, to improve precision, we combine the two compulsory schooling changes by pooling all HSE respondents born between 1920 and 1970. We then capture cohort trends with a flexible age profile and use both compulsory schooling changes as instruments for completed education. Assuming the cohort trends are sufficiently flexible and assuming that the two compulsory schooling changes generate similar health effects of education, these combined IV estimates should be more precise than the separate IV estimates. As seen in Appendix Tables A3a and A3b, the combined IV estimates follow the same pattern as the separate IV estimates, but are more precise than those. ${ }^{45}$

\footnotetext{
${ }^{44}$ Power calculations suggest that if we separate men and women, we would not have sufficient power to detect effect sizes of more than 10 percent for outcomes for which the base means are 0.2 or smaller. Details available upon request.

${ }^{45}$ Only the smoking outcomes suggest effects in the direction of the least squares estimates and these are sensitive to functional form. This is not entirely surprising since there are strong (non-monotonic) cohort trends in smoking behaviors. This suggests that this pooled 50-year analysis is not appropriate for smoking outcomes. This problem does not affect the separate analyses of the 1947 and 1972 reforms.
} 
For example, we can rule out reductions in the probability of being in fair or poor health larger than three percentage points off a mean of 25 percent. For the outcomes of health fair or bad, long illness, reduced activity, obese, and BMI, the confidence intervals of the IV estimates exclude the OLS estimate. For some of the remaining outcomes - overweight, hypertension, and diastolic blood pressure - the OLS effects are small. For the rest, the IV effects imply that an extra year of education reduces the likelihood of those outcomes by less than 10 percent.

Second, to assess separate effects for men and women, we use data on self-reported health from the 1991 and 2001 Censuses. Since these censuses provide enormous sample sizes, they generate much more precise estimates than survey-based analyses. Table 7 presents reduced-form estimates of the impacts of the two compulsory schooling changes on these self-reported outcomes. The first two columns present reduced-form estimates with and without age controls; the next two columns present reduced-form estimates separately for men and women. Since the Census does not contain education information, least squares and instrumental variables estimates are not presented.

Generally speaking, these reduced-form effects are very small. The estimates in the first two rows of panel A suggest that the 1947 compulsory schooling change had a small but statistically significant impact on self-reported health. For example, the compulsory schooling change is seen to reduce the probability of self-reporting having "fair or bad" health and the probability of selfreporting having "bad" health by 0.4 percentage points. Since the 1947 change was associated with a completed schooling increase of 0.5 years, this implies that an extra year of education reduced these probabilities by around 0.8 percentage points. As a point of reference, recall that the analogous HSE-based least square estimate is 9 percentage points. ${ }^{46}$ The bottom two rows of panel A suggest that the 1947 changes had no statistically significant effects on the probability of self-reporting a limiting long-term illness. When we estimate these regressions separately for men and women, the estimates are broadly similar. Figure 9 gives graphical representations of these estimates.

The estimates in the first two rows of panel B suggest that the 1947 and 1972 changes had similar effects, although the 1972 estimates are less precise. For example, the reduced-form estimates suggest that the 1972 change decreased the probability of being in "fair or bad" health by around

\footnotetext{
${ }^{46}$ The Census questions are slightly different from those in the Health Survey of England, hence one must be careful about making direct comparisons. The general health question in the Census is: "Over the last twelve months, would you say your health has been..." and allows respondents to respond "Good" "Fairly good" or "Not good." The longstanding illness question is worded "Do you have any long-term illness, health problem or disability which limits your daily activities or the work you can do? Include problems which are due to old age."
} 
0.15 percentage points. Scaled up by a factor of 3.3 (the 1972 change increased years of education by around 0.3 , see Table 1), this suggests that an additional year of education reduces this probability by around 0.5 percentage points off of a base of 31.43 percent, again a very small effect. Estimates of the impact of the 1972 change on the probability of reporting being in bad health are smaller than the estimates for the 1947 change. This may be because these cohorts are younger, hence are less likely to report being in bad health (8.4\% versus $17.7 \%)$. Estimates of the impacts of these changes on the probability of self-reporting a limiting long-term illness are again statistically insignificant.

When the effects of the 1972 change are estimated separately for men and women, there is some evidence to suggest larger effects on men, although even these census-based estimates are not precise enough to reject that these coefficients are the same. See the bottom panel of Figure 9 for the associated graphs. Overall, our analyses of the Census data suggests that the additional education induced by the 1947 and 1972 changes had at best very small effects on self-reported health and that these effects did not differ systematically between men and women.

\section{Discussion}

In this section, we discuss our estimates in light of the previous literature. We then propose several explanations for our null findings.

\section{A Relation to the Previous Literature}

The most closely-related study to ours is Lleras-Muney (2005). She uses U.S. compulsory school laws to identify the effects of education on a census-based measure of mortality. ${ }^{47}$ Her estimates suggest that an additional year of education has a relatively large effect on mortality, reducing 10-year mortality rates by roughly three percentage points off a base mortality rate of about 10 percent.

Since we estimate effects on a different dependent variable (the probability of death over various age intervals), our results cannot be directly compared with these. To obtain comparable estimates, we construct a 10-year mortality rate using Census data for 1991 and 2001. Specifically, for each month-of-birth cohort, we measure mortality between 1991 and 2001 as one minus the 2001 population count divided by the 1991 population count. We then use these data to estimate the

\footnotetext{
${ }^{47}$ She measures the mortality rate of cohort c between 1950 and 1960 as one minus the fraction of the cohort alive in 1950 that was also alive in 1960 .
} 
impact of the school leaving changes on these outcomes (these regressions are weighted by initial population size).

This exercise yields much smaller estimates than those obtained by Lleras-Muney (2005). For example, we estimate that for men, being born after April 1933 reduces the 1991-2001 mortality rate by roughly 0.2 percentage points, around 1.5 percent of the mean mortality rate among those born just before April 1933 (15.1 percent). Even if we scale this estimate by the first-stage estimate (i.e., multiply the estimate by two), it is still much smaller than the least squares and the instrumental variables estimates reported by Lleras-Muney (2005). For women, the regression discontinuity reduced-form estimate is 0.2 percentage points (off a base mortality rate of 8.5 percent) and is not statistically distinguishable from zero.

There are several reasons why our estimates might be smaller than those reported by LlerasMuney (2005). First, the compulsory school laws are different across the two countries. In particular, while the compulsory school laws studied in the U.S. are used in combination with child labor restrictions and compulsory attendance laws, the British laws refer only to school attendance. If changes to child labor laws affect whether children work in potentially dangerous environments, we might expect the U.S. laws to have larger effects on health.

Second, the laws were less binding in the U.S. Prior to the law changes, typically around five percent of the relevant U.S. cohorts dropped out at the earliest possible age (Lleras-Muney, 2005). This contrasts with the large fractions that dropped out at the earliest possible age in Britain. Below we discuss whether the size of the education effects induced by the British law changes can explain the small effects that we find.

Third, there are important differences in the methods used in the two studies. In particular, since the British school leaving laws are made at the national level, and since they generate sharp changes in educational attainment, we can use regression discontinuity methods that can accommodate flexible cohort trends in health outcomes. In contrast, Lleras-Muney (2005) uses difference-in-difference methods to exploit cohort and state variation in compulsory schooling laws. This approach relies on the stronger assumption that these laws are uncorrelated with state-specific trends in these outcomes.

Although this is the first paper to use the British compulsory schooling changes to assess the mortality effects of education, Oreopoulos (2006) and Silles (2009) have used these changes to as- 
sess the effects of education on self-reported health (as measured in the General Household Survey (GHS)). Oreopoulos (2006) used a regression discontinuity approach at the year-of-birth level. His estimates using the 1947 reform suggest large education effects on self-reported health. For example, his instrumental variable for the effect of an extra year of education on the probability of being in poor health is -0.032 (off of a mean of 0.150 ). In results not reported, we show that the use of year-of-birth comparisons using our data can yield erroneously large IV estimates and thus explain our differing results. ${ }^{48}$ Silles (2009) used both compulsory schooling changes in an instrumental variables procedure that pools across a wide range of cohorts. She finds large effects of education on self-reported health, often much larger than the corresponding least squares estimates. Since her approach is similar to the one used by Harmon \& Walker (1995) to assess the earnings effects of these changes, it is subject to the same concerns regarding cohort trends. ${ }^{49}$

\section{B How Can We Explain These Results?}

It is not easy to account for our results. It is, for example, hard to argue that the British system of health care weakens what would otherwise be large health returns. First, while the National Health Service (NHS) does provide universal health insurance, the system is known to be inequitable and open to manipulation by more-educated patients. While the combination of gatekeepers and resource constraints should in theory limit the extent to which more-educated patients can shop for specialists and treatments, more-educated patients can work this system by, for example, persuading their general practitioner (GP) to refer them for treatment or, if that fails, switching GPs or going directly to a specialist (Lyall, 2008). ${ }^{50}$ Even if the NHS did serve to weaken health returns somewhat, we would still expect more-educated patients to engage in less risky behaviors (e.g., smoking) and more efficient self-management (Goldman \& Smith, 2002). Consistent with this hypothesis, some evidence suggests that highly-educated parents in the U.K. are more responsive to changes in medical knowledge concerning the perceived safety of childhood vaccines (Anderberg et al., 2008).

\footnotetext{
${ }^{48}$ In later work, Oreopoulos (2008), using a different sample, estimates that the health returns to education are much smaller than those reported in Oreopoulos (2006).

${ }^{49}$ Silles (2009) checks robustness by comparing average outcomes among cohorts born three years either side of the relevant cohorts. This comparison supports the IV estimates, although it will also be biased by pre-existing trends.

${ }^{50}$ Until recently, to benefit from new treatments, patients first had to be referred to a specialist by a GP. The specialist then decided whether to treat the patient and patients requiring treatment were placed on a waiting list (patients could avoid waiting by opting for private treatment). See Aaron \& Schwartz (1984) for a comparison of the U.K. and U.S. health systems.
} 
It is also hard to attribute these results to the content of these additional years of education. One might worry that the quality of these additional years was low, perhaps because they were not accompanied by sufficient new resources, and there are reports of children being taught in temporary and overcrowded classrooms. Yet other commentary suggests that schools and teachers were wellprepared for the extra years, in part because these changes were fully anticipated. ${ }^{51}$ Ultimately, arguments based on the quality of the extra years are hard to reconcile with the economic returns to these extra years.

Similarly, it is not clear why the wider circumstances facing affected cohorts - the Great Depression, the Second World War and the military service requirements - should have lowered the health returns to the extra education induced by the 1947 change. To the extent that the Second World War disrupted education, and to the extent that there are diminishing health returns to education, we might expect the health returns to the additional year to be especially high. One can construct stories as to why military service could weaken the health effects of education, but we estimated that the 1947 change generated small health returns for women, who were not required to perform military service. In the end, the consistency of our findings across the two compulsory schooling changes pushes against explanations based on the circumstances surrounding the 1947 change.

Our final proposed explanations for these results center on the size of the affected populations. In particular, because these changes affected large numbers of students (up to $50 \%$ of the relevant cohort), they may not have changed these students' peer groups and may not have changed their relative educational and economic performance. The idea that relative economic well-being affects health has been much discussed in the literature; U.K. studies form the basis of much of the evidence. ${ }^{52}$ If health depends on relative economic performance and the relevant comparison group is the birth cohort, then we would not expect the compulsory schooling changes, which affected entire birth cohorts, to improve health outcomes. As noted by Deaton \& Paxson (1999), however, the assumption that the birth cohort is the appropriate reference group is a strong one. For example, in the case of the 1947 change, it means that cohorts born in April 1933 must take as their reference group cohorts born in April 1933 through August 1933 (required to stay until age fifteen) and not cohorts born between September 1932 and March 1933 (able to leave at age fourteen). Since all of

\footnotetext{
${ }^{51}$ This information comes from the Times Educational Supplement on 5 April 1947.

${ }^{52}$ See the series of articles by Sir Michael Marmot, including Marmot (1994).
} 
these students were in the same academic cohort - hence would have taken classes together, played on the same sports teams and so on - this seems like a strong assumption. As such, this explanation may be unsatisfactory.

Another explanation could be based on the fact that these compulsory school changes are likely to have generated only weak peer effects. In particular, because these changes affected so many students, the affected students are likely to have left school with the same types of peers as the unaffected students. Since a range of studies (Gaviria \& Raphael, 2001; Powell et al., 2005; Trogdon et al., 2008; Duncan et al., 2005) suggest that teenage peers affect health outcomes and behaviors, including the propensity to smoke and the probability of being overweight, the absence of teenage peer effects could explain why education appears not to affect health in this setting. Weighing against this explanation however is the likely impact of these compulsory school changes on adult peer groups, especially workplace peer groups (to the extent that these changes affected earnings). Since there is evidence suggesting that workplace peers might also affect health behaviors (Cutler \& Glaeser (2007)), the peer effects explanation seems somewhat ad hoc.

These explanations all assume that the health effects of education are large, and attribute our null results to specific features of the British setting. But it is also possible that the health effects of education are, generally, rather small. As education is likely determined by many of the same factors that determine health, it may be difficult to isolate the causal effects of education. In that case, identification strategies that rely on relatively weak assumptions, such as regression discontinuity designs, may be especially fruitful. The only other regression discontinuity analysis of education and mortality of which we are aware, Albouy \& Lequien (2009), also finds small effects on mortality, although their estimates are much less precise than ours. This is partly because the French compulsory schooling changes had smaller effects on educational attainment (first-stage tstatistics 4 and 2) and partly because the mortality measure is survey-based, hence involves much smaller samples. For data availability reasons, they do not consider non-mortality outcomes.

\section{Conclusion}

While policies designed to improve population health often focus on reforms of health care systems, a recent economics literature suggests that social policies may be useful alternative policy instruments (e.g., Head Start (Ludwig \& Miller, 2007), hospital desegregation (Almond et al., 2006)). 
One such policy is education policy. In the US, there is an explicit directive within the U.S. health goals (i.e., US Healthy People) to raise the percent of students graduating from high school to 90 percent. In Britain, positive health effects have been cited among the advantages of a further raising of the school-leaving age.

In this paper, we try to shed light on the extent to which these education policies could achieve health goals. We show that the British compulsory schooling changes had dramatic effects on the educational attainment of people born just days apart, but we find that the health returns to this extra education were, at best, small. We believe there is little reason to suppose that these findings reflect specific features of the British compulsory schooling changes. Instead, the obvious explanation is that these types of education interventions have generally small causal effects on health casting doubts on the health returns to these types of policies.

We stress that our findings do not imply small health returns to all types of education interventions. In particular, it is possible that interventions at different points in the education distribution may generate larger health returns. For instance, de Walque (2007) and Grimard \& Parent (2007) find that the Vietnam draft, which induced some individuals to go college, led to a decline in rates of smoking. The possibly heterogeneous effects of education on health warrant further study. 


\section{References}

2008. Migration Statistics 2008 Annual Report.

Aaron, Henry J, \& Schwartz, William B. 1984. The Painful Prescription: Rationing Hospital Care. Washington, DC: Brookings Institution.

Acheson, D., Barker, D., Chambers, J., Graham, H., Marmot, M., \& Whitehead, M. 1998. Independent Inquiry into Inequalities in Health (Acheson Report). London: The Stationery Office.

Adams, Peter, Hurd, Michael D., McFadden, Daniel, Merrill, Angela, \& Ribeiro, Tiago. 2003. Healthy, Wealthy, and Wise? Tests for Direct Causal Paths between Health and Socioeconomic Status. Journal of Econometrics, 112(1), 3-56.

Adams, Scott J. 2002. Educational Attainment and Health: Evidence from a Sample of Older Adults. Education Economics, 10(1), 97-109.

Albouy, Valerie, \& Lequien, Laurent. 2009. Does Compulsory Education Lower Mortality? Journal of Health Economics, 28(1), 155-168.

Almond, Douglas, Greenstone, Michael, \& Chay, Kenneth. 2006. Civil Rights, the War on Poverty, and Black-White Convergence in Infant Mortality in the Rural South and Mississippi. Mimeo.

Anderberg, Dan, Chevalier, Arnaud, \& Wadsworth, Jonathan. 2008. Anatomy of a Health Scare: Education, Income and the MMR Controversy in the UK. IZA Discussion Paper No. 3590.

Arendt, Jacob Nielsen. 2005. Does Education Cause Better Health? A Panel Data Analysis Using School Reforms for Identification. Economics of Education Review, 24(2), 149-160.

Arkes, Jeremy. 2003. Does Schooling Improve Adult Health? RAND Working Paper, Santa Monica, CA. Banks, James, Marmot, Michael, Oldfield, Zoe, \& Smith, James P. 2006. The SES Health Gradient on Both Sides of the Atlantic. NBER Working Paper No. 12674.

Becker, Gary S, \& Mulligan, Casey B. 1997. The Endogenous Determination of Time Preference. Quarterly Journal of Economics, 112(3), 729-758.

Beckett, Megan. 2000. Converging Health Inqualities in Later Life: an Artifact of Mortality Selection? Journal of Health and Social Behavior, 41, 106-119.

Berger, M.C., \& Leigh, J.P. 1989. Schooling, Self-Selection, and Health. Journal of Human Resources, 24(3), 433-55.

Buonnono, Paolo. 2006. Long-term effects of conscription: Lessons from the U.K. University of Bergamo, Department of Economics, Working Paper No.0604.

Card, David E. 1999. The Causal Effect of Education on Earnings. In: Ashenfelter, Orley, \& Card, David E (eds), The Handbook of Labor Economics Vol 3a. Amsterdam: Elsevier/North Holland.

Christenson, Bruce A, \& Johnson, Nan E. 1995. Educational Inequality in Adult Mortality: An Assessment with Death Certificate Data from Michigan. Demography, 32(2), 215-229.

Crawford, Claire, Dearden, Lorraine, \& Meghir, Costas. 2007. When you are born matters: the impact of date of birth on child cognitive outcomes in England.

Currie, Janet, \& Moretti, Enrico. 2003. Mother education and the intergenerational transmission of human capital: evidence from college openings and longitudinal data. Quarterly Journal of Economics, 118(4), $1495-1532$.

Cutler, David, \& Lleras-Muney, Adriana. 2007. Understanding Differences in Health Behaviors by Education. Journal of Health Economics, 29(1), 1-28.

Cutler, David, Deaton, Angus, \& Lleras-Muney, Adriana. 2006. The Determinants of Mortality. The Journal of Economic Perspectives, 97-120.

Cutler, David M, \& Glaeser, Edward L. 2007. Social Interactions and Smoking. NBER Working Paper No. $1347 \%$.

Cutler, David M, \& Lleras-Muney, Adriana. 2006. Education and Health: Evaluating Theories and Evidence. NBER Working Paper 12352, Cambridge, MA.

de Walque, Damien. 2007. Does education affect smoking behaviors?: Evidence using the Vietnam draft as an instrument for college education. Journal of Health Economics, 26(5), 877-895.

Deaton, Angus, \& Paxson, Christina. 1999. Mortality, Income and Income Inequality over Time in Britain and the United States. Pages 427-4800 of: Wise, David A (ed), Perspectives on the Economics of Aging. 
Chicago, IL.: University of Chicago Press for NBER.

Deschenes, Olivier. 2009. The Effect of Education on Mortality: Evidence from the Baby-Boom Generation. Devereux, Paul, \& Hart, Robert A. 2008. Forced to Be Rich? Returns to Compulsory Schooling in Britain. IZA Discussion Paper No. 3305.

Duncan, Greg, Boisjoly, Johanne, Kremer, Michael, Levy, Dan, \& Eccles, Jasque. 2005. Peer Effects in Drug Use and Sex Among College Students. Journal of Abnormal Child Psychology, 33(3), 375-385.

Efron, Bradley. 1988. Logistic Regression, Survival Analysis, and the Kaplan-Meier Curve. Journal of the American Statistical Association, 83(402), 414-425.

Fuchs, Victor R. 1982. Time preference and health: an exploratory study. In: Fuchs, V R (ed), Economic Aspects of Health. New York: Russell Sage Foundation.

Gaviria, A, \& Raphael, S. 2001. School-based peer effects and juvenile behavior. Review of Economics and Statistics, 83(2), 257-268.

Goldin, Claudia, \& Katz, Lawrence. 2009. Why the United States Led in Education: Lessons from Secondary School Expansion, 1910 to 1940. In: Eltis, David, Lewis, Frank D., \& Sokoloff, Kenneth L. (eds), Human Capital and Institutions: A Long-Run View. Cambridge: Cambridge University Press.

Goldman, Dana P, \& Smith, James P. 2002. Can patient self-management help explain the SES health gradient? Proceedings of the National Academy of Science, 99(16), 10929-34.

Griliches, Zvi. 1977. Estimating the Returns to Schooling: Some Econometric Problems. Econometrica, 45(1), 1-22.

Grimard, Franque, \& Parent, Daniel. 2007. Education and smoking: Were Vietnam war draft avoiders also more likely to avoid smoking? Journal of Health Economics, 26(5), 896-926.

Grossman, Michael. 2004. The Demand for Health, 30 Years Later: A Very Personal Retrospective and Prospective Reflection. Journal of Health Economics, 23(4), 629-636.

Grossman, Michael. 2005. Education and Non-market Outcomes. NBER Working Paper 11582, Cambridge, $M A$.

Harmon, Colm, \& Walker, Ian. 1995. Estimates of the Economic Return to Schooling for the UK. American Economic Review, 85(5), 1278-1296.

HSMO. 1948. Education in 1947: Report of the Ministry of Education to Parliament. London, UK.

Idler, E L, \& Benyamini, Y. 1997. Self-rated health and mortality: A review of 27 community studies. Journal of Health and Social Behavior, 38(1), 21-37.

Imbens, Guido, \& Lemieux, Thomas. 2008. Regression Discontinuity Designs: A Guide to Practice. Journal of Econometrics, 142(2), 615-635.

Imbens, Guido W, \& Angrist, Joshua D. 1994. Identification and Estimation of Local Average Treatment Effects. Econometrica, 62(2), 467-475.

Johnston, David W, Propper, Carol, \& Shields, Michael A. 2009. Comparing Subjective and Objective Measures of Health: Evidence from Hypertension for the Income/Health Gradient. Journal of Health Economics, 28(3), 540-552.

Jurges, Hendrik, Kruk, Eberhard, \& Reinhold, Steffen. 2009. The Effect of Compulsory Schooling on Health - Evidence from Biomarkers. Mannheim Research Institute for the Economics of Aging Working Paper 183-2009.

Katz, Larry, Kling, Jeffrey, \& Liebman, Jeffrey. 2007. Experimental analysis of neighborhood effects. Econometrica, 75(1), 83-119.

Kenkel, Donald, Lillard, Dean, \& Mathios, Alan. 2006. The Roles of High School Completion and GED Receipt in Smoking and Obesity. Journal of Labor Economics, 24(3), 635-660.

Kitagawa, Evelyn M, \& Hauser, Philip M. 1968. Educational Differentials in Mortality by Cause of Death: United States, 1960. Demography, 5(1), 318-353.

Lee, David S, \& Card, David. 2008. Regression Discontinuity Inference with Specification Error. Journal of Econometrics, 142(2), 655-674.

Lee, David S, \& Lemieux, Thomas. 2009. Regression Discontinuity Designs in Economics. NBER Working Paper No. 14723.

Lee, David S, \& McCrary, Justin. 2009. The Deterrence Effect of Prison: Dynamic Theory and Evidence. Lleras-Muney, Adriana. 2002. Were Compulsory Attendance and Child Labor Laws Effective? An Analysis 
from 1915 to 1939. The Journal of Law and Economics, 45(2), 401-435.

Lleras-Muney, Adriana. 2005. The Relationship Between Education and Adult Mortality in the United States. Review of Economic Studies, 72, 189-221.

Ludwig, Jens, \& Miller, Doug. 2007. Does Head Start Improve Children's Life Chances? Evidence from a Regression Discontinuity Design*. The Quarterly Journal of Economics, 122(1), 159-208.

Lyall, Sarah. 2008 (February). Paying Patients Test British Health Care System.

Lynch, Scott M. 2003. Cohort and Life-Course Patterns in the Relationship Between Education and Health: A Hierarchical Approach. Demography, 40(2), 309-331.

Malamud, Ofer, \& Wozniak, Abigail. 2006. The Impact of College Education on Geographic Mobility: Evidence from the Vietnam Generation.

Marmot, Michael G. 1994. Social Differences in Health Within and Between Populations. Daedalus, 123(4), 197-216.

Mazumder, Bhash. 2007. How Did Schooling Laws Improve Long-Term Health and Lower Mortality? Federal Reserve Bank of Chicago Working Paper No. 2006-23.

McCrary, Justin, \& Royer, Heather. 2006. The Effect of Female Education on Fertility and Infant Health: Evidence from School Entry Laws Using Exact Date of Birth. NBER Working Paper No. 12329.

McDonough, Peggy, Williams, David R, House, James S, \& Duncan, Greg J. 1999. Gender and the Socioeconomic Gradient in Mortality. Journal of Health and Social Behavior, 40(1), 17-31.

of Health, Department, \& Security, Social. 1980. Inequalities in Health: Report of a Working Group Chaired by Sir Douglas Black.

O'Keefe, Dennis. 1975. Economic Aspects of Raising the School Leaving Age in England and Wales in 1947. The Economic History Review, New Series, 28(3), 500-516.

Oreopoulos, Philip. 2006. Estimating Average and Local Average Treatment Effects of Education when Compulsory School Laws Really Matter. American Economic Review, 96(1), 152-175.

Oreopoulos, Philip. 2008. Estimating Average and Local Average Treatment Effects of Education when Compulsory School Laws Really Matter: Corrigendum. American Economic Review.

Oreopoulos, Philip, \& Salvanes, Kjell G. 2009. How Large are Returns to Schooling? Hint: Money is not Everything. NBER Working Paper 15339, Cambridge, MA.

Pappas, Gregory, Queen, Susan, Hadden, Wilbur, \& Fisher, Gail. 1993. The Increasing Disparity in Mortality Between Socioeconomic Groups in the United States, 1960 and 1986. New England Journal of Medicine, 329(2), 103-109.

Powell, Lisa, Tauras, John, \& Ross, Hana. 2005. The Importance of Peer Effects, Cigarette Prices and Tobacco Control Policies for Youth Smoking Behavior. Journal of Health Economics, 24(5), 950-968.

Prynne, CJ, Paul, AA, Price, GM, Day, KC, Hilder, WS, \& Wadsworth, MEJ. 2007. Food and Nutrient Intake of a National Sample of 4-year-old Children in 1950: Comparison with the 1990s. Public Health Nutrition, 2(04), 537-547.

Rose, G., \& Marmot, MG. 1981. Social Class and Coronary Heart Disease. Heart, 45(1), 13-19.

Scott, Leonard Victor. 1993. Conscription and the Attlee Governments: The Politics and Policy of National Service 1945-1951. Oxford, UK: Oxford University Press.

Seager, Ashley. 2009 (January). School-leaving Age May Rise to 18 in Effort to Tackle Unemployment.

Sharp, C. 1997. Local Education Authority Admission Policies and Practices. In: Sharp, C, \& Turner, G (eds), Four-Year-Olds in School: Policy and Practice: An NFER/SCDC Seminar Report. London: Newcombe House.

Silles, Mary A. 2009. The Causal Effect of Education on Health: Evidence from the United Kingdom. Economics of Education Review, 28(1), 122-128.

Snyder, Stephen, \& Evans, William. 2006. The Effect of Income on Mortality: Evidence from the Social Security Notch. Review of Economics and Statistics, 88(3), 482-495.

Sturm, Ronald. 2002. The Effects of Obesity, Smoking, and Drinking on Medical Problems and Costs. Health Affairs, 21(2), 245-253.

Sullivan, Daniel, \& von Wachter, Till. 2007. Mortality, Mass-Layoffs, and Career Outcomes: An Analysis using Administrative Data. NBER Working Paper No. 13626.

Timmins, Nicholas. 1996. The Five Giants: A Biography of the Welfare State. London, UK: Fortuna Press. 
Titmuss, Richard M. 1950. History of the Second World War. United Kingdom Civil Series: Problems of Social Policy.

Trogdon, Justin, Nonnemaker, James, \& Pais, Joanne. 2008. Peer Effects in Adolescent Overweight. Journal of Health Economics, 27(5), 1388-1399.

Weinstein, Milton C., \& Skinner, Jonathan A. 2010. Comparative Effectiveness and Health Care Spending - Implications for Reform. New England Journal of Medicine, 362(5), 460-465.

Whitehead, Margaret. 1987. The Health Divide: Inequalities in Health in the 1980's. Health Education Council.

Williams, David R, \& Collins, Chiquita. 1995. US Socioeconomic and Racial Differences in Health: Patterns and Explanations. Annual Review of Sociology, 21, 349-386.

Woodhead, Martin. 1989. Schools starts ar five...or four years old?: the rationale for changing admission policies in England and Wales. Journal of Education Policy, 4(1), 1-21.

Zweiniger-Bargielowska, Ina. 2000. Austerity in Britain: Rations, Controls and Consumption, 1939-1955.

Oxford University Press. 


\section{Appendix A: Additional Robustness Checks}

In this appendix, we present a number of additional tables and figures as robustness checks. We discuss these tables and figures in the main text.

\section{Appendix B: Measuring Years of Education}

Throughout the paper we refer to the health impacts of "years of education." This is defined as the age at which someone left full-time education minus five. In this Appendix we describe why years of education is measured in this way.

The starting point is the two survey datasets used in this paper: the Health Survey of England (HSE) and the General Household Survey (GHS). These surveys ask respondents the following questions:

HSE "At what age did you finish your continuous full-time education at school or college?"

GHS "How old were you when you left there, or when you finished or stopped your course?" [In response to "Now thinking just of your full-time education, what type of school or college did you last attend full-time?"]

The relationship between "age left full-time education" and "years of education" is governed by English laws that determine the period of compulsory schooling (i.e., compulsory full-time education). These laws state that students must have started school by the term after they turn five, although students have, traditionally, started school in the term in which they turned five (Sharp, 1997). ${ }^{53}$ Before 1962, these laws stated that students could not leave until the end of the term in which they reached the minimum school leaving age. The U.K. education system has three terms that run September-December, January-April, and April-July; exact dates vary by school district. Hence, students born in October could not leave until Christmas, students born in February could not leave until Easter and students born in May could not leave until July. After 1962, these laws stated that students born September-January could not leave until April, and students born February-August could not leave until June. We illustrate the structure of these laws in Appendix Figure B1a.

Based on these laws, we can calculate the minimum number of years and school terms of full-time education that must have been completed by someone reporting leaving at the minimum leaving age and the maximum number of years and school terms of full-time education that must have been completed by someone reporting leaving at the minimum leaving age. This is illustrated in Appendix Figure B1b. The minimum is always nine years and one term for those able to leave before the 1947 change, ten years and one or two terms for those able to leave before the 1972 change and eleven years and one or two terms for the rest. Because respondents that report leaving at the minimum leaving age may not have left at the first available opportunity, the maximum is greater than this. In particular, as seen in Appendix Figure B1b, respondents that report leaving at the minimum leaving age could have completed one or two terms more than the minimum years and school terms of full-time education that is completed by those that leave at the first available opportunity.

With this discussion in mind, we calculate "years of education" as the age left full-time education minus five. That $\mathrm{X}$ years of education then refers to $\mathrm{X}$ years and one term, $\mathrm{X}$ years and two terms or $\mathrm{X}+1$ years is not a problem: standard measures of completed years or grades of education share the same property (i.e., we do not observe if fractions of grades are completed). In addition, any

\footnotetext{
${ }^{53}$ Sharp (1997) claims that these laws changed to accommodate earlier starting as pupil numbers fell in the 1970 s. This is confirmed by the survey evidence in Crawford et al. (2007).
} 
measurement error in years of education will bias downwards the estimated impact of the 1947 and 1972 law changes on educational attainment. This will bias upwards our two-stage least squares estimates of the health effects of education. Since these estimates are consistently small, this phenomenon is likely of little importance here.

\section{Compliance post-1972}

As seen in Figure 2, non-compliance among summer-borns increases after 1972. That is, after 1972, a large fraction of students born in June, July and August appear to leave full-time education at age fifteen or younger. In fact, while there may be a small amount of non-compliance throughout the entire period studied, this post-1972 phenomenon is likely another consequence of the structure of the laws.

Before 1972, when the minimum leaving age was fifteen, students were required to stay in full-time education until part way through grade nine. Like all grades except grade ten, grade nine finishes in mid-July. Hence only students born in late July and August could have left at fourteen (recall that students can leave at the end of the term in which they turn fifteen, where the summer term ends in July but for the purposes of the minimum leaving age is defined to run until September). After 1972, when the minimum leaving age became age sixteen, students had to stay until part way through grade ten. Grade ten finishes with the "O level" exam period and, technically, students finish when they complete their last exam. Since the exam period starts in late May and finishes in mid-June, starting in 1972, students born in late June, July, and August could leave at fifteen, technically younger than the minimum leaving age (sixteen). This can account for the apparent increase in post-1972 non-compliance. Since the exam period is an unusual period of schooling, even respondents that were in school throughout this period may report leaving in April. This would further contribute to the apparent increase in non-compliance.

While this phenomenon could introduce some error into our measurement of years of education, since all of our models control for quarter- or month-of-birth dummy variables, we think it will have little impact on our analysis. Provided these month-of-birth or quarter-of-birth patterns are consistent over time in the post-reform period, they will be controlled for in our regressions. ${ }^{54}$ As expected, the non-compliance phenomenon is much less striking once we regression adjust for month or quarter of birth.

\section{Appendix C: The Impacts of the Compulsory Schooling Changes on Earnings}

In this Appendix, we report estimates of the earnings impacts of the two law changes. Although other studies have estimated these impacts, our empirical specification differs from that used in those studies, hence it is worth using it to re-analyze these impacts. The main difference between our specification and those used previously is the level at which across-cohort comparisons are made. While the previous literature made these comparisons at the year-of-birth level, we make these comparisons mainly at the month-of-birth level.

\section{Previous estimates}

Three studies have used these compulsory schooling law changes to estimate the earnings returns to education: Harmon \& Walker (1995), Oreopoulos (2006) and Devereux \& Hart (2008). All use year-of-birth comparisons. Harmon \& Walker (1995) was the first study to use the law changes to generate instrumental variables estimates of the earnings returns to education. They use Family Expenditure Survey (FES) data for the years 1978-1986 and focus on males aged 18-64. The instruments in their model are dummy variables indicating the leaving age facing respondents

\footnotetext{
${ }^{54}$ We can allow for the seasonal patterns to be different pre- and post-reform and our estimates are qualitatively unchanged.
} 
(fifteen or sixteen) and they also control for survey year, age and age squared. They obtain instrumental variables estimates of the effect of an additional year of education on log earnings of 0.15 , much larger than the least squares estimate they calculate, 0.06 . They obtain similar estimates when they used an ordered probit to model years of education (to account for the categorical nature of the data).

Oreopoulos (2006) notes that while Harmon \& Walker (1995) control for age and survey year, they may not take full account of cohort trends. Oreopoulos (2006) instead focuses on the 1947 change and accounts for cohort trends using a regression discontinuity approach that controls for a fourth-order polynomial in year of birth. In addition to exploiting variation induced by the 1947 change, he also uses a difference-in-difference approach to exploit variation in the timing of this British change relative to a comparable change that took place in Northern Ireland in the 1950s. Using both approaches, he obtains large instrumental variables estimates for men and women, comparable to those found by Harmon \& Walker (1995). For example, using only British data, his instrumental variables estimate of the effect of an additional year of education on log earnings is 0.15 with a standard error of 0.06 for men and 0.15 with a standard error of 0.13 for women. These estimates are based on General Household Survey (GHS) data for the years 1983-1998; the sample includes those born in Britain between 1921 and 1951 (aged 32-64 at the time of the surveys).

Devereux \& Hart (2008) estimate earnings returns using regression discontinuity models based on similar specifications and estimation samples. Again, they only have access to data at the year-ofbirth level. The innovation in their study is the use of large samples of high-quality administrative earnings data. For men, their estimates are much closer to conventional least squares estimates (around 0.05-0.06); for women, their estimates are not statistically different from zero. Devereux \& Hart (2008) also report estimates using GHS data and GHS samples that correspond closely to the sample based on the administrative data (excluding the self-employed, including foreign-born). For men, they obtain instrumental variables estimates of the effect of an additional year of education on weekly earnings of nearly 6 percent (standard error of 2 percent). For women the corresponding estimates are 1.5 percent (standard error of 3 percent). They conclude that the earnings returns to additional years of education may be closer to least squares estimates than was previously thought.

\section{New estimates based on month of birth}

Both the 1947 and 1972 law changes were introduced part way through the year. As such, we estimate their earnings impacts using models at the month-of-birth level. Our estimation sample is similar to that used by Devereux \& Hart (2008), who also focus on British-only data. In particular, we choose the sample of employees that were born in Britain between 1921 and 1945 and that report working between 1 and 84 hours in the previous week. We also discard observations for which real hourly wages (in 2001) are less than one pound or greater than 150 pounds. Unfortunately, month of birth is not available in the GHS until 1985. This means that our samples are smaller than those used by Devereux \& Hart (2008). It also means that if we used the same age restrictions (between ages 25 and 60), we would not observe outcomes for those born before 1925. We therefore expand the age range to include those up to age 64; Harmon \& Walker (1995) and Oreopoulos (2006) focus on similar age ranges.

Appendix Table C1 reports estimates of the reduced-form effects of the 1947 change on both earnings and on the probability of being observed working a certain number of hours (i.e., selecting into the sample). We report separate estimates for men and women and for each outcome we report estimates from two specifications. In column (1) we report the estimate from a specification similar to that used by Devereux \& Hart (2008). That is, we use a global polynomial (over the same data window) with a fourth-order polynomial in the running variable (in our case month of birth). In 
column (2) we report estimates based on a local linear regression approach.

If the treatment is defined as "years of primary and secondary schooling," as in Devereux \& Hart (2008), the instrumental variable estimates will be roughly twice as large as the reported reduced-form estimates; if the treatment is defined as "years of full-time education" (i.e., primary and secondary plus post-secondary education), the instrumental variables estimates will be closer to three times as large. That is because, empirically, the law changes have a larger impact on total years of primary and secondary schooling than they do on total years of full-time education. Presumably that is because the extra year of secondary schooling is, for some, a substitute for additional post-secondary education that would otherwise have been obtained. In the extreme case, if all students that leave at the compulsory age pursue at least one year of post-secondary education, and if students compelled to stay for an extra year in secondary school reduce by one year the amount of post-secondary education pursued, the compulsory schooling change will have large impacts on total years of primary and secondary schooling and no impact on total years of full-time education.

The estimates presented in this Table suggest that for men, the 1947 change increased earnings by nearly 8 log points. The global polynomial estimates (column (1)) are very close to the preferred local linear estimates (column (2)). The local linear estimates are also fairly robust to bandwidth choice. As Devereux \& Hart (2008) also found, estimates for hourly earnings are slightly smaller than those for weekly earnings. Appendix Figure C1 shows the graph corresponding to the weekly earnings estimates. This figure superimposes fitted lines from the local linear approach on the scatterplot of raw data by month of birth.

It is tempting to use the point estimates in Appendix Table C1 to claim that the 1947 change had earnings effects on the order of those of Harmon \& Walker (1995) and Oreopoulos (2006). We think that our samples are too small to pinpoint the precise magnitude of these effects. For example, when we focus on the 90 per cent of this sample that works "normal" hours (which we use the data to define as 35-60), the estimates (second set of rows in Appendix Table C1) are much closer to those reported by Devereux \& Hart (2008). Instead, we view our results as consistent with all of the previous literature in that we find that this reform had statistically significant effects on male earnings.

Turning to women, we find negative but not statistically significant effects of the 1947 change on earnings. Again, these effects are smaller when we focus on the 90 per cent of this sample with regular hours (10-50, again defined using the data). These findings are broadly in line with those of Devereux \& Hart (2008), who also find negative but statistically insignificant estimates. To the extent that we worry about these negative point estimates, it is important to note that the point estimates for the "observed working" outcomes suggest that the 1947 change may have induced some women to enter the labor force.

In Appendix Table C2, we present estimates of the effects of the 1972 change, not investigated by Oreopoulos (2006) or Devereux \& Hart (2008). Because this reform had smaller impacts on years of education, around 0.2-0.3, it is harder to detect earnings effects in samples of this size. For example, a reduced-form earnings effect of 0.015 would scale up to an instrumental variables estimate of 0.06, roughly the size of the estimate found for the 1947 change by Devereux \& Hart (2008). For men, the point estimates exceed 0.015 using small bandwidths but not otherwise. There is however some evidence of positive selection into the labor force for men, which might lead us to understate these earnings effects. For women with regular hours, point estimates of the earnings effects are much larger, although again imprecise. In addition, there is evidence that the 1972 change selected women out of the labor force, which might bias these estimates upwards. Overall, given the size of these GHS samples and the relatively small effects of the 1972 change, the earnings effects are difficult to determine. Our data are more powerful for determining the health and mortality effects 
of the change, given the measurement error in earnings in these survey data.

\section{Appendix D: Migration Issues}

As emphasized in the data section, our mortality counts will exclude individuals who left England. As there is some evidence from Malamud \& Wozniak (2006) that higher-educated individuals have higher propensities to migrate, migration could cause us to undercount deaths among the post-reform cohorts relative to the pre-reform cohorts. Since this will bias us towards finding a protective health effect of education, and since we find little evidence of a mortality-reducing effect of education, we are less concerned about migration biases than we would have been had we found large mortality effects.

Nevertheless, we estimate the effect of the 1947 compulsory school reform on migration to the United States. ${ }^{55}$ Of course, this analysis excludes other large receiving countries. In 2007, Australia (59 thousand emigrants), Spain (21 thousand emigrants), France (20 thousand emigrants), the United States (19 thousand emigrants), and Poland (18 thousand emigrants) were the top five intended countries for emigrants from the United Kingdom (ONS, 2008). Birth cohort details needed for the research design are not available in the public-use versions of the Canadian and Australian Censuses. Emigrants to the United States from the United Kingdom accounted for roughly 6 percent of all emigrant flows in 2007 (ONS, 2008).

To test for migration differences by cohort, we use the 1960, 1970, and 1980 U.S. Census data and the 2005-2007 American Community Surveys (the only datasets with information on quarter of birth). For each dataset, we present separate regression discontinuity estimates of the effect of the reform on the fraction of individuals of each birth cohort appearing in the United States (Appendix Table D1). Consistent with the results of Malamud \& Wozniak (2006), nearly all of these estimates are positive, although only 5 (out of 15 ) are statistically significant at the 5 percent level. For the male/female pooled regressions, the magnitudes vary from a 1-percent positive effect (1980 Census) to a 24-percent positive effect (2006 ACS). Note that a 1.5 year effect on life expectancy would generate a -2 percentage point effect on mortality between the ages of 45 and 69 (see Appendix E). Since roughly 2 percent of the 1933 quarter 2 British-born birth cohort migrated to the United States, the reform would have had to have reduced US-bound migration to zero in order to explain our null mortality findings. Since our mortality estimates are small and our migration estimates are, on balance, positive, we do not think that differential migration patterns can explain our mortality results.

\section{Appendix E: Mortality Simulations}

In our main analysis, we report estimates of the effects of the compulsory schooling changes on age-based mortality rates. Overall we find little evidence that either law change affected mortality. One might wonder how the estimates of the previous literature would translate into estimates using our regression framework. For this reason, we conduct a series of simulations assuming effects on life expectancy of the size of those found in Lleras-Muney (2005).

We perform our simulation in several steps:

1. First, we construct age-specific mortality rates using age $\mathrm{x}$ year death data from the Human Mortality Database at Berkeley. These data provide the number of deaths by age, so we are able to compute the probability of death for each year of life. We compute these age-specific mortality rates using the mortality rates for the 1933 birth cohort for the 1947 law change and the 1957 birth cohort for the 1972 law change. However, by 2006, the last year of data, both of these cohorts have many members still living. To address this, we use the age-specific mortality

\footnotetext{
${ }^{55}$ We cannot cleanly identify the effect of the second reform on immigration to the U.S. because of a lack of data by month of birth (the 1972 reform affected cohorts born part-way through the third quarter of 1957 - (i.e., September 1957 and later)).
} 
rates of the 1910 cohort, a cohort that is old enough to have had much of its members die. For the 1933 cohort, we use the age-specific mortality rates of the 1910 cohort beginning at age 74 , then compute the fraction of the 1933 cohort still living at age 74 . Then, our estimated mortality rates for the $74+$ ages for the 1933 cohort are the age-specific mortality rates for the 1910 cohort divided by the fraction of the 1910 cohort dying between the ages of 74 and 96 multiplied by the fraction of the 1933 cohort alive at age 74 . We perform an analogous procedure for the 1957 cohort although we need to estimate the age-specific mortality rates using the 1910 cohort over a wider span of ages.

2. Second, for each individual born, we simulate years of education as a linear function of a random draw and their date of birth. More specifically, for the 1947 reform, we use the following equation to generate simulated years of schooling:

$$
\text { education }=0.00471 R+0.47 D+10.08+u
$$

where education is years of schooling, $\mathrm{R}$ is the running variable in birth quarter relative to 1933 quarter 2, D is a dummy variable equal to 1 if the quarter of birth is 1933 quarter 2 or later, and $\mathrm{u}$ is a random variable. The random variable $\mathrm{u}$ is distributed normal with standard deviation of 1.48 (based on the observed standard deviation of years of education). The coefficients in this equation are also based on the data (i.e., 0.00471 is the cohort trend in years of schooling, 0.47 is the effect of the 1947 reform on years of schooling, and 10.08 is the average years of schooling for the pre-reform cohort). In this simulation, the date of birth affects education both through the effect of the changes to compulsory schooling laws and through cohort-level changes in education. A similar simulating equation is used for the 1972 reform.

3. Third, for each individual, we simulate age at death. From step 1, we have the probability of death at each integer age and, thus, the cumulative distribution of age at death. We draw from this empirical distribution to obtain each individual's preliminary simulated age of death. In practice, we assign individuals non-integer ages by linearly interpolating the cumulative distribution of age at death between integer ages. To take account of across-cohort trends in mortality and the postulated effect of education on life expectancy, we generate age of death as a linear function of this preliminary age at death, cohort level trends in age at death, a 1.5 year effect of education on life expectancy and some individual-level and cohort-level mean-zero noise. The variance of this noise is intended to emulate the variance observed in the data. That is,

$$
\text { expectancy }=\text { expectancy }_{\text {sim }}+(0.05+\epsilon) R+(1.5+\nu)(\text { education }-10.55)+\eta
$$

where expectancy is age at death, expectancysim is the simulated age at death computed above, $\epsilon$ is a cohort-specific normally-distributed random variable with standard deviation of 0.05 (the value of this random variable is the same for all individuals in the same birth cohort), $\mathrm{R}$ is the running variable in birth quarter relative to 1933 quarter 2, $\nu$ is a random normal variable with standard deviation of 1 , and $\eta$ is a random normal variable with standard deviation of 5 . Here we allow for the coefficients on the cohort trends and education trends to be stochastic. This adds variability to our simulated data to match the patterns we see in the observed data. Note that the 0.05 coefficient on the running variable denotes the cohort trend in life expectancy, 1.5 is the effect of education on life expectancy found by Lleras-Muney (2005), and 10.55 (e.g., $10.08+0.47)$ is the average level of schooling for the post-reform cohort.

4. Next we impose sample restrictions consistent with our data (i.e., we only observe deaths occurring between 1970 and 2007) and calculate the age-based mortality rates as in our main analysis. 
We report the graphical results of our simulation in Appendix Figures E1 and E2. These figures show that a 1.5 year effect of education on life expectancy would generate noticeable discontinuities in our mortality outcomes. Since we see no such discontinuities in our 1947 graphs, our analysis suggests that an extra year of education has effects on life expectancy much smaller than 1.5 years. For the 1972 change, the mortality effects are more difficult to detect. This is because of the infrequency of death at the ages observed for that population. These effects should still, however, be noticeable in the graphs. 
Figure 1: Years of full-time education by quarter of birth

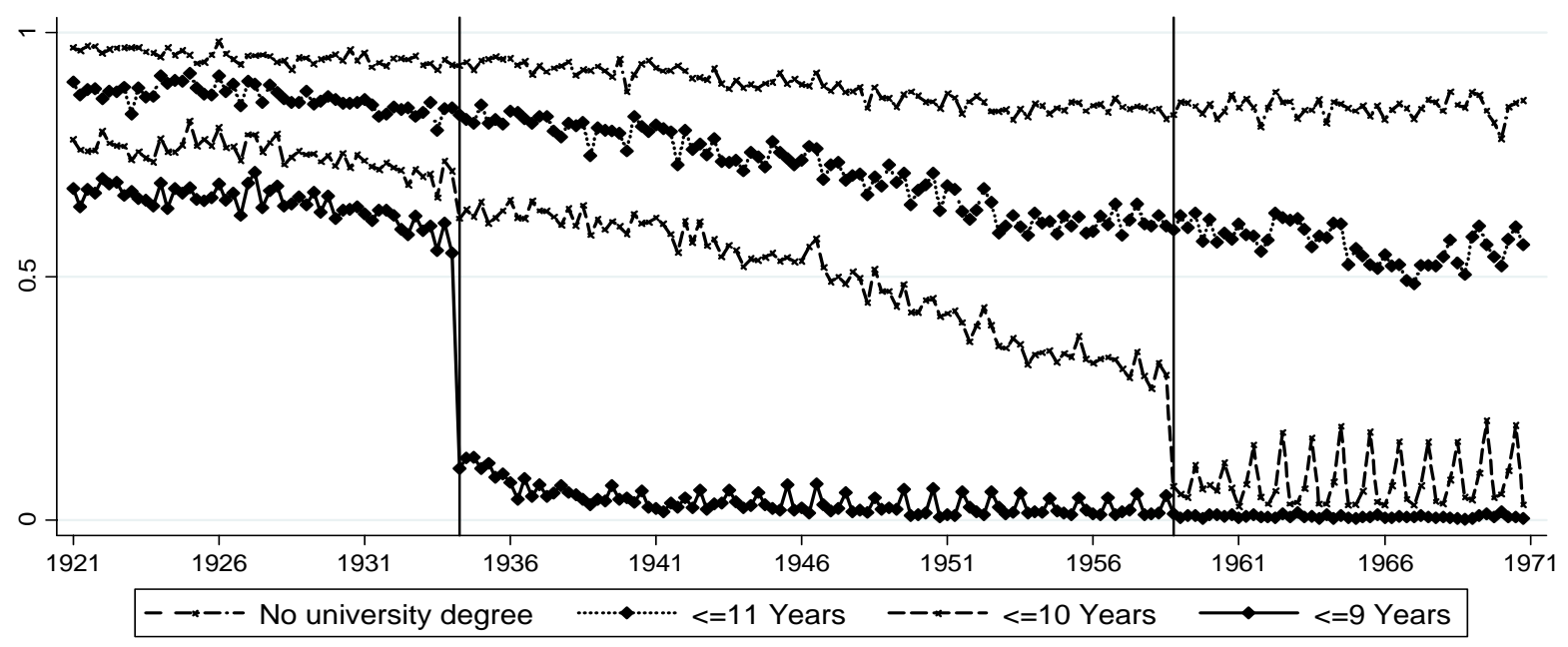

Notes: Raw fractions are based on pooled waves (1991-2004) of the Health Survey of England. The vertical lines are cutoffs corresponding to the first cohorts subject to the new compulsory schooling laws. The first of these took effect on 1 April 1947, the second on 1 September 1957. 
Figure 2: The impact of the compulsory schooling changes on educational attainment

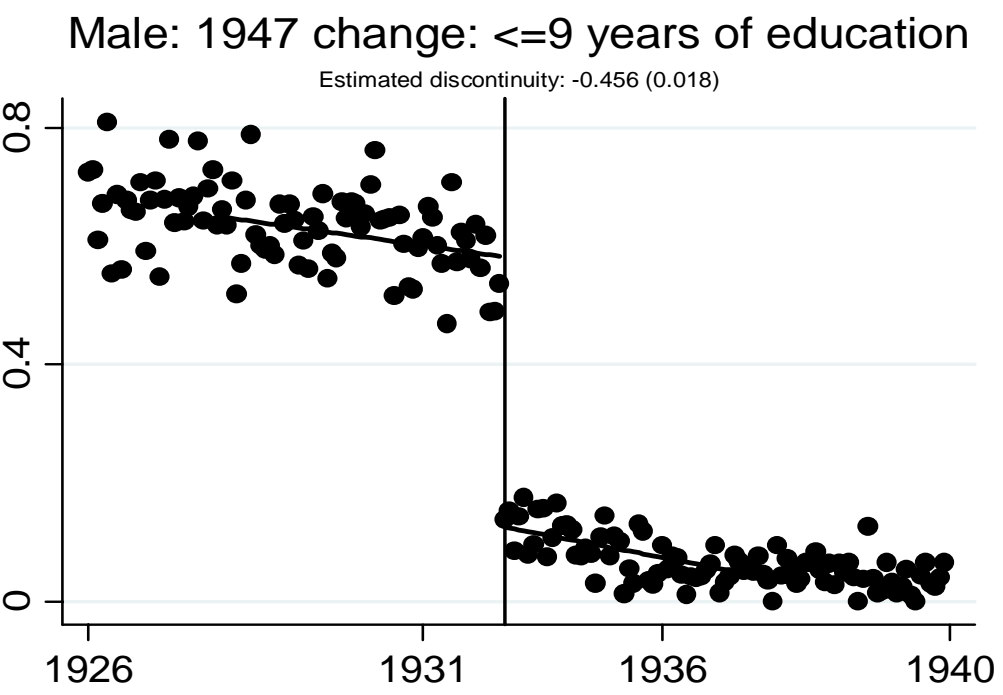

Female: 1947 change: $<=9$ years of education

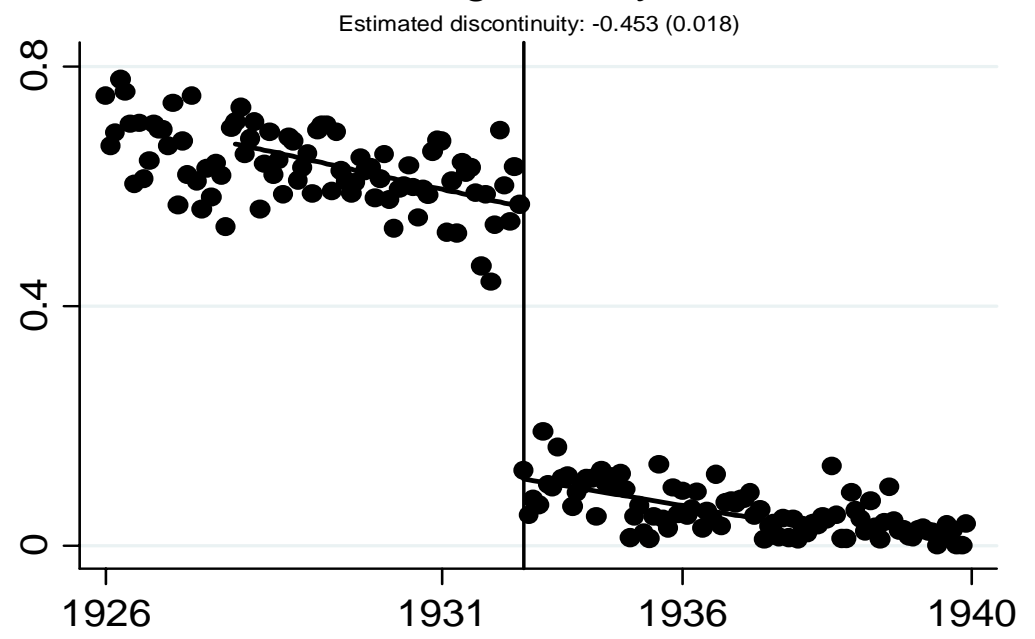

Male: 1972 change: <=10 years of education Female: 1972 change: <=10 years of education
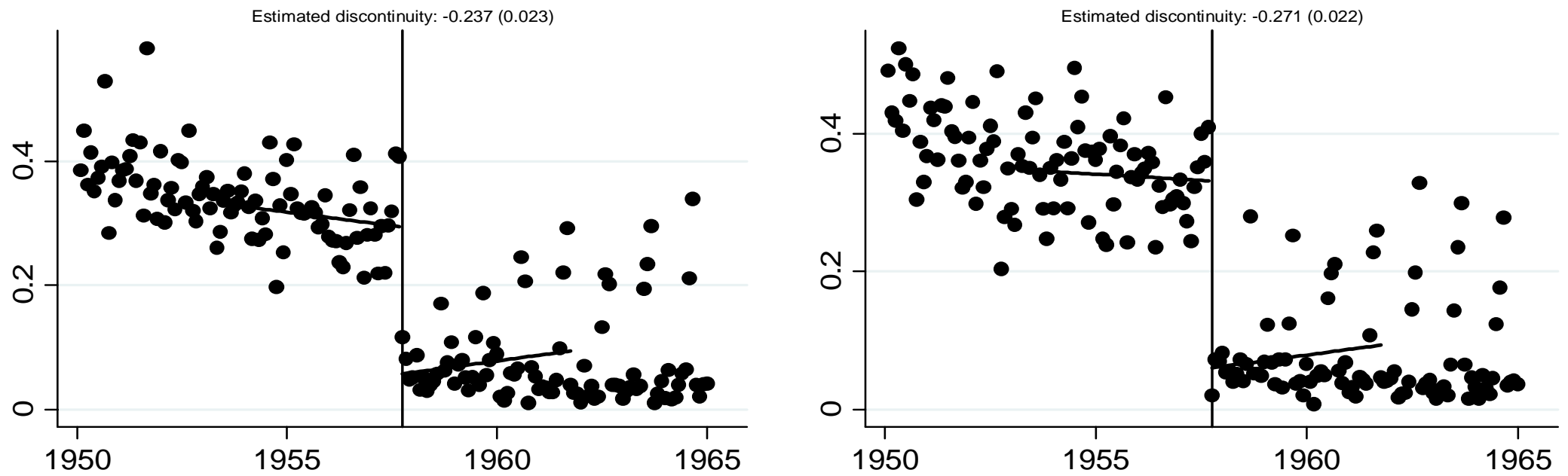

Notes: Samples are based on the Health Survey of England: 1991-2004. Points represent means among people in each month-of-birth cell. The estimated discontinuities are based on local linear regressions; the standard errors of the estimates are presented in parentheses. The fitted values of these local linear regressions are also plotted. 
Figure 3: The impact of the 1947 change on mortality

Male: Mortality Rate for Ages 45-69

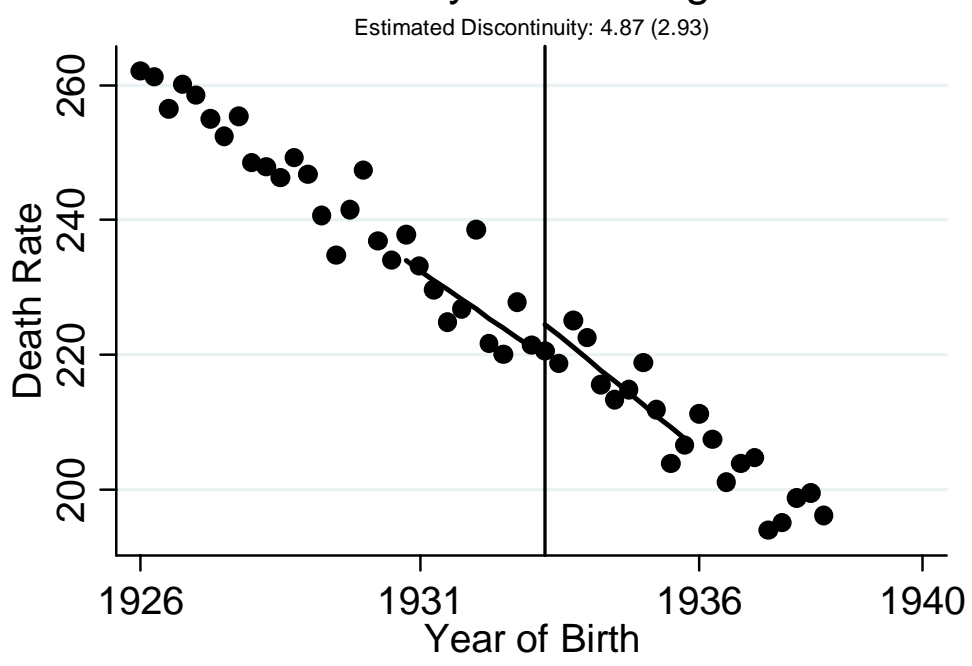

Female: Mortality Rate for Ages 45-69

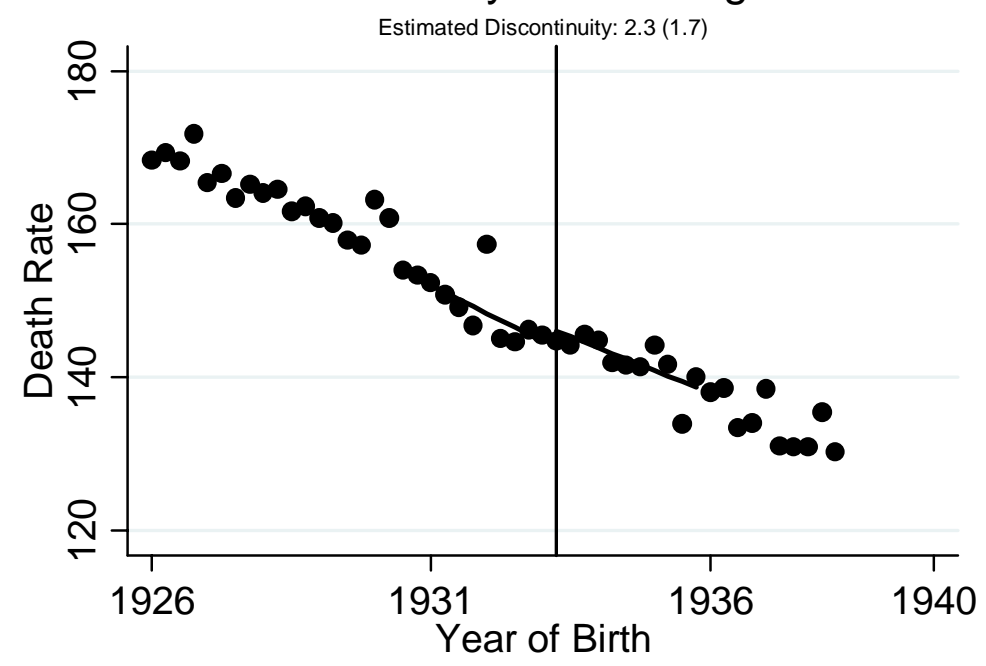

All: Mortality Rate for Ages 45-69

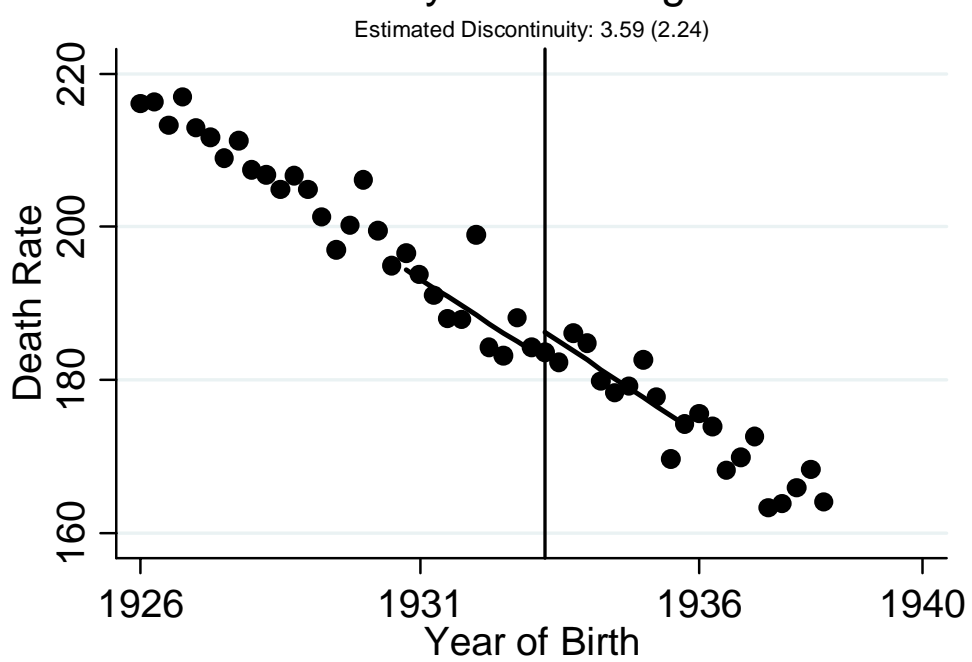

Notes: The death rate is defined as the fraction of the cohort dying between the specified ages multiplied by 1000 where the denominator is the size of the cohort at birth. Points represent the death rate for each quarter-of-birth cell. The estimated discontinuities are based on local linear regressions; the standard errors of the estimates are presented in parentheses. The fitted values of these local linear regressions are also plotted. 
Figure 4: The impact of the 1947 change on mortality by 5-year age group

All: Mortality Rate for Ages 45-49

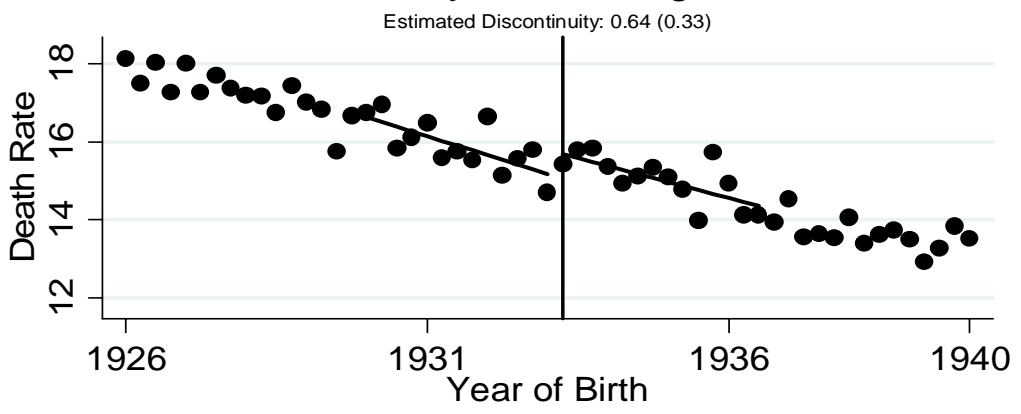

All: Mortality Rate for Ages 55-59

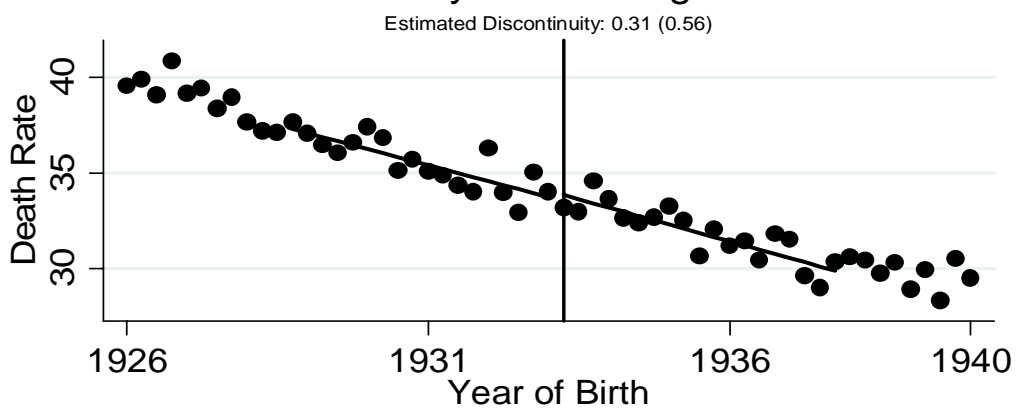

All: Mortality Rate for Ages 65-69

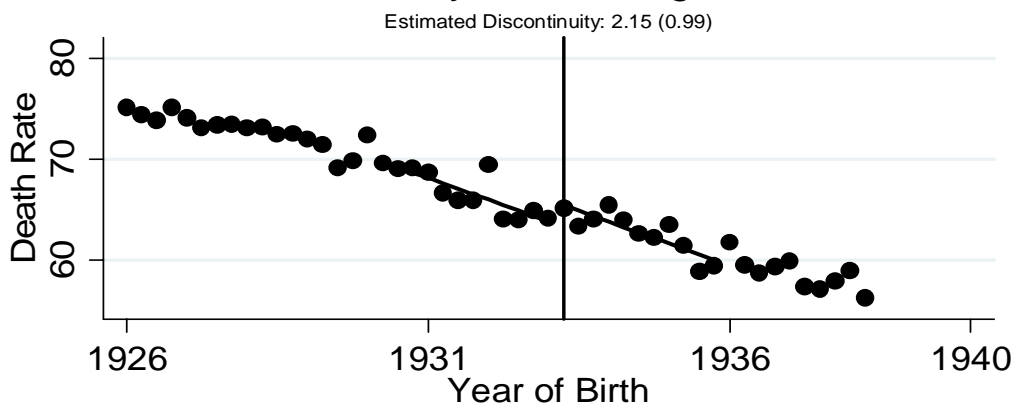

All: Mortality Rate for Ages 50-54

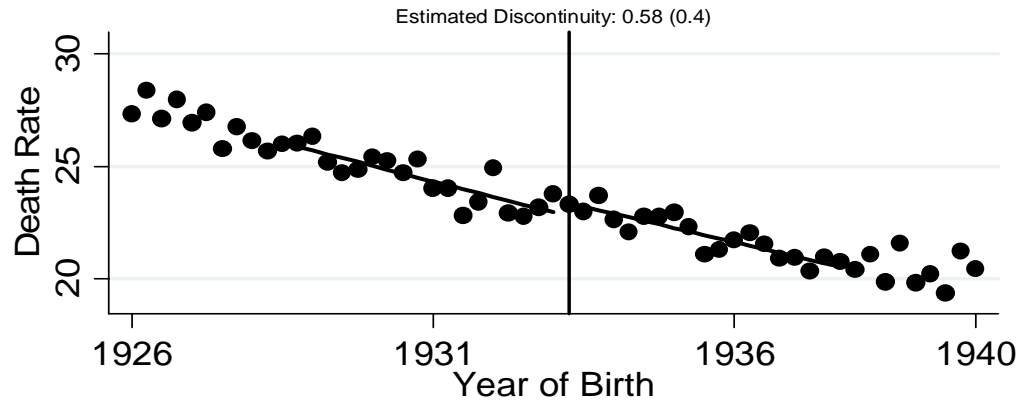

All: Mortality Rate for Ages 60-64

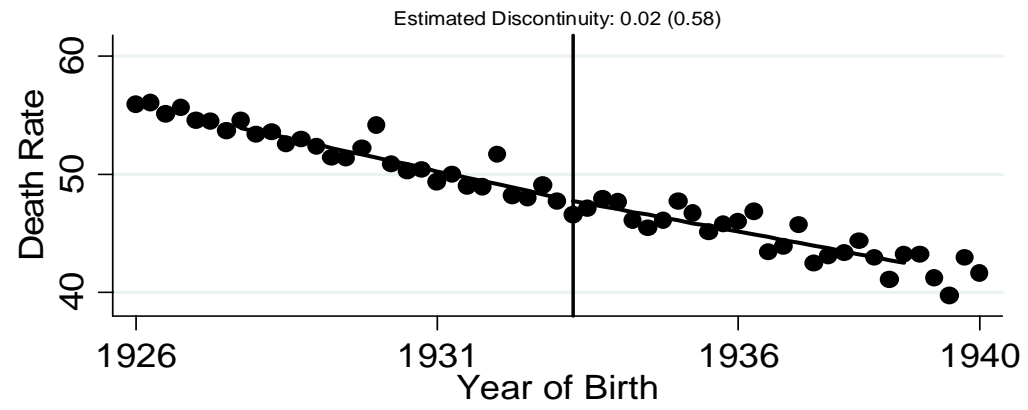

Notes: The death rate is defined as the fraction of the cohort dying between the specified ages multiplied by 1000 where the denominator is the size of the cohort at birth. Points represent the death rate for each quarter-of-birth cell. The estimated discontinuities are based on local linear regressions; the standard errors of the estimates are presented in parentheses. The fitted values of these local linear regressions are also plotted. 
Figure 5: The impact of the 1947 change on mortality by cause

All: Respiratory Mortality Rate for Ages 45-64

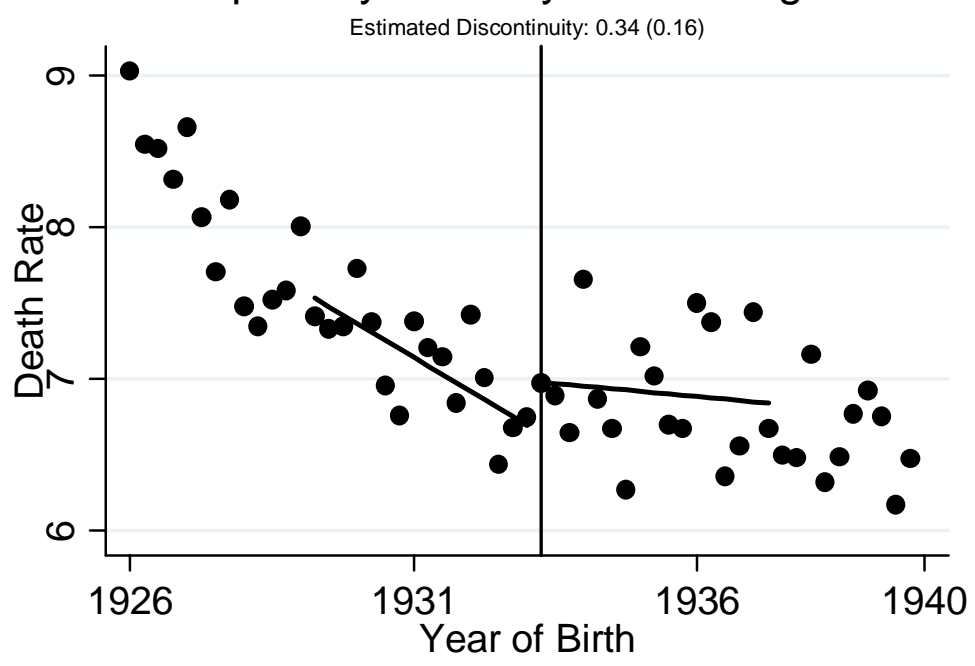

All: Other Mortality Rate for Ages 45-64

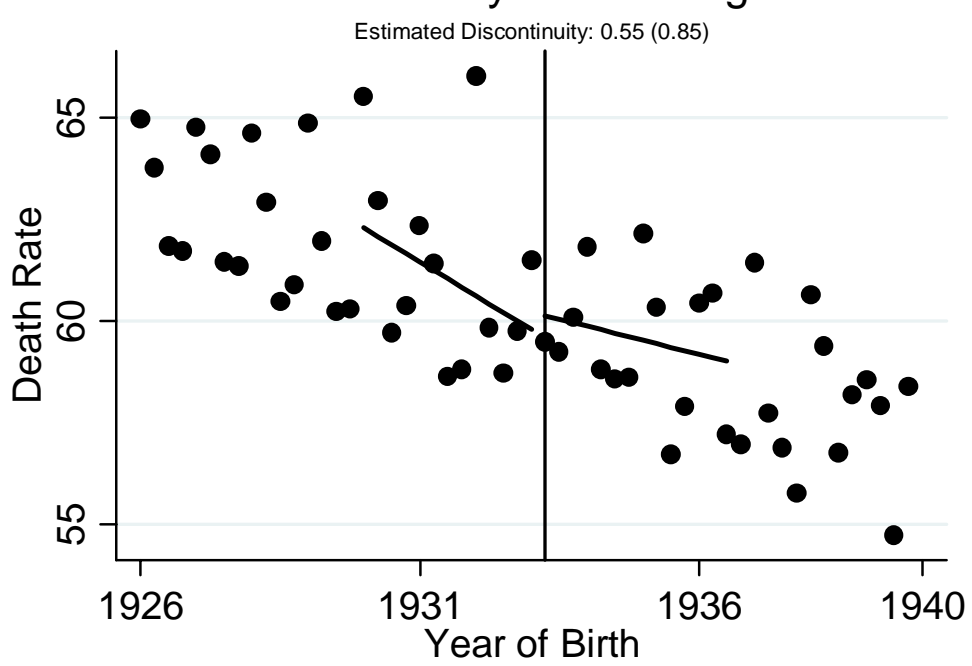

All: Circulatory Mortality Rate for Ages 45-64

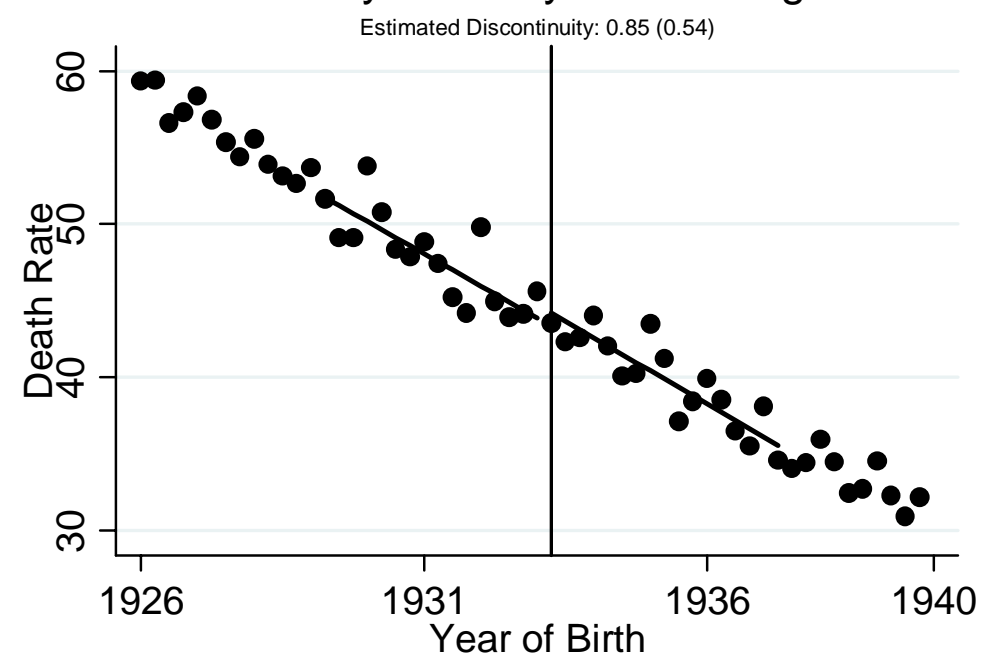

Notes: The death rate is defined as the fraction of the cohort dying between the specified ages multiplied by 1000 where the denominator is the size of the cohort at birth. Points represent the death rate for each quarter-of-birth cell. The estimated discontinuities are based on local linear regressions; the standard errors of the estimates are presented in parentheses. The fitted values of these local linear regressions are also plotted. 
Figure 6: The impact of the 1972 change on mortality

Male: Mortality Rate for Ages 20-44

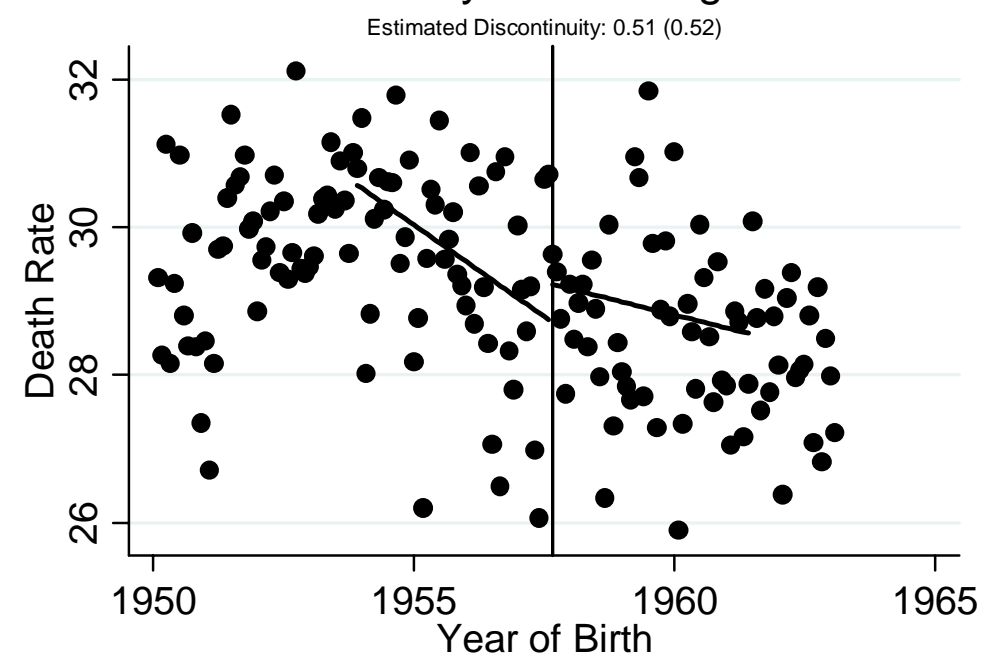

All: Mortality Rate for Ages 20-44

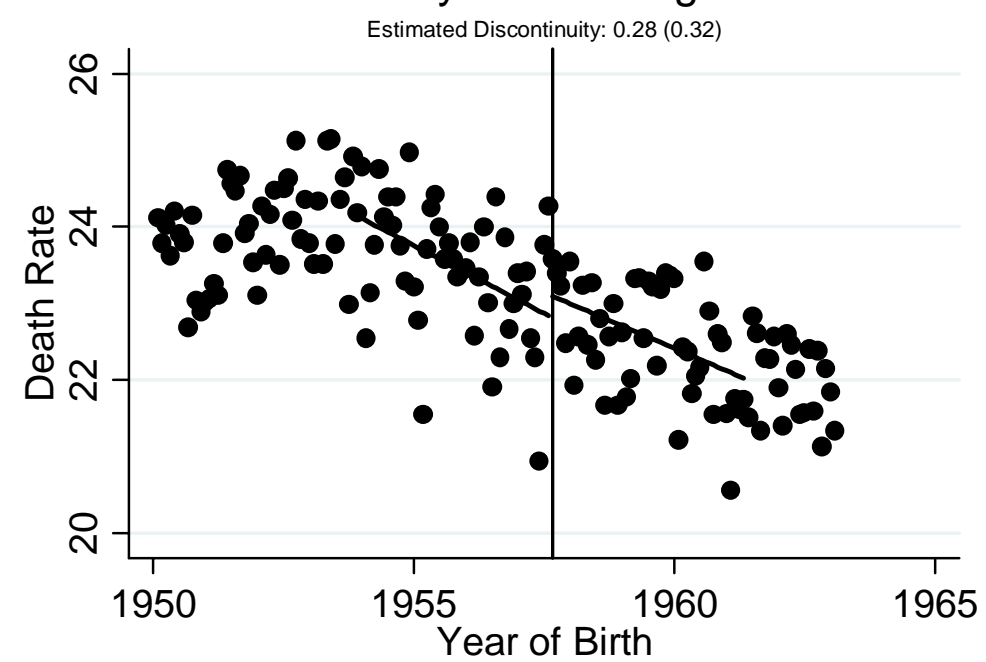

Female: Mortality Rate for Ages 20-44

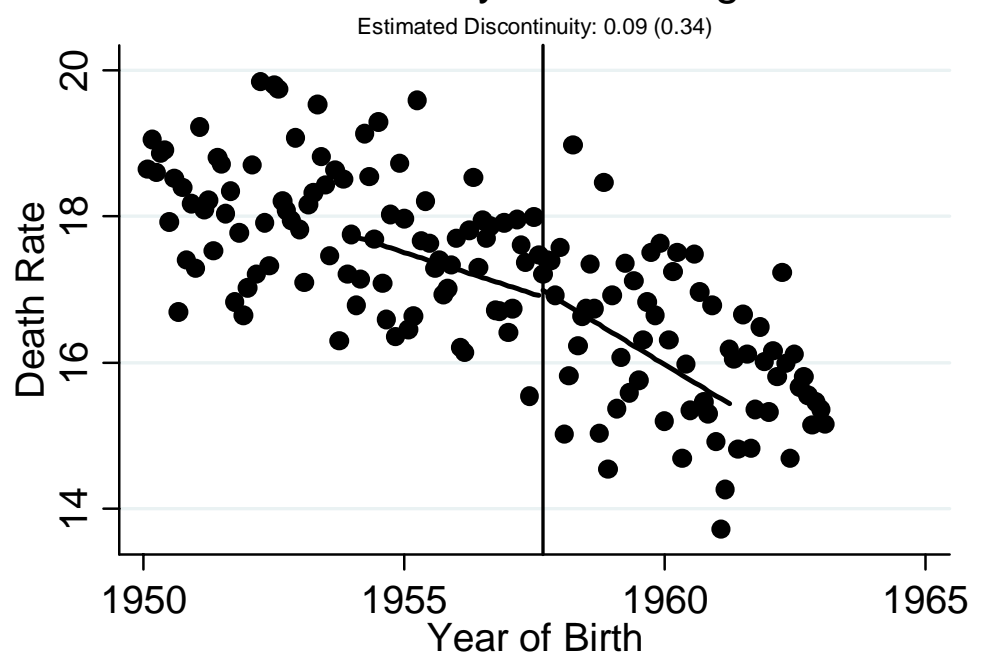

Notes: The death rate is defined as the fraction of the cohort dying between the specified ages multiplied by 1000 where the denominator is the size of the cohort at birth. Points represent the death rate for each month-of-birth cell. The estimated discontinuities are based on local linear regressions; the standard errors of the estimates are presented in parentheses. The fitted values of these local linear regressions are also plotted. 
Figure 7: The impact of the 1972 change on mortality by 5-year age group

All: Mortality Rate for Ages 20-24

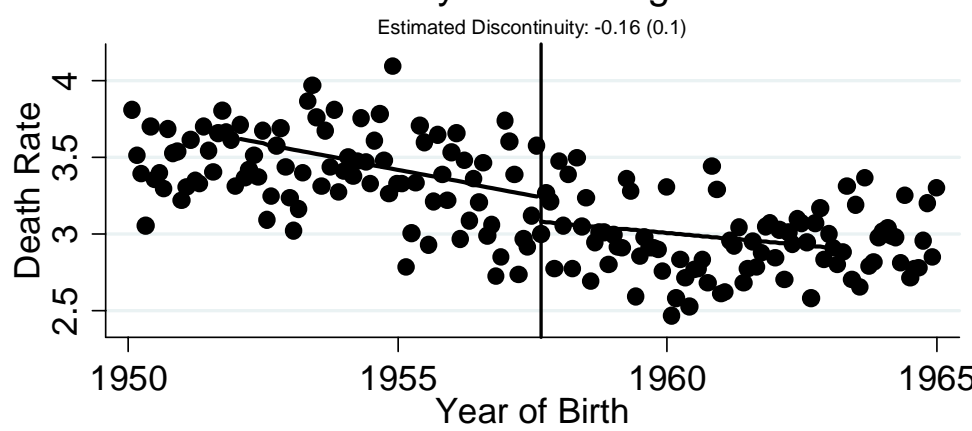

All: Mortality Rate for Ages 30-34

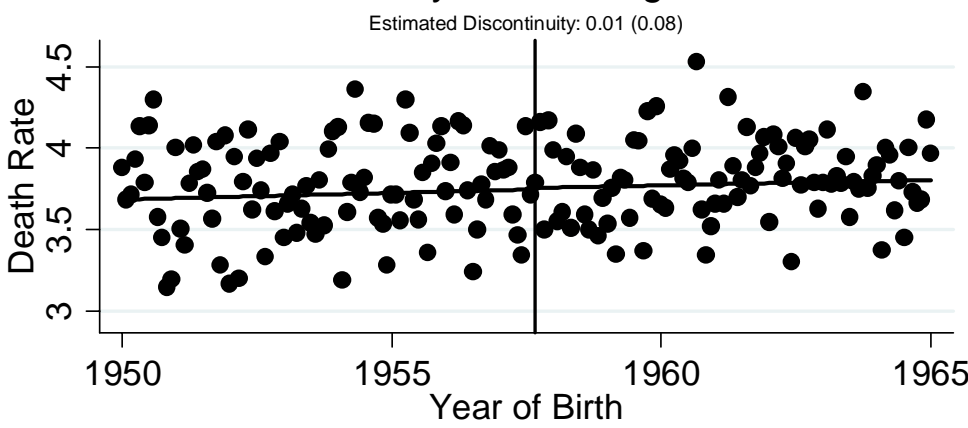

All: Mortality Rate for Ages 40-44

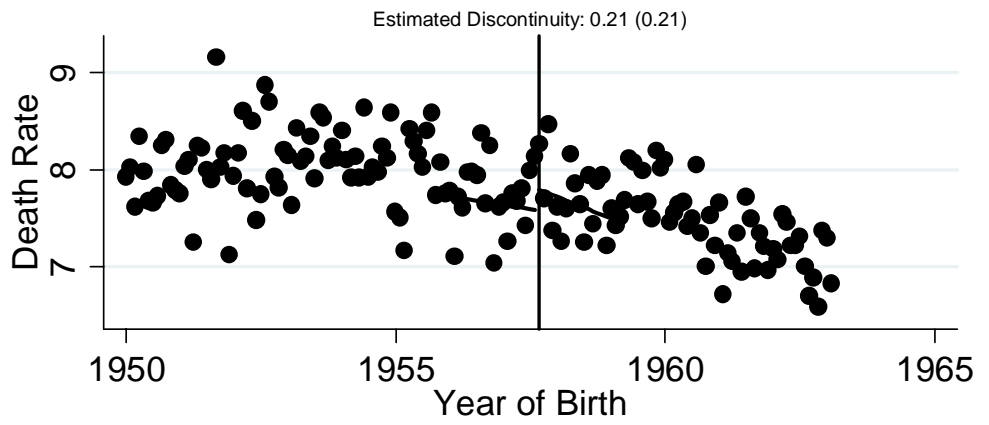

All: Mortality Rate for Ages 25-29

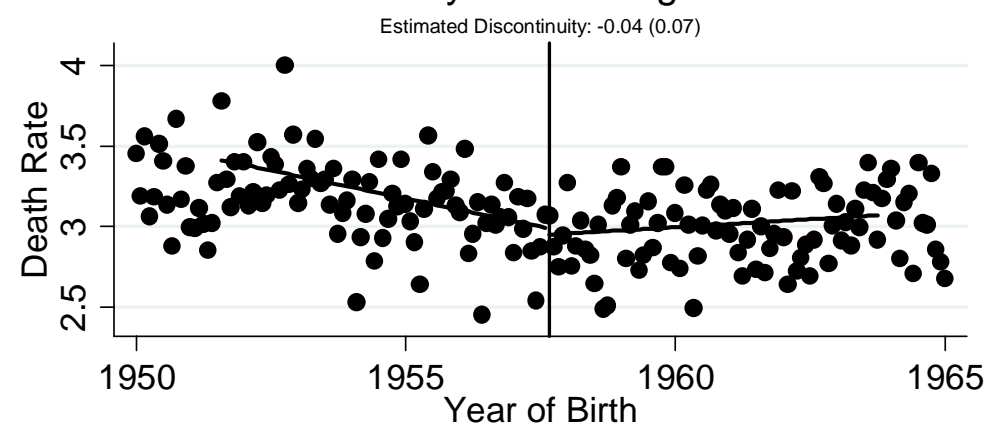

All: Mortality Rate for Ages 35-39

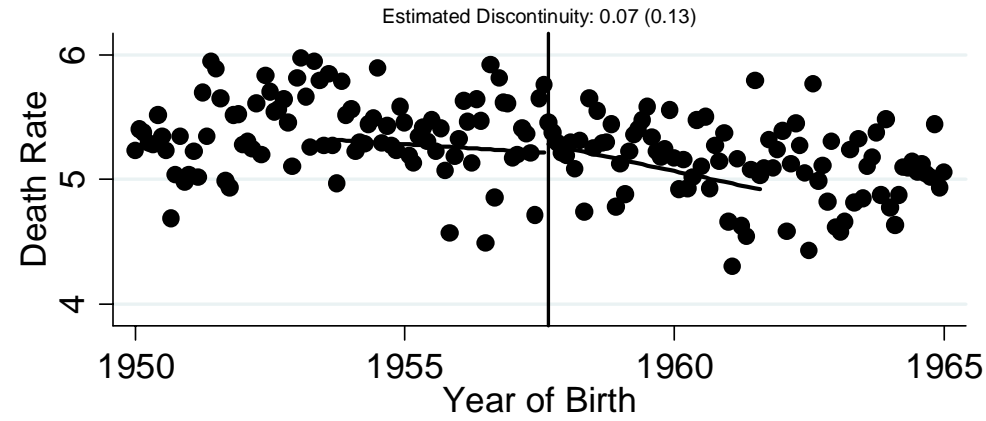

Notes: The death rate is defined as the fraction of the cohort dying between the specified ages multiplied by 1000 where the denominator is the size of the cohort at birth. Points represent the death rate for each month-of-birth cell. The estimated discontinuities are based on local linear regressions; the standard errors of the estimates are presented in parentheses. The fitted values of these local linear regressions are also plotted. 
Figure 8: The impact of the 1947 and 1972 changes on health outcomes and behaviors
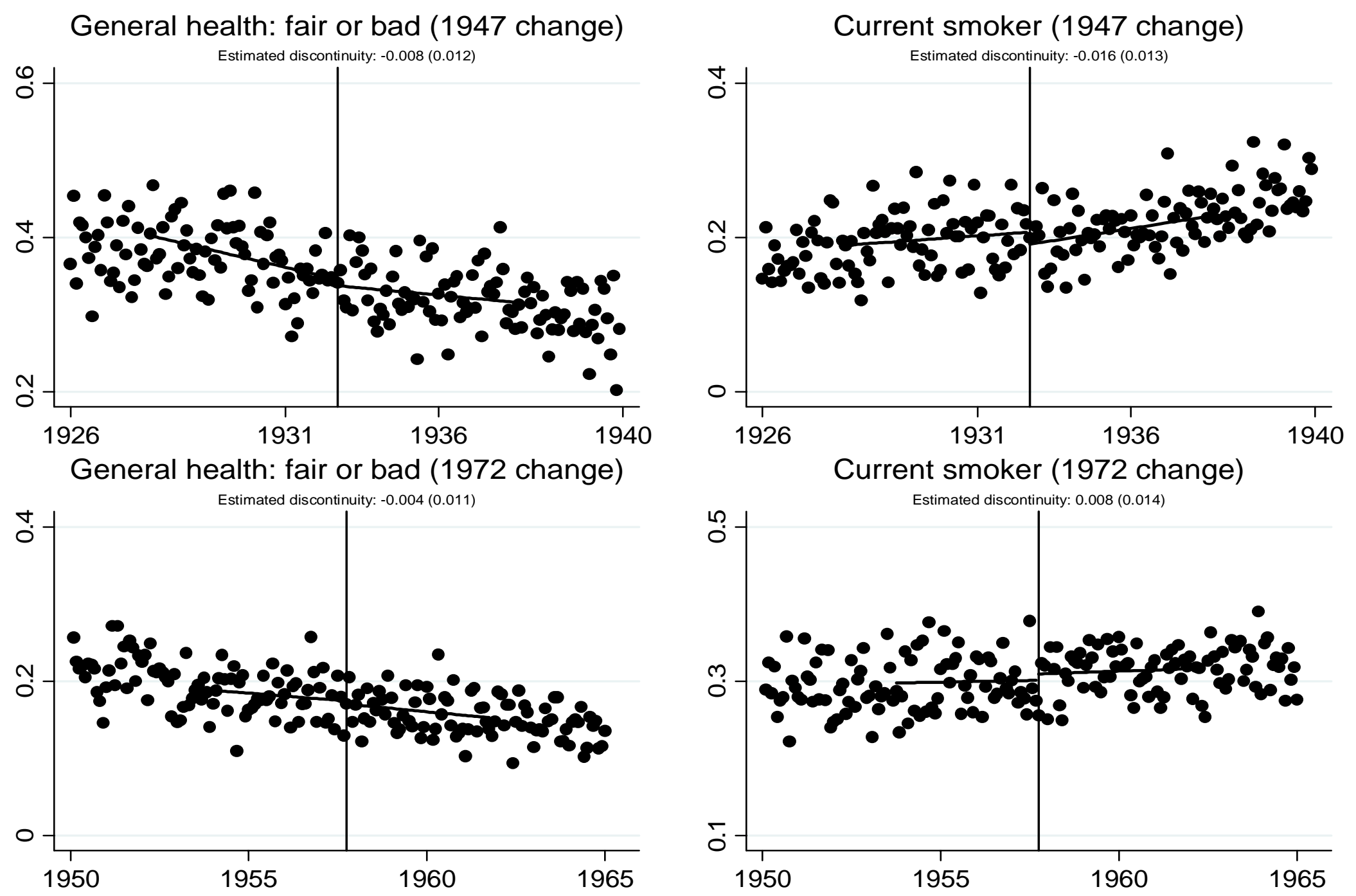

Notes: Samples based on Health Survey of England: 1991-2004. Points represent means among people in each month-of-birth cell. Estimated discontinuities are based on local linear regressions; the standard errors of the estimates are presented in parentheses. The fitted values of these local linear regressions are also plotted. 
Figure 9: The impact on reporting being in fair or worse health in the 2001 Census
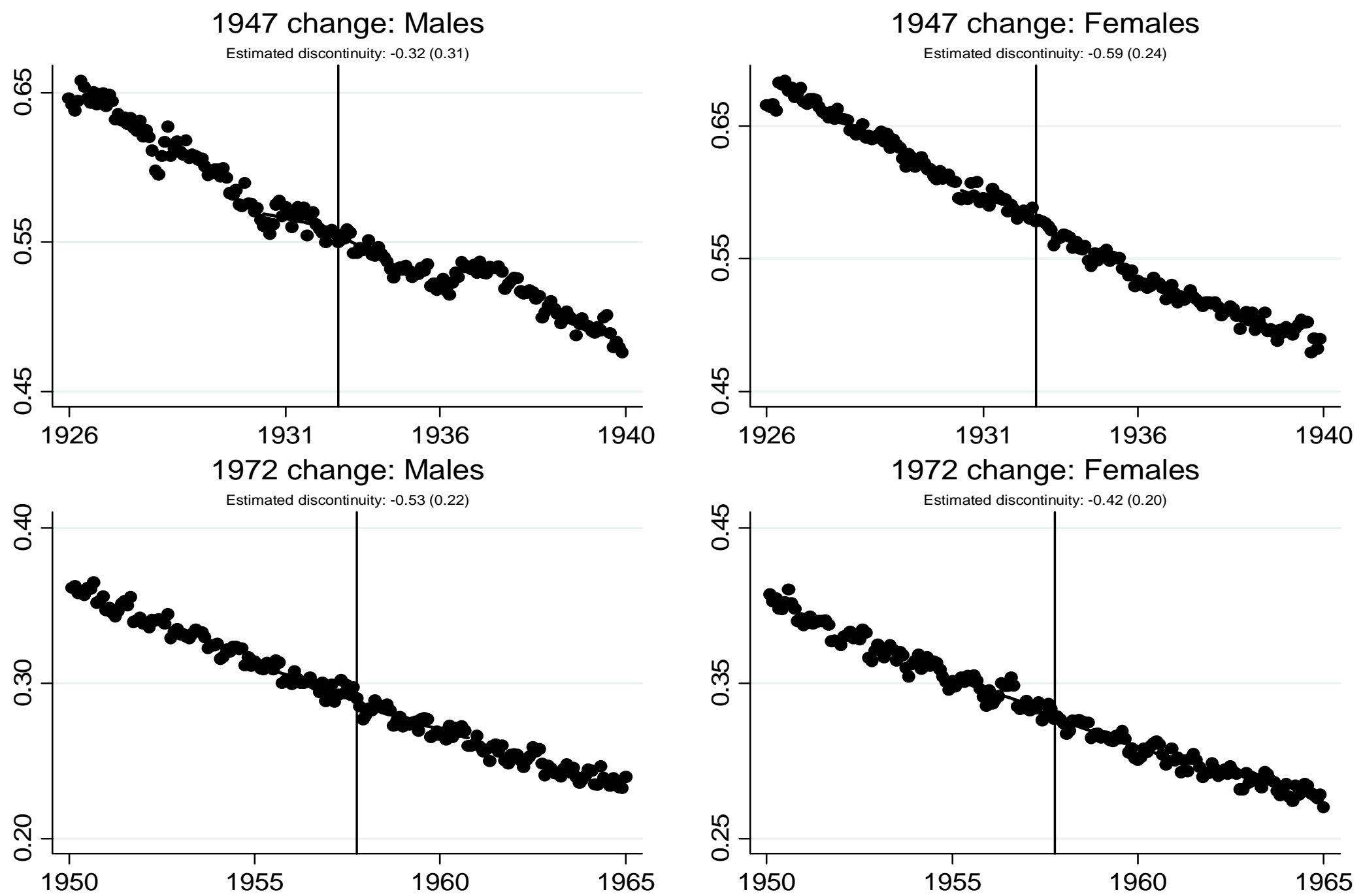

Notes: Points represent means among people in each month-of-birth cell. The estimated discontinuities are based on local linear regressions; the standard errors of the estimates are presented in parentheses. The fitted values of these local linear regressions are also plotted. 
Appendix Figure B1a: Stylized description of compulsory school laws by month of birth

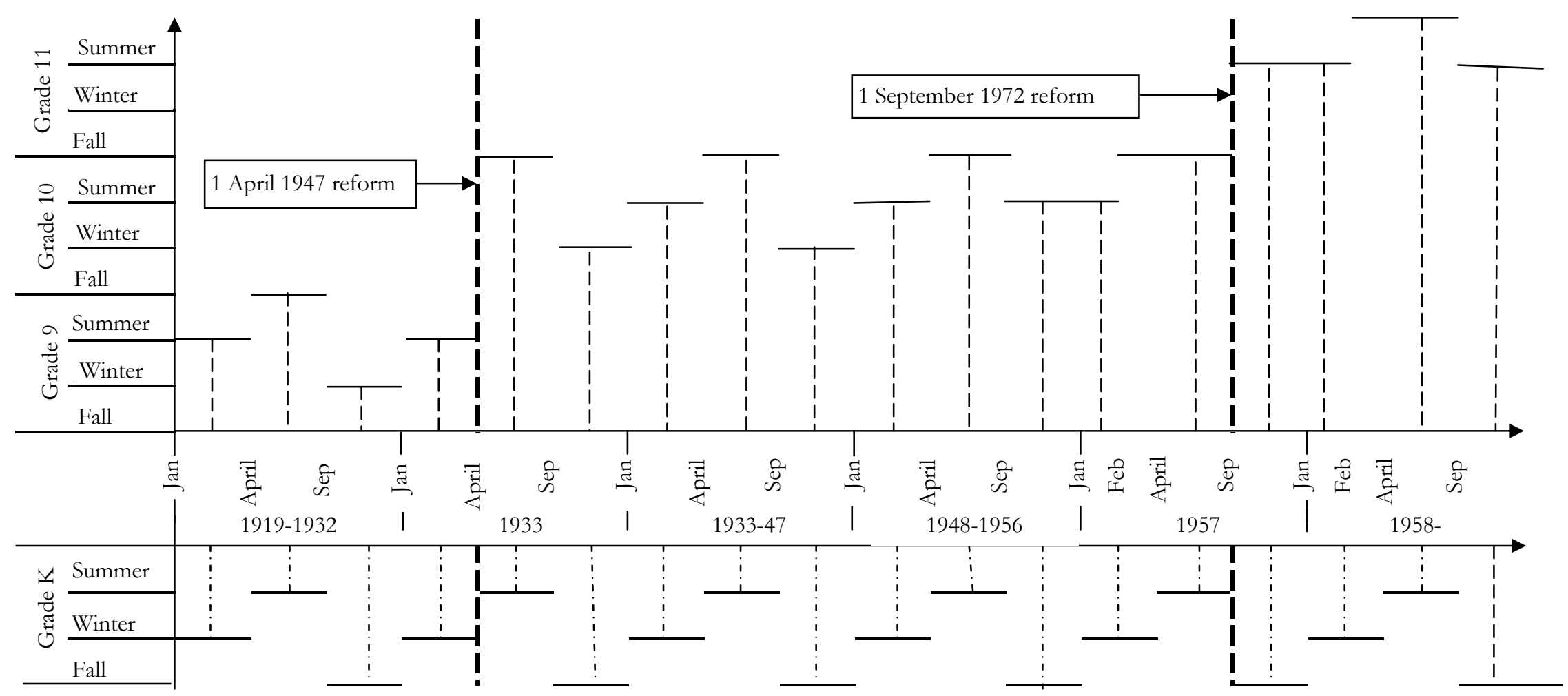

Notes: Not all local schools authorities followed the school entry policy depicted above: some admitted all students at the start of the academic year in which they turned five (i.e., in September); others had two rather than three points of entry. 


\section{Appendix Figure B1b: Maximum/Minimum years and terms of full-time education for those leaving at minimum leaving age by birthdate}

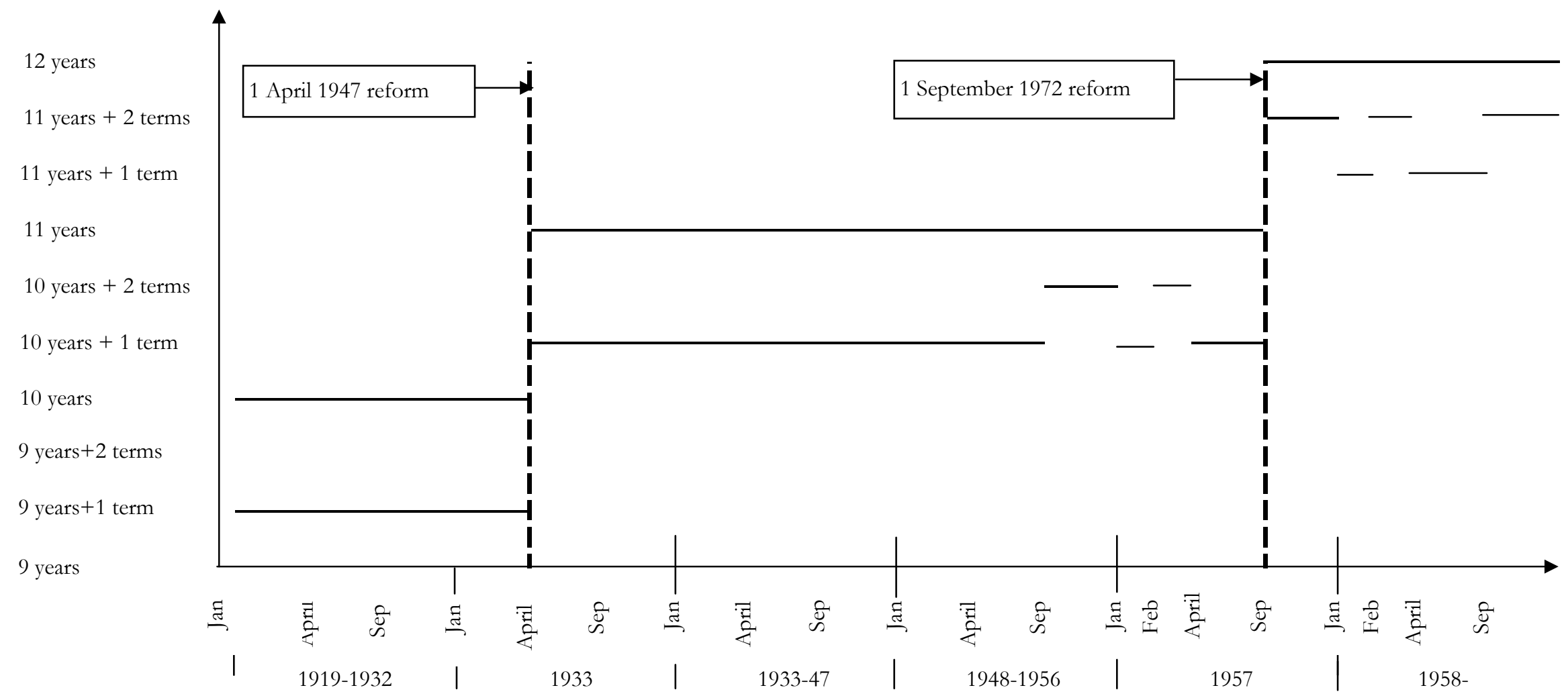

Notes: The x-axis denotes different birth cohorts. For example, the first part of the x-axis refers to those between January and April over the years 1919-1932. The y-axis displays the minimum and maximum years and terms of full-time education for those who report leaving at the minimum school leaving age. There exists a minimum and a maximum because students that report leaving at the minimum school leaving age (e.g., 15) could have left at the first available opportunity or could have continued for one or two more terms before leaving. For example, people born between January and April in the years 1919-1932 who report leaving at the compulsory school leaving age (14) would have spent 9 years and one term in full-time education had they left at the first opportunity. If they did not leave at the first opportunity, they could have received 9 years and two terms or 10 years of education. Since they report leaving at 14, they could not have received ten years and one term of education (or more). See Appendix B for more details. 
Appendix Figure C1: The impact of the 1947 change on male earnings

Log gross weekly earnings: males

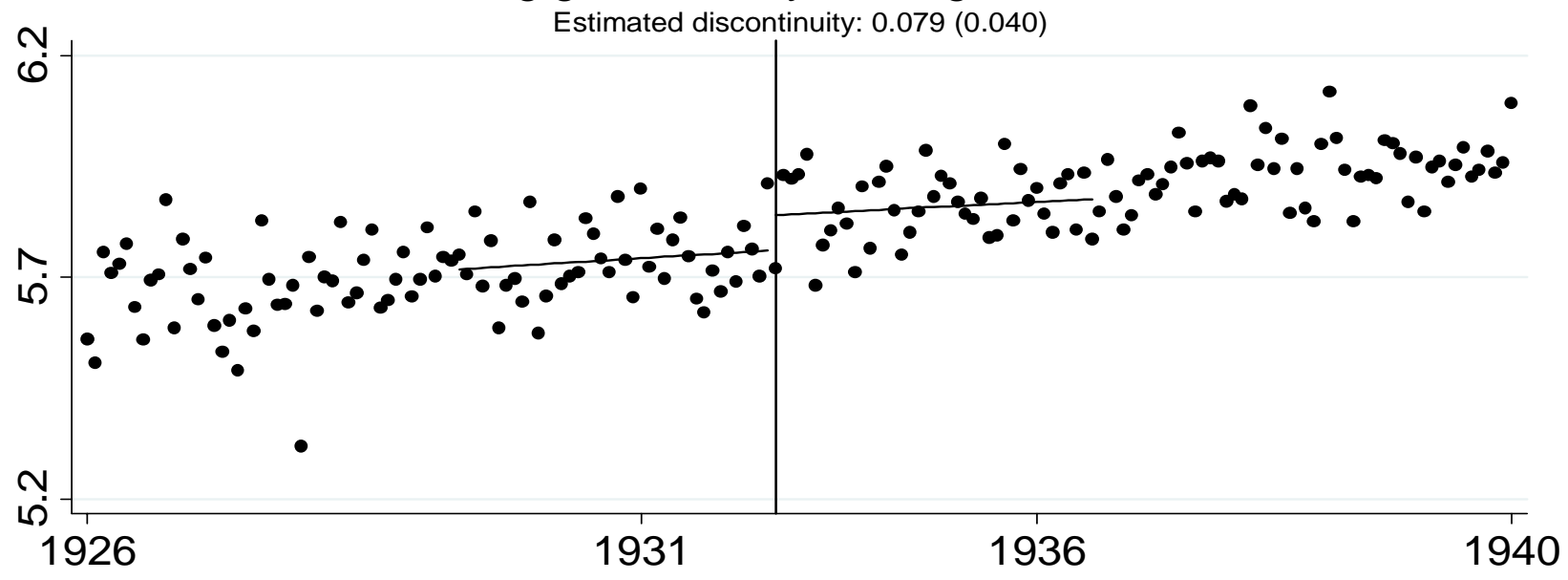

Notes: Scatter plot based on sample as described in notes to Appendix Table C1a. Fitted solid line based on birth cohort (defined by month of birth) interacted with being born after April 1933. Estimated discontintuity refers to coefficient on this dummy variable; its standard error is presented in parentheses. 
Appendix Figure E1: The simulated impact of the 1947 change on mortality
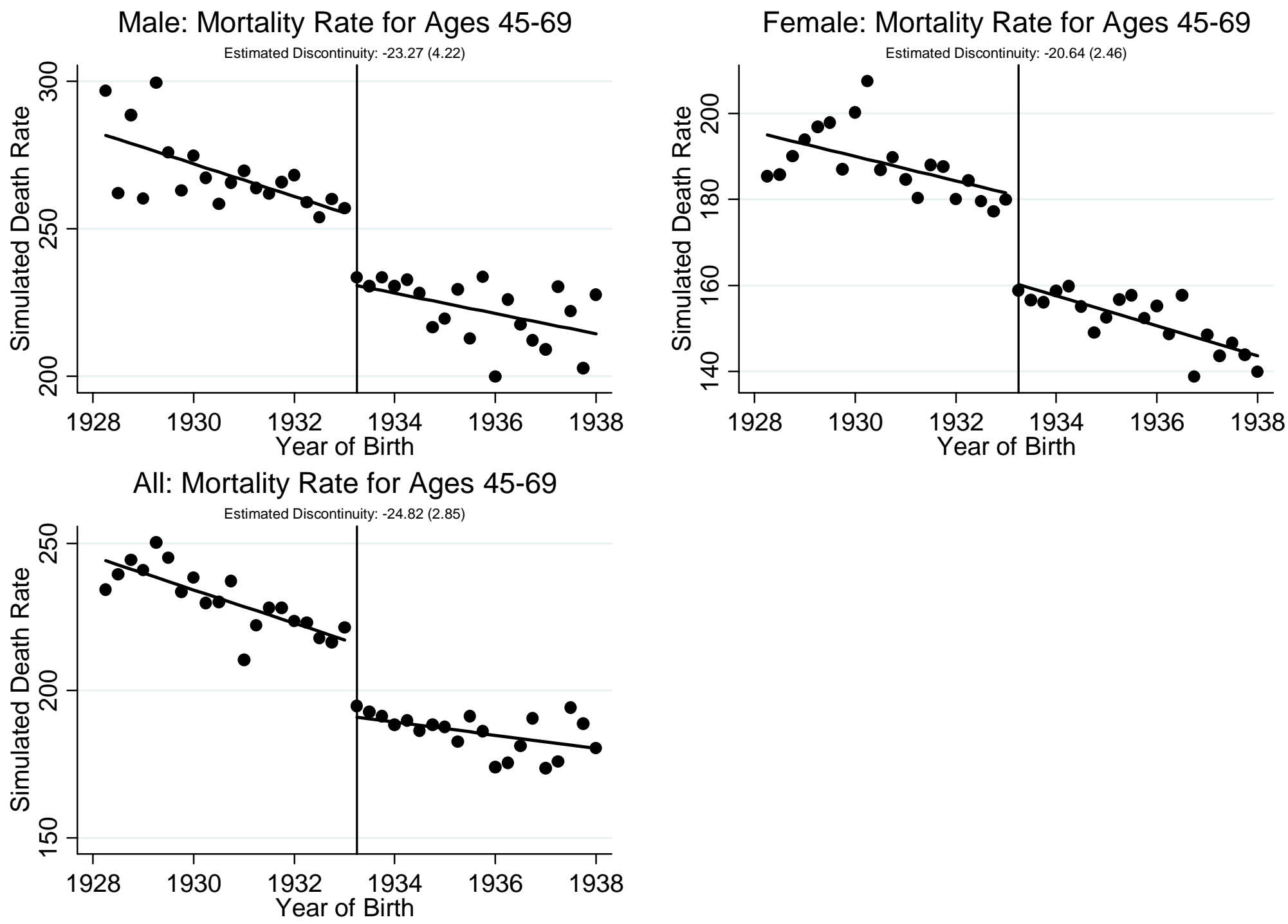

Notes: The death rate is defined as the fraction of the cohort dying between the specified ages multiplied by 1000 where the denominator is the size of the cohort at birth. Points represent the death rate for each quarter-of-birth cell. The estimated discontinuities are based on local linear regressions; the standard errors of the estimates are presented in parentheses. The fitted values of these local linear regressions are also plotted. 
Appendix Figure E2: The simulated impact of the 1972 change on mortality

Male: Mortality Rate for Ages 20-44

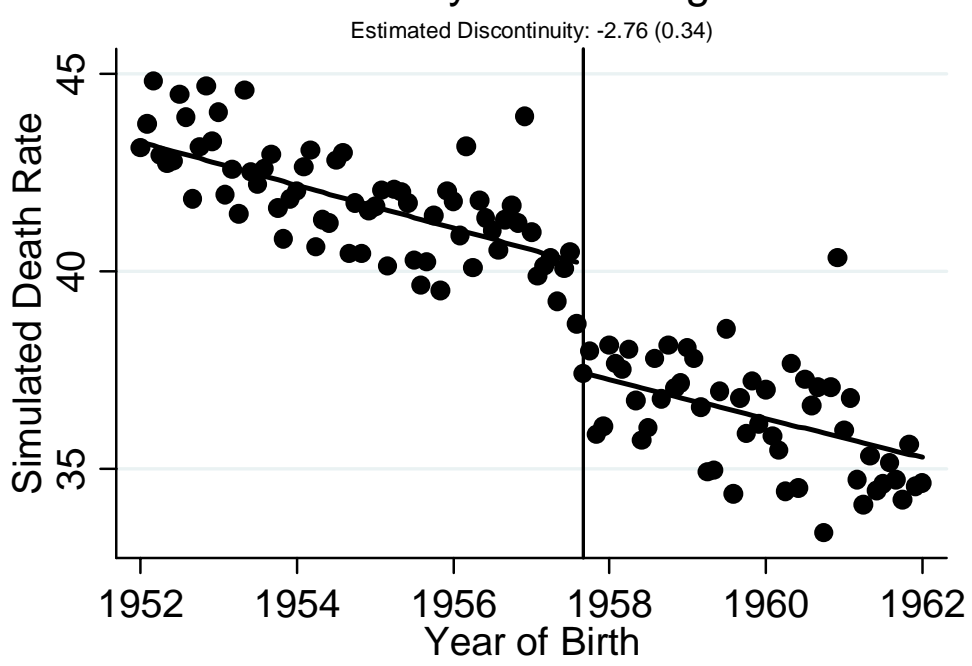

All: Mortality Rate for Ages 20-44

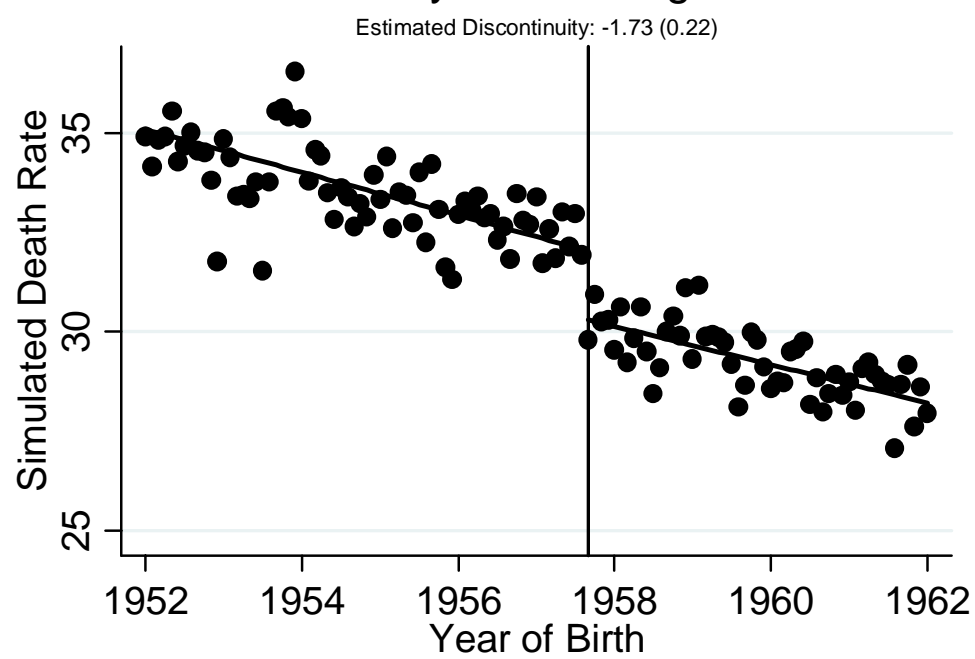

Female: Mortality Rate for Ages 20-44

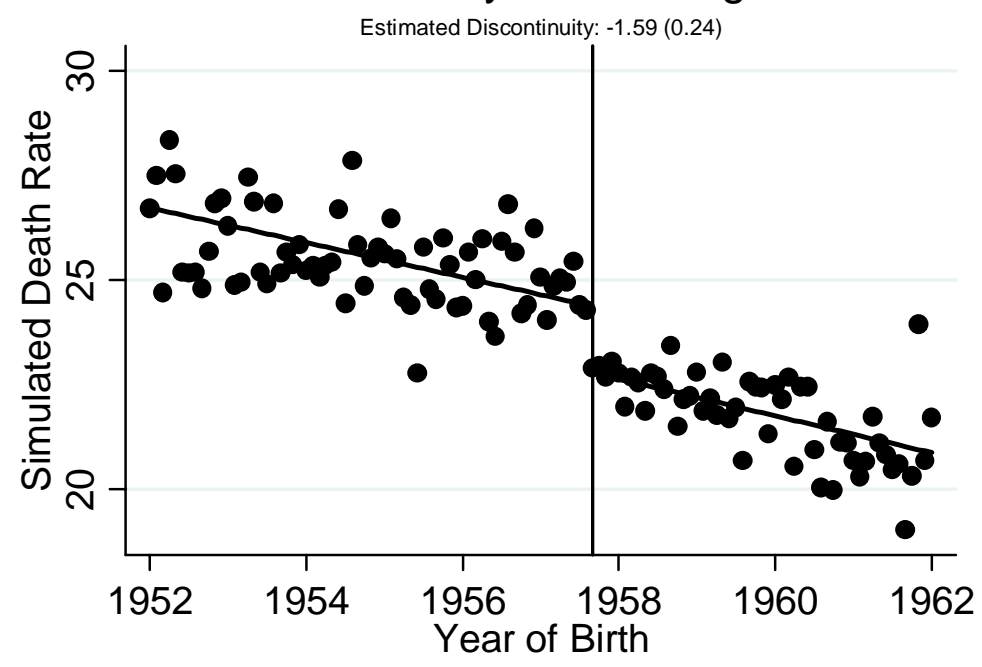

Notes: The death rate is defined as the fraction of the cohort dying between the specified ages multiplied by 1000 where the denominator is the size of the cohort at birth. Points represent the death rate for each month-of-birth cell. The estimated discontinuities are based on local linear regressions; the standard errors of the estimates are presented in parentheses. The fitted values of these local linear regressions are also plotted. 
Table 1: The impact of the compulsory schooling changes on educational attainment

\begin{tabular}{|c|c|c|c|c|c|c|c|c|c|c|c|c|}
\hline \multirow{3}{*}{1947 ROSLA } & \multirow{2}{*}{\multicolumn{2}{|c|}{$=<=9$ Years }} & \multirow{2}{*}{\multicolumn{2}{|c|}{$\overline{<<=10 \text { Years }}$}} & \multirow{2}{*}{\multicolumn{2}{|c|}{$<=11$ Years }} & \multirow{2}{*}{\multicolumn{2}{|c|}{$=<12$ Years }} & \multirow{2}{*}{\multicolumn{2}{|c|}{$=<=13$ Years }} & \multirow{2}{*}{\multicolumn{2}{|c|}{ Years of Education }} \\
\hline & & & & & & & & & & & & \\
\hline & $(1)$ & $(2)$ & (1) & (2) & (1) & $(2)$ & (1) & (2) & $(1)$ & $(2)$ & (1) & (2) \\
\hline & \multicolumn{12}{|c|}{ Panel A: Men } \\
\hline & -0.456 & -0.453 & -0.036 & -0.032 & 0.019 & 0.022 & 0.018 & 0.022 & 0.017 & 0.021 & 0.439 & 0.420 \\
\hline & $(0.018)$ & $(0.018)$ & $(0.018)$ & $(0.017)$ & $(0.014)$ & $(0.014)$ & $(0.014)$ & $(0.014)$ & $(0.012)$ & $(0.011)$ & $(0.059)$ & $(0.062)$ \\
\hline Dependent variable mean & 0.58 & 0.58 & 0.70 & 0.70 & 0.83 & 0.83 & 0.87 & 0.87 & 0.91 & 0.91 & 10.11 & 10.11 \\
\hline \multirow[t]{4}{*}{ Observations } & 8524 & 8524 & 8524 & 8524 & 8524 & 8524 & 8524 & 8524 & 8524 & 8524 & 8524 & 8524 \\
\hline & \multicolumn{12}{|c|}{ Panel B: Women } \\
\hline & -0.453 & -0.452 & -0.087 & -0.076 & -0.002 & -0.001 & -0.003 & 0.002 & -0.002 & 0.001 & 0.547 & 0.527 \\
\hline & $(0.018)$ & $(0.016)$ & $(0.019)$ & $(0.016)$ & $(0.014)$ & $(0.014)$ & $(0.012)$ & $(0.012)$ & $(0.011)$ & $(0.011)$ & $(0.058)$ & $(0.054)$ \\
\hline Dependent variable mean & 0.58 & 0.58 & 0.71 & 0.71 & 0.84 & 0.84 & 0.90 & 0.90 & 0.93 & 0.93 & 10.04 & 10.04 \\
\hline Observations & 9669 & 9669 & 9669 & 9669 & 9669 & 9669 & 9669 & 9669 & 9669 & 9669 & 9669 & 9669 \\
\hline
\end{tabular}

1972 ROSLA

\begin{tabular}{cc|cc|cc|cc|ccc}
\hline \hline \multicolumn{2}{c|}{$<=10$ Years } & \multicolumn{2}{c|}{$<=11$ Years } & \multicolumn{2}{c|}{$<=12$ Years } & \multicolumn{2}{c|}{$<=13$ Years } & \multicolumn{2}{c}{ Years of Education } \\
$(1)$ & $(2)$ & $(1)$ & $(2)$ & $(1)$ & $(2)$ & $(1)$ & $(2)$ & $(1)$ & $(2)$ \\
\hline \multicolumn{10}{c}{ Panel A: Men } \\
\hline-0.237 & -0.218 & -0.041 & -0.029 & -0.045 & -0.038 & -0.020 & -0.015 & 0.367 & 0.318 \\
$(0.023)$ & $(0.016)$ & $(0.020)$ & $(0.018)$ & $(0.017)$ & $(0.016)$ & $(0.015)$ & $(0.014)$ & $(0.064)$ & $(0.049)$ \\
0.30 & 0.30 & 0.63 & 0.63 & 0.71 & 0.71 & 0.78 & 0.78 & 11.54 & 11.54 \\
9118 & 9118 & 9118 & 9118 & 9118 & 9118 & 9118 & 9118 & 9118 & 9118 \\
\hline \multicolumn{10}{c}{ Panel B: Women } \\
\hline-0.271 & -0.243 & -0.021 & -0.011 & -0.001 & -0.003 & 0.016 & 0.016 & 0.294 & 0.252 \\
$(0.022)$ & $(0.015)$ & $(0.020)$ & $(0.017)$ & $(0.017)$ & $(0.016)$ & $(0.014)$ & $(0.012)$ & $(0.058)$ & $(0.050)$ \\
0.33 & 0.33 & 0.61 & 0.61 & 0.71 & 0.71 & 0.82 & 0.82 & 11.51 & 11.51 \\
10801 & 10801 & 10801 & 10801 & 10801 & 10801 & 10801 & 10801 & 10801 & 10801 \\
\hline
\end{tabular}

Dependent variable mean

Observations

Dependent variable mean

Observations

Notes: Table gives the estimated effect of compulsory schooling law change on various outcomes. All regressions estimated using pooled waves of the

Health Survey of England. All regressions in columns (1) include a linear function of month of birth and a linear interaction of month of birth and a dummy variable for being born after the relevant threshold. All regressions in column (2) also include for male dummy, calendar month-of-birth dummies, year-ofsurvey dummies, month-of-survey dummies and a third-order polynomial in age. The dependent variable mean is the mean for the last pre-reform cohort. Robust standard errors clustered by month of birth are presented in parentheses. 
Table 2: The impact of the 1947 change on mortality rates

\begin{tabular}{|c|c|c|c|c|c|c|c|}
\hline & \multirow[b]{2}{*}{ Hazard Rate: 1970-2007 } & \multicolumn{6}{|c|}{ Probability of Dying Between... } \\
\hline & & Ages 45-49 & Ages 50-54 & Ages 55-59 & Ages 60-64 & Ages 65-69 & Ages 45-69 \\
\hline & \multicolumn{7}{|c|}{ Panel A: Men } \\
\hline \multirow[t]{2}{*}{ Reduced-Form Estimate } & 1.011 & 0.608 & 0.726 & 0.446 & 0.350 & 3.206 & 4.866 \\
\hline & $(0.005)$ & $(0.341)$ & $(0.475)$ & $(0.440)$ & $(0.627)$ & $(1.359)$ & $(2.932)$ \\
\hline Death Rate for 1933Q1 & NA & 17.48 & 28.68 & 41.72 & 57.61 & 75.85 & 221.33 \\
\hline Observations & 30552 & 43 & 45 & 31 & 45 & 21 & 21 \\
\hline Bandwidth in Quarters & 11 & 22 & 23 & 16 & 23 & 11 & 11 \\
\hline \multirow{3}{*}{ Reduced-Form Estimate } & \multicolumn{7}{|c|}{ Panel B: Women } \\
\hline & 1.004 & 0.841 & 0.063 & 0.168 & -0.064 & 1.930 & 2.296 \\
\hline & $(0.006)$ & $(0.385)$ & $(0.347)$ & $(0.421)$ & $(0.448)$ & $(0.576)$ & $(1.703)$ \\
\hline Death Rate for 1933Q1 & NA & 11.78 & 18.63 & 25.97 & 37.43 & 51.72 & 145.52 \\
\hline Observations & 30552 & 25 & 47 & 47 & 55 & 21 & 21 \\
\hline \multirow[t]{2}{*}{ Bandwidth in Quarters } & 11 & 13 & 24 & 24 & 28 & 11 & 11 \\
\hline & \multicolumn{7}{|c|}{ Panel C: Overall } \\
\hline \multirow[t]{2}{*}{ Reduced-Form Estimate } & 1.008 & 0.740 & 0.643 & 0.411 & 0.117 & 2.577 & 3.590 \\
\hline & $(0.004)$ & $(0.334)$ & $(0.315)$ & $(0.371)$ & $(0.477)$ & $(0.831)$ & $(2.240)$ \\
\hline Death Rate for 1933Q1 & NA & 14.70 & 23.77 & 34.03 & 47.76 & 64.07 & 184.31 \\
\hline Observations & 61104 & 27 & 37 & 37 & 45 & 21 & 21 \\
\hline Bandwidth in Quarters & 11 & 14 & 19 & 19 & 23 & 11 & 11 \\
\hline
\end{tabular}

Notes: The first set of estimates, the hazard rate results, report the log-odds ratio for the probability of dying for those just to the right of the birth cohort threshold for the 1947 change versus those just to the left of the threshold. The bandwidth for the hazard analysis is chosen based on the bandwidth for the 45-69 age group mortality regression. For these regressions, the standard errors are clustered at the level of the month-of-birth cohort. These regressions include calendar month-ofbirth fixed effects, age fixed effects, and a fully-interacted linear polynomial in month-of-birth cohort relative to April 1947. The second set of estimates give the estimated effect of the 1947 change in compulsory schooling laws on mortality rates between the ages specified. The death rate equals the number of deaths between the denoted ages divided by the size of the quarterly birth cohort at birth multiplied by 1000 . All of these mortality rate regressions use data by quarter-of-birth birth cohort from the Office of National Statistics. All mortality rate regressions include calendar quarter-of-birth fixed effects and are weighted by cohort size. For the nonhazard rate results, chosen bandwidths are based on a cross-validation procedure described in the text. Robust standard errors are presented in parentheses. 
Table 3: The impact of the 1947 change on mortality rates by cause

\begin{tabular}{|c|c|c|c|c|c|}
\hline & Ages 45-49 & Ages 50-54 & Ages 55-59 & Ages 60-64 & Ages 45-64 \\
\hline \multirow{3}{*}{ Reduced-Form Estimate } & \multicolumn{5}{|c|}{ Panel A: Respiratory Deaths } \\
\hline & 0.032 & 0.033 & 0.089 & 0.064 & 0.340 \\
\hline & $(0.032)$ & $(0.065)$ & $(0.065)$ & $(0.125)$ & $(0.161)$ \\
\hline Death Rate for 1933Q1 & 0.80 & 0.81 & 1.58 & 3.55 & 6.75 \\
\hline Observations & 39 & 31 & 39 & 27 & 33 \\
\hline Bandwidth in Quarters & 20 & 16 & 20 & 14 & 17 \\
\hline \multirow{3}{*}{ Reduced-Form Estimate } & \multicolumn{5}{|c|}{ Panel B: Circulatory Deaths } \\
\hline & 0.080 & 0.212 & -0.152 & -0.049 & 0.849 \\
\hline & $(0.291)$ & $(0.319)$ & $(0.167)$ & $(0.312)$ & $(0.542)$ \\
\hline Death Rate for 1933Q1 & 5.66 & 9.69 & 12.50 & 17.79 & 45.64 \\
\hline Observations & 17 & 25 & 73 & 33 & 33 \\
\hline \multirow[t]{2}{*}{ Bandwidth in Quarters } & 9 & 13 & 37 & 17 & 17 \\
\hline & \multicolumn{5}{|c|}{ Panel C: Deaths from Other Causes } \\
\hline \multirow[t]{2}{*}{ Reduced-Form Estimate } & 0.405 & 0.358 & -0.185 & -0.256 & 0.554 \\
\hline & $(0.147)$ & $(0.218)$ & $(0.352)$ & $(0.445)$ & $(0.853)$ \\
\hline Death Rate for 1933Q1 & 7.65 & 12.28 & 18.05 & 23.53 & 61.50 \\
\hline Observations & 47 & 23 & 25 & 23 & 27 \\
\hline Bandwidth in Quarters & 24 & 12 & 13 & 12 & 14 \\
\hline
\end{tabular}

Notes: Table gives estimated effect of 1947 change in compulsory schooling laws on mortality rates between the ages specified. The death rate equals the number of deaths between the denoted ages divided by the size of the quarterly birth cohort at birth multiplied by 1000 . All regressions use data by quarter-of-birth cohort from the Office of National Statistics. All regressions include calendar quarter-ofbirth fixed effects and a male dummy variable and are weighted by birth cohort size. Chosen

bandwidths are based on a cross-validation procedure described in the text. Robust standard errors are presented in parentheses. 
Table 4: The impact of the 1972 change on mortality rates

\begin{tabular}{|c|c|c|c|c|c|c|c|}
\hline & \multirow[b]{2}{*}{ Hazard Rate: 1978-2007 } & \multicolumn{6}{|c|}{ Probability of Dying Between... } \\
\hline & & Ages 20-24 & Ages 25-29 & Ages 30-34 & Ages 35-39 & Ages 40-44 & Ages 20-44 \\
\hline & \multicolumn{7}{|c|}{ Panel A: Men } \\
\hline Reduced-Form Estimate & $\begin{array}{c}1.022 \\
(0.012)\end{array}$ & $\begin{array}{c}0.051 \\
(0.260)\end{array}$ & $\begin{array}{l}-0.0002 \\
(0.1243)\end{array}$ & $\begin{array}{c}0.158 \\
(0.129)\end{array}$ & $\begin{array}{c}0.129 \\
(0.202)\end{array}$ & $\begin{array}{c}0.202 \\
(0.280)\end{array}$ & $\begin{array}{c}0.515 \\
(0.519)\end{array}$ \\
\hline Death Rate for August 1957 & NA & 5.27 & 3.95 & 4.90 & 7.01 & 9.58 & 30.71 \\
\hline Observations & 32922 & 61 & 131 & 179 & 95 & 61 & 91 \\
\hline Bandwidth in Months & 46 & 31 & 66 & 90 & 48 & 31 & 46 \\
\hline Reduced-Form Estimate & $\begin{array}{c}0.967 \\
(0.017)\end{array}$ & $\begin{array}{l}-0.125 \\
(0.086)\end{array}$ & $\begin{array}{l}-0.063 \\
(0.078)\end{array}$ & $\begin{array}{l}-0.162 \\
(0.070)\end{array}$ & $\begin{array}{c}0.008 \\
(0.132)\end{array}$ & $\begin{array}{c}0.232 \\
(0.187)\end{array}$ & $\begin{array}{c}0.091 \\
(0.345)\end{array}$ \\
\hline Death Rate for August 1957 & NA & 1.80 & 2.15 & 2.46 & 4.44 & 6.62 & 17.47 \\
\hline Observations & 31684 & 141 & 167 & 327 & 95 & 91 & 87 \\
\hline \multirow[t]{2}{*}{ Bandwidth in Months } & 44 & 71 & 84 & 168 & 48 & 46 & 44 \\
\hline & \multicolumn{7}{|c|}{ Panel C: Overall } \\
\hline Reduced-Form Estimate & $\begin{array}{c}1.001 \\
(0.009)\end{array}$ & $\begin{array}{l}-0.158 \\
(0.101)\end{array}$ & $\begin{array}{l}-0.038 \\
(0.069)\end{array}$ & $\begin{array}{c}0.009 \\
(0.079)\end{array}$ & $\begin{array}{c}0.070 \\
(0.129)\end{array}$ & $\begin{array}{c}0.214 \\
(0.209)\end{array}$ & $\begin{array}{c}0.284 \\
(0.318)\end{array}$ \\
\hline Death Rate for August 1957 & NA & 3.58 & 3.07 & 3.71 & 5.76 & 8.14 & 24.26 \\
\hline Observations & 64610 & 135 & 147 & 179 & 95 & 37 & 89 \\
\hline Bandwidth in Months & 45 & 68 & 74 & 90 & 48 & 19 & 45 \\
\hline
\end{tabular}

Notes: The first set of estimates, the hazard rate results, report the log-odds ratio for the probability of dying for those just to the right of the birth cohort threshold for the 1972 change versus those just to the left of the threshold. The bandwidth for the hazard analysis is chosen based on the bandwidth for the 2049 age group mortality regression. For these regressions, the standard errors are clustered at the level of the month-of-birth cohort. Hazard rate regressions include calendar month-of-birth fixed effects, age fixed effects, and a fully-interacted linear polynomial in month-of-birth cohort relative to September 1957. The second set of estimates gives the estimated effect of the 1972 change in compulsory schooling laws on mortality rates between the ages specified. The death rate equals the number of deaths between the denoted ages divided by the size of the monthly birth cohort at birth multiplied by 1000 . All these mortality rate regressions use data by month-of-birth cohort from the Office of National Statistics. All mortality rate regessions include calendar month-of-birth fixed effects and are weighted by cohort size. For the non-hazard rate results, chosen bandwidths are based on a cross-validation procedure described in the text. Robust standard errors are presented in parentheses. 
Table 5a: The effects of education on health - 1947 change

\begin{tabular}{|c|c|c|c|c|c|c|}
\hline Outcome & 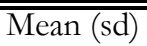 & $\overline{\mathrm{OLS}}$ & $\overline{\mathrm{RF}} \mathrm{w} / \mathrm{o} \mathrm{X}$ & $\overline{\overline{\mathrm{RF}}}$ & $\overline{\overline{I V}}$ & $\overline{\mathrm{N}}$ \\
\hline & \multicolumn{6}{|c|}{ Panel A: Self-reported } \\
\hline \multirow[t]{2}{*}{ Health fair or bad } & 0.35 & -0.088 & -0.008 & -0.009 & -0.018 & 18180 \\
\hline & & $(0.006)$ & $(0.012)$ & $(0.012)$ & $(0.025)$ & \\
\hline \multirow[t]{2}{*}{ Long illness } & 0.61 & -0.028 & 0.014 & 0.010 & 0.022 & 18186 \\
\hline & & $(0.006)$ & $(0.015)$ & $(0.014)$ & $(0.029)$ & \\
\hline \multirow[t]{3}{*}{ Reduced activity } & 0.19 & -0.019 & 0.001 & 0.001 & 0.001 & 18189 \\
\hline & & $(0.005)$ & $(0.010)$ & $(0.010)$ & $(0.021)$ & \\
\hline & \multicolumn{6}{|c|}{ Panel B: Objectively-measured } \\
\hline \multirow[t]{2}{*}{ Obese $(\mathrm{BMI}>30)$} & 0.25 & -0.023 & 0.027 & 0.026 & 0.054 & 16508 \\
\hline & & $(0.006)$ & $(0.014)$ & $(0.014)$ & $(0.031)$ & \\
\hline \multirow[t]{2}{*}{ Overweight $(\mathrm{BMI}>25)$} & 0.74 & -0.018 & -0.016 & -0.021 & -0.043 & 16508 \\
\hline & & $(0.006)$ & $(0.015)$ & $(0.014)$ & $(0.028)$ & \\
\hline \multirow[t]{2}{*}{ BMI } & 27.70 & -0.223 & 0.108 & 0.0703 & 0.148 & 16508 \\
\hline & $(4.50)$ & $(0.058)$ & $(0.138)$ & $(0.132)$ & $(0.273)$ & \\
\hline \multirow[t]{2}{*}{ Hypertension } & 0.62 & -0.024 & -0.020 & -0.018 & -0.036 & 13574 \\
\hline & & $(0.007)$ & $(0.015)$ & $(0.015)$ & $(0.031)$ & \\
\hline \multirow[t]{2}{*}{ Diastolic blood pressure } & 79.35 & -0.267 & 0.192 & 0.313 & 0.635 & 13574 \\
\hline & $(12.08)$ & $(0.163)$ & $(0.375)$ & $(0.371)$ & $(0.759)$ & \\
\hline
\end{tabular}

Notes: These estimates are based on Health Survey of England data: 1991-2004. Reported outcome means and standard deviations in parentheses (for continuous outcomes) are for the last pre-reform cohort. The column labeled OLS presents the ordinary least squares estimates, the column labeled RF w/o X presents the reducedform estimates excluding control variables, the column labeled RF presents the reduced-form estimates including control variables, the column labeled IV presents the instrumental variables estimates, and the column labeled $\mathrm{N}$ is the number of observations. Both the RF and IV estimates adjust for sex dummy, month-of-birth dummies, month- and year-of-interview dummies and third-order polynomial in age at time of survey (measured in months). Robust standard errors clustered at the month-of-birth level are presented in parentheses.

\begin{tabular}{|c|c|c|c|c|c|c|}
\hline Outcome & Mean & $\overline{\text { OLS }}$ & $\begin{array}{c}\mathrm{RF} \\
\mathrm{w} / \mathrm{o} \mathrm{X}\end{array}$ & $\overline{\mathrm{RF}}$ & 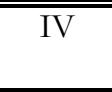 & $\overline{\mathrm{N}}$ \\
\hline Currently smoke & 0.20 & $\begin{array}{l}-0.056 \\
(0.005)\end{array}$ & $\begin{array}{l}-0.016 \\
(0.013)\end{array}$ & $\begin{array}{l}-0.010 \\
(0.013)\end{array}$ & $\begin{array}{l}-0.021 \\
(0.026)\end{array}$ & 18193 \\
\hline Ever smoke & 0.71 & $\begin{array}{l}-0.032 \\
(0.005)\end{array}$ & $\begin{array}{c}0.004 \\
(0.016)\end{array}$ & $\begin{array}{c}0.013 \\
(0.014)\end{array}$ & $\begin{array}{c}0.027 \\
(0.030)\end{array}$ & 18193 \\
\hline Currently drink & 0.80 & $\begin{array}{c}0.047 \\
(0.005)\end{array}$ & $\begin{array}{c}0.018 \\
(0.011)\end{array}$ & $\begin{array}{c}0.017 \\
(0.010)\end{array}$ & $\begin{array}{c}0.036 \\
(0.021)\end{array}$ & 18190 \\
\hline Eat fruit daily & 0.65 & $\begin{array}{c}0.053 \\
(0.007)\end{array}$ & $\begin{array}{c}0.015 \\
(0.019)\end{array}$ & $\begin{array}{c}0.013 \\
(0.016)\end{array}$ & $\begin{array}{c}0.028 \\
(0.036)\end{array}$ & 11781 \\
\hline Each veg daily & 0.65 & $\begin{array}{c}0.054 \\
(0.007)\end{array}$ & $\begin{array}{c}0.033 \\
(0.016)\end{array}$ & $\begin{array}{c}0.041 \\
(0.015)\end{array}$ & $\begin{array}{c}0.090 \\
(0.030)\end{array}$ & 11768 \\
\hline Take vitamins & 0.35 & $\begin{array}{c}0.041 \\
(0.007)\end{array}$ & $\begin{array}{c}0.027 \\
(0.019)\end{array}$ & $\begin{array}{c}0.023 \\
(0.019)\end{array}$ & $\begin{array}{c}0.046 \\
(0.038)\end{array}$ & 14311 \\
\hline Physically active & 0.33 & $\begin{array}{r}0.046 \\
(0.007) \\
\end{array}$ & $\begin{array}{c}0.003 \\
(0.018) \\
\end{array}$ & $\begin{array}{c}0.007 \\
(0.017) \\
\end{array}$ & $\begin{array}{c}0.014 \\
(0.036) \\
\end{array}$ & 10855 \\
\hline
\end{tabular}

Notes: See notes for Table 5a. 
Table 6a: The effects of education on health -1972 change

\begin{tabular}{|c|c|c|c|c|c|c|}
\hline Outcome & Mean (sd) & OLS & RF w/o X & $\overline{\mathrm{RF}}$ & $\overline{\mathrm{IV}}$ & $\overline{\mathrm{N}}$ \\
\hline \multicolumn{7}{|c|}{ Panel A: Self-reported health measures } \\
\hline \multirow[t]{2}{*}{ Health fair or bad } & 0.18 & -0.072 & -0.004 & -0.005 & -0.017 & 19913 \\
\hline & & $(0.008)$ & $(0.011)$ & $(0.010)$ & $(0.036)$ & \\
\hline \multirow[t]{2}{*}{ Long illness } & 0.37 & -0.049 & -0.001 & -0.0001 & -0.001 & 19910 \\
\hline & & $(0.009)$ & $(0.013)$ & $(0.0124)$ & $(0.044)$ & \\
\hline \multirow[t]{3}{*}{ Reduced activity } & 0.16 & -0.031 & -0.024 & -0.025 & -0.091 & 19907 \\
\hline & & $(0.007)$ & $(0.011)$ & $(0.010)$ & $(0.038)$ & \\
\hline & \multicolumn{6}{|c|}{ Panel B: Objective health measures } \\
\hline \multirow[t]{2}{*}{ Obese $(\mathrm{BMI}>30)$} & 0.18 & -0.029 & -0.008 & -0.006 & -0.023 & 18473 \\
\hline & & $(0.008)$ & $(0.010)$ & $(0.010)$ & $(0.037)$ & \\
\hline \multirow[t]{2}{*}{ Overweight (BMI>25) } & 0.56 & -0.025 & 0.010 & 0.007 & 0.027 & 18473 \\
\hline & & $(0.009)$ & $(0.015)$ & $(0.014)$ & $(0.052)$ & \\
\hline \multirow[t]{2}{*}{ BMI } & 26.28 & -0.338 & 0.044 & 0.042 & 0.155 & 18473 \\
\hline & (4.71) & $(0.097)$ & $(0.129)$ & $(0.122)$ & $(0.443)$ & \\
\hline \multirow[t]{2}{*}{ Hypertension } & 0.20 & -0.002 & 0.004 & 0.003 & 0.009 & 15097 \\
\hline & & $(0.009)$ & (0.013) & $(0.014)$ & $(0.049)$ & \\
\hline \multirow[t]{2}{*}{ Diastolic blood pressure } & 74.17 & -0.115 & 0.300 & 0.274 & 0.985 & 15097 \\
\hline & $(10.48)$ & $(0.225)$ & $(0.361)$ & $(0.342)$ & (1.235) & \\
\hline
\end{tabular}

Notes: These estimates are based on Health Survey of England data: 1991-2004. Reported outcome means and standard deviations in parentheses (for continuous outcomes) are for the last pre-reform cohort. The column labeled OLS presents the ordinary least squares estimates, the column labeled RF w/o X presents the reducedform estimates excluding control variables, the column labeled RF presents the reduced-form estimates including control variables, the column labeled IV presents the instrumental variables estimates, and the column labeled $\mathrm{N}$ is the number of observations. Both the RF and IV estimates adjust for sex dummy, month-of-birth dummies, month- and year-of-interview dummies and third-order polynomial in age at time of survey (measured in months). Robust standard errors clustered at the month-of-birth level are presented in parentheses.

\begin{tabular}{|c|c|c|c|c|c|c|}
\hline Outcome & Mean & 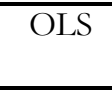 & $\begin{array}{c}\mathrm{RF} \\
\mathrm{w} / \mathrm{O} \mathrm{X}\end{array}$ & $\overline{\mathrm{RF}}$ & 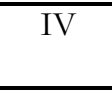 & $\overline{\mathrm{N}}$ \\
\hline Currently smoke & 0.30 & $\begin{array}{l}-0.118 \\
(0.009)\end{array}$ & $\begin{array}{c}0.008 \\
(0.014)\end{array}$ & $\begin{array}{c}0.010 \\
(0.013)\end{array}$ & $\begin{array}{c}0.036 \\
(0.048)\end{array}$ & 19919 \\
\hline Ever smoke & 0.66 & $\begin{array}{l}-0.076 \\
(0.008)\end{array}$ & $\begin{array}{l}-0.002 \\
(0.012)\end{array}$ & $\begin{array}{l}-0.004 \\
(0.012)\end{array}$ & $\begin{array}{l}-0.014 \\
(0.041)\end{array}$ & 19919 \\
\hline Currently drink & 0.91 & $\begin{array}{c}0.027 \\
(0.006)\end{array}$ & $\begin{array}{c}0.010 \\
(0.008)\end{array}$ & $\begin{array}{c}0.009 \\
(0.008)\end{array}$ & $\begin{array}{c}0.031 \\
(0.028)\end{array}$ & 19916 \\
\hline Eat fruit daily & 0.52 & $\begin{array}{c}0.060 \\
(0.011)\end{array}$ & $\begin{array}{c}0.000 \\
(0.014)\end{array}$ & $\begin{array}{l}-0.001 \\
(0.014)\end{array}$ & $\begin{array}{l}-0.002 \\
(0.050)\end{array}$ & 12907 \\
\hline Each veg daily & 0.56 & $\begin{array}{c}0.040 \\
(0.011)\end{array}$ & $\begin{array}{l}-0.018 \\
(0.019)\end{array}$ & $\begin{array}{l}-0.007 \\
(0.019)\end{array}$ & $\begin{array}{l}-0.026 \\
(0.067)\end{array}$ & 12899 \\
\hline Take vitamins & 0.24 & $\begin{array}{c}0.037 \\
(0.009)\end{array}$ & $\begin{array}{c}0.008 \\
(0.014)\end{array}$ & $\begin{array}{c}0.010 \\
(0.013)\end{array}$ & $\begin{array}{c}0.033 \\
(0.045)\end{array}$ & 16050 \\
\hline Physically & 0.54 & $\begin{array}{c}0.065 \\
(0.012)\end{array}$ & $\begin{array}{l}-0.015 \\
(0.019)\end{array}$ & $\begin{array}{l}-0.015 \\
(0.019)\end{array}$ & $\begin{array}{l}-0.059 \\
(0.076)\end{array}$ & 11785 \\
\hline
\end{tabular}

Notes: See notes for Table 6a. 
Table 7: The impact of the compulsory schooling changes on selfreported health

\begin{tabular}{|c|c|c|c|c|c|}
\hline & $(1)$ & $(2)$ & (3) & (4) & $(5)$ \\
\hline & Dep var & & & RF w/o X & $\mathrm{RF}$ w/o X \\
\hline & mean & $\mathrm{RF} w / \mathrm{o} \mathrm{X}$ & $\mathrm{RF} w / \mathrm{X}$ & Female & Male \\
\hline & \multicolumn{5}{|c|}{ Panel A: 1947 ROSLA } \\
\hline \multirow[t]{2}{*}{ Health fair or bad (2001) } & 57.45 & -0.460 & -0.381 & -0.492 & -0.266 \\
\hline & & $(0.217)$ & $(0.190)$ & $(0.224)$ & $(0.308)$ \\
\hline \multirow[t]{2}{*}{ Health bad (2001) } & 17.66 & -0.319 & -0.345 & -0.268 & -0.424 \\
\hline & & $(0.206)$ & $(0.154)$ & $(0.163)$ & $(0.253)$ \\
\hline \multirow[t]{2}{*}{ Limiting long-term illness (2001) } & 39.59 & -0.192 & -0.070 & 0.063 & -0.212 \\
\hline & & $(0.203)$ & $(0.180)$ & $(0.188)$ & $(0.324)$ \\
\hline \multirow[t]{3}{*}{ Limiting long-term illness (1991) } & 21.42 & 0.215 & 0.169 & 0.129 & 0.210 \\
\hline & & $(0.155)$ & $(0.109)$ & $(0.162)$ & $(0.216)$ \\
\hline & \multicolumn{5}{|c|}{ Panel B: 1972 ROSLA } \\
\hline \multirow[t]{2}{*}{ Health fair or bad (2001) } & 31.43 & -0.478 & -0.152 & -0.055 & -0.243 \\
\hline & & $(0.162)$ & $(0.107)$ & $(0.171)$ & $(0.175)$ \\
\hline \multirow[t]{2}{*}{ Health bad (2001) } & 8.38 & -0.169 & -0.069 & -0.027 & -0.109 \\
\hline & & $(0.077)$ & $(0.068)$ & $(0.083)$ & $(0.097)$ \\
\hline \multirow[t]{2}{*}{ Limiting long-term illness (2001) } & 13.74 & -0.183 & -0.087 & -0.097 & -0.077 \\
\hline & & $(0.073)$ & $(0.072)$ & $(0.100)$ & $(0.111)$ \\
\hline \multirow[t]{2}{*}{ Limiting long-term illness (1991) } & 5.10 & -0.095 & -0.048 & -0.048 & -0.048 \\
\hline & & $(0.049)$ & $(0.046)$ & $(0.073)$ & $(0.070)$ \\
\hline
\end{tabular}

Notes: These estimates based on 1991 or 2001 Census data. Reported outcome means are for the last prereform cohort. The column labeled RF w/o X presents the reduced-form estimates excluding control variables and the column labeled RF presents the reduced-form estimates including control variables. Columns (2) and (3) estimates adjust for sex and month-of-birth dummies. Robust standard errors are presented in parentheses. 


\section{Appendix Table A1a: Pooled models of the effects of education on health - 1947 change}

\begin{tabular}{|c|c|c|c|c|c|c|}
\hline Outcome & Mean & OLS & RF w/o X & $\mathrm{RF}$ & IV & $\mathrm{N}$ \\
\hline \multicolumn{7}{|c|}{ Panel A: Health measures } \\
\hline \multirow[t]{2}{*}{ Health fair or bad } & 0.25 & -0.068 & 0.008 & 0.006 & 0.013 & 40899 \\
\hline & & $(0.003)$ & $(0.007)$ & $(0.007)$ & $(0.016)$ & \\
\hline \multirow[t]{2}{*}{ Long illness } & 0.54 & -0.030 & 0.024 & 0.021 & 0.046 & 40909 \\
\hline & & $(0.004)$ & $(0.009)$ & $(0.009)$ & $(0.020)$ & \\
\hline \multirow[t]{3}{*}{ Reduced activity } & 0.17 & -0.020 & 0.009 & 0.008 & 0.018 & 40915 \\
\hline & & $(0.003)$ & $(0.007)$ & $(0.007)$ & $(0.016)$ & \\
\hline & \multicolumn{6}{|c|}{ Panel B: Health behaviors } \\
\hline \multirow[t]{2}{*}{ Currently smoke } & 0.23 & -0.058 & -0.015 & -0.007 & -0.015 & 29570 \\
\hline & & $(0.004)$ & $(0.011)$ & $(0.010)$ & $(0.022)$ & \\
\hline \multirow[t]{2}{*}{ Ever smoke } & 0.74 & -0.028 & 0.007 & 0.014 & 0.031 & 29566 \\
\hline & & $(0.004)$ & $(0.012)$ & $(0.011)$ & $(0.023)$ & \\
\hline \multirow{2}{*}{ Currently drink } & 0.81 & 0.044 & 0.011 & 0.013 & 0.028 & 29567 \\
\hline & & (0.004) & $(0.008)$ & $(0.008)$ & $(0.016)$ & \\
\hline
\end{tabular}

Notes: These estimates are based on models that pool GHS data for 1986-1996 and HSE data for 1991-2004.

The column labeled "OLS" presents the ordinary least squares estimates, the column labeled RF w/o X presents the reduced-form estimates excluding control variables, the column labeled RF presents the reduced-form estimates including control variables, the column labeled IV presents the instrumental variables estimates, and the column labeled $\mathrm{N}$ is the number of observations. Both the RF and IV estimates adjust for GHS dummy, sex dummy, calendar month-of-birth dummies, month- and year-of-interview dummies and a third-order polynomial in age at time of survey (measured in months). Robust standard errors clustered at the month-of-birth level are presented in parentheses. The reported mean is the mean for the last pre-reform cohort.

\begin{tabular}{|c|c|c|c|c|c|c|}
\hline \multicolumn{2}{|l|}{ Individual outcomes } & $\overline{\text { OLS }}$ & $\begin{array}{c}\mathrm{RF} \\
\mathrm{w} / \mathrm{oXX}\end{array}$ & $\overline{\overline{R F}}$ & $\overline{\mathrm{IV}}$ & $\overline{\mathrm{N}}$ \\
\hline Health bad, longstanding & Avg coeff & -0.045 & 0.002 & 0.001 & 0.002 & \\
\hline illness, reduced activity & $\begin{array}{l}\text { Std coeffs } \\
\text { (se) }\end{array}$ & $\begin{array}{l}-0.096 \\
(0.008) \\
\end{array}$ & $\begin{array}{c}0.005 \\
(0.019) \\
\end{array}$ & $\begin{array}{l}-0.002 \\
(0.019) \\
\end{array}$ & $\begin{array}{l}-0.004 \\
(0.039) \\
\end{array}$ & 54555 \\
\hline $\begin{array}{l}\text { Obese, overweight, } \\
\text { hypertension }\end{array}$ & $\begin{array}{l}\text { Avg coeff } \\
\text { Std coeffs } \\
\text { (se) }\end{array}$ & $\begin{array}{l}-0.021 \\
-0.053 \\
(0.009) \\
\end{array}$ & $\begin{array}{l}-0.018 \\
-0.005 \\
(0.022) \\
\end{array}$ & $\begin{array}{l}-0.019 \\
-0.008 \\
(0.022) \\
\end{array}$ & $\begin{array}{l}-0.039 \\
-0.016 \\
(0.044) \\
\end{array}$ & 46590 \\
\hline $\begin{array}{l}\text { Currently smoke, ever } \\
\text { smoke }\end{array}$ & $\begin{array}{l}\text { Avg coeff } \\
\text { Std coeffs } \\
\text { (se) }\end{array}$ & $\begin{array}{l}-0.044 \\
-0.081 \\
(0.008) \\
\end{array}$ & $\begin{array}{l}-0.006 \\
-0.015 \\
(0.029) \\
\end{array}$ & $\begin{array}{c}0.001 \\
0.001 \\
(0.027) \\
\end{array}$ & $\begin{array}{c}0.003 \\
0.001 \\
(0.056) \\
\end{array}$ & 36386 \\
\hline $\begin{array}{l}\text { Eat fruit, eat veg, take } \\
\text { vitamins, active }\end{array}$ & $\begin{array}{l}\text { Avg coeff } \\
\text { Std coeffs } \\
\text { (se) }\end{array}$ & $\begin{array}{c}0.049 \\
0.083 \\
(0.007) \\
\end{array}$ & $\begin{array}{c}0.019 \\
0.041 \\
(0.023) \\
\end{array}$ & $\begin{array}{c}0.021 \\
0.044 \\
(0.021) \\
\end{array}$ & $\begin{array}{c}0.045 \\
0.093 \\
(0.042) \\
\end{array}$ & 48715 \\
\hline
\end{tabular}

Notes: Each panel presents summary estimates for the group of variables listed in the first column. The first row of each panel presents the average of the individual estimates from Table 5. The second row presents the average of the standardized estimates (see text for details). The third row reports the associated standard error of this standardized summary measure (see text for details). See Appendix Table A1a for description of the columns. 


\section{Appendix Table A2a: Pooled models of the effects of education on health - 1972 change}

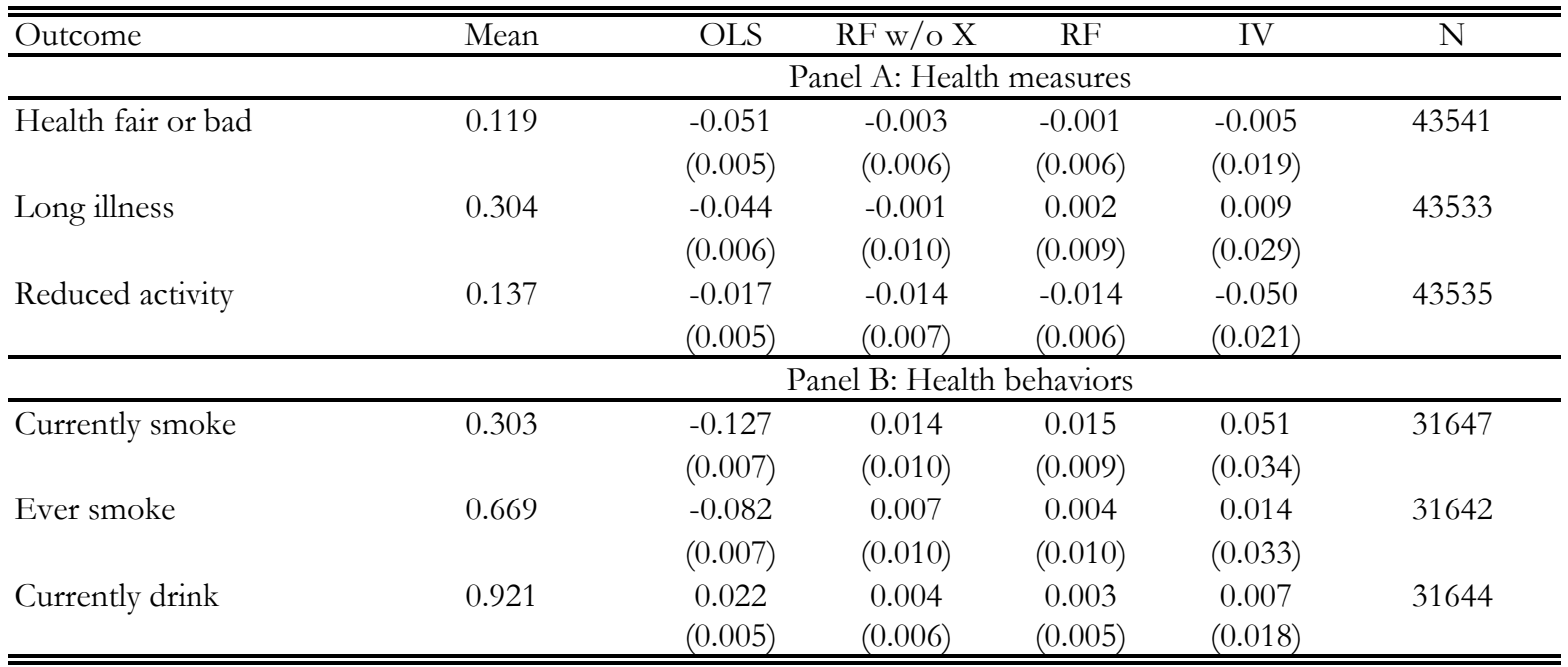

Notes: These estimates based on models that pool GHS data for 1986-1996 and HSE data for 1991-2004. The reported mean is the mean for the last pre-reform cohort. The column labeled "OLS" presents the ordinary least squares estimates, the column labeled RF w/o X presents the reduced-form estimates excluding control variables, the column labeled RF presents the reduced-form estimates including control variables, the column labeled IV presents the instrumental variables estimates, and the column labeled $\mathrm{N}$ is the number of observations. Both the RF and IV estimates adjust for GHS dummy, sex dummy, calendar month-of-birth dummies, month- and year-ofinterview dummies and a third-order polynomial in age at time of survey (measured in months). Robust standard errors clustered at the month-of-birth level are presented in parentheses.

\begin{tabular}{|c|c|c|c|c|c|c|}
\hline$\overline{\text { Outcome }}$ & & $\overline{\text { OLS }}$ & $\begin{array}{c}\mathrm{RF} \\
\mathrm{w} / \mathrm{o} \mathrm{X}\end{array}$ & $\overline{\mathrm{RF}}$ & $\overline{\mathrm{IV}}$ & $\overline{\mathrm{N}}$ \\
\hline Health bad, longstanding & Avg coeff & -0.072 & -0.004 & -0.005 & -0.017 & \\
\hline illness, reduced activity & $\begin{array}{l}\text { Std coeffs } \\
\text { (se) }\end{array}$ & $\begin{array}{l}-0.124 \\
(0.015) \\
\end{array}$ & $\begin{array}{l}-0.026 \\
(0.023) \\
\end{array}$ & $\begin{array}{c}-0.026 \\
(0.018) \\
\end{array}$ & $\begin{array}{l}-0.093 \\
(0.067) \\
\end{array}$ & 59730 \\
\hline $\begin{array}{l}\text { Obese, overweight, } \\
\text { hypertension }\end{array}$ & $\begin{array}{l}\text { Avg coeff } \\
\text { Std coeffs } \\
\text { (se) }\end{array}$ & $\begin{array}{l}-0.027 \\
-0.064 \\
(0.014) \\
\end{array}$ & $\begin{array}{c}0.001 \\
0.003 \\
(0.022) \\
\end{array}$ & $\begin{array}{c}0.000 \\
0.005 \\
(0.022) \\
\end{array}$ & $\begin{array}{c}0.002 \\
0.020 \\
(0.082) \\
\end{array}$ & 52043 \\
\hline $\begin{array}{l}\text { Currently smoke, ever } \\
\text { smoke }\end{array}$ & $\begin{array}{l}\text { Avg coeff } \\
\text { Std coeffs } \\
\text { (se) }\end{array}$ & $\begin{array}{l}-0.097 \\
-0.176 \\
(0.014) \\
\end{array}$ & $\begin{array}{c}0.003 \\
0.007 \\
(0.024) \\
\end{array}$ & $\begin{array}{c}0.003 \\
0.007 \\
(0.023) \\
\end{array}$ & $\begin{array}{c}0.011 \\
0.026 \\
(0.085) \\
\end{array}$ & 39838 \\
\hline $\begin{array}{l}\text { Eat fruit, eat veg, take } \\
\text { vitamins, active }\end{array}$ & $\begin{array}{l}\text { Avg coeff } \\
\text { Std coeffs } \\
\text { (se) }\end{array}$ & $\begin{array}{c}0.050 \\
0.079 \\
(0.012)\end{array}$ & $\begin{array}{l}-0.006 \\
-0.011 \\
(0.019)\end{array}$ & $\begin{array}{l}-0.003 \\
-0.007 \\
(0.019)\end{array}$ & $\begin{array}{l}-0.013 \\
-0.028 \\
(0.072)\end{array}$ & 53641 \\
\hline
\end{tabular}

Notes: Each panel presents summary estimates for the group of variables listed in the first column. The first row of each panel presents the average of the individual estimates from Table 6. The second row presents the average of the standardized estimates (see text for details). The third row reports the associated standard error of this standardized summary measure (see text for details). See Appendix Table A2a for description of the columns. 


\begin{tabular}{|c|c|c|c|c|c|c|}
\hline Outcome & Mean (sd) & OLS & IV-2 & IV-3 & IV-4 & $\mathrm{N}$ \\
\hline Health fair or bad & 0.25 & $\begin{array}{l}-0.081 \\
(0.003)\end{array}$ & $\begin{array}{c}-0.002 \\
(0.014) \\
0.94 \\
\end{array}$ & $\begin{array}{c}-0.002 \\
(0.014) \\
0.96 \\
\end{array}$ & $\begin{array}{c}-0.005 \\
(0.014) \\
0.62 \\
\end{array}$ & 106589 \\
\hline Long illness & 0.46 & $\begin{array}{l}-0.033 \\
(0.003)\end{array}$ & $\begin{array}{c}0.014 \\
(0.016) \\
0.19 \\
\end{array}$ & $\begin{array}{c}0.012 \\
(0.015) \\
0.21 \\
\end{array}$ & $\begin{array}{c}0.023 \\
(0.016) \\
0.79 \\
\end{array}$ & 106601 \\
\hline Reduced activity & 0.16 & $\begin{array}{l}-0.021 \\
(0.002)\end{array}$ & $\begin{array}{c}0.013 \\
(0.012) \\
0.73 \\
\end{array}$ & $\begin{array}{c}0.014 \\
(0.012) \\
0.77 \\
\end{array}$ & $\begin{array}{c}0.014 \\
(0.012) \\
0.24 \\
\end{array}$ & 106578 \\
\hline Obese (BMI >30) & 0.21 & $\begin{array}{l}-0.024 \\
(0.003)\end{array}$ & $\begin{array}{c}0.018 \\
(0.016) \\
0.27\end{array}$ & $\begin{array}{c}0.016 \\
(0.015) \\
0.31\end{array}$ & $\begin{array}{c}0.028 \\
(0.016) \\
0.39\end{array}$ & 97115 \\
\hline Overweight (BMI>25) & 0.62 & $\begin{array}{l}-0.012 \\
(0.003)\end{array}$ & $\begin{array}{c}0.010 \\
(0.017) \\
0.22\end{array}$ & $\begin{array}{c}0.003 \\
(0.016) \\
0.29\end{array}$ & $\begin{array}{c}-0.0003 \\
(0.017) \\
0.12\end{array}$ & 97115 \\
\hline$\overline{\mathrm{BMI}}$ & $\begin{array}{l}26.83 \\
(4.63)\end{array}$ & $\begin{array}{l}-0.215 \\
(0.030)\end{array}$ & $\begin{array}{c}0.270 \\
(0.173) \\
0.02 \\
\end{array}$ & $\begin{array}{c}0.205 \\
(0.164) \\
0.04 \\
\end{array}$ & $\begin{array}{c}0.312 \\
(0.162) \\
0.43 \\
\end{array}$ & 97115 \\
\hline Hypertension & 0.36 & $\begin{array}{l}-0.015 \\
(0.003)\end{array}$ & $\begin{array}{c}-0.029 \\
(0.018) \\
0.54\end{array}$ & $\begin{array}{c}-0.029 \\
(0.018) \\
0.55\end{array}$ & $\begin{array}{c}-0.025 \\
(0.018) \\
0.96\end{array}$ & 79298 \\
\hline Diastolic blood pressure & $\begin{array}{c}76.0 \\
(11.86)\end{array}$ & $\begin{array}{l}-0.206 \\
(0.084)\end{array}$ & $\begin{array}{c}-0.094 \\
(0.445) \\
0.06\end{array}$ & $\begin{array}{c}0.038 \\
(0.423) \\
0.09\end{array}$ & $\begin{array}{c}-0.389 \\
(0.423) \\
0.34\end{array}$ & 79298 \\
\hline
\end{tabular}

Notes: This table presents estimates of the effects of years of education on various outcomes using data from the Health Survey of England (pooled waves 1991-2004). The instruments are 1) a dummy variable equal to 1 if subject to the 1947 ROSLA and equal to 0 otherwise and 2) a dummy variable equal to 1 if subject to the 1972 ROSLA and equal to 0 otherwise. Over-identification test statistics ( $\mathrm{p}$-values) are presented in the third row of each panel. Estimates in the IV-2 column are based on a second-order polynomial in age, estimates in the IV-3 and IV-4 columns are based on third- and fourth-order polynomials in age respectively. The models also regression adjust for sex, calendar month-of-birth dummies and year- and month-of-survey dummies. The IV estimates also adjust for a polynomial in month of birth. Robust standard errors are clustered by month of birth. Mean (sd) refers to the mean (standard deviation for continuous outcomes) of the entire sample. 


\begin{tabular}{|c|c|c|c|c|c|c|}
\hline Outcome & Mean (sd) & OLS & IV-2 & $\overline{\mathrm{IV}-3}$ & $\overline{\mathrm{IV}-4}$ & $\overline{\mathrm{N}}$ \\
\hline Currently smoke & 0.27 & $\begin{array}{l}-0.072 \\
(0.003)\end{array}$ & $\begin{array}{c}-0.017 \\
(0.014) \\
0.21 \\
\end{array}$ & $\begin{array}{c}-0.020 \\
(0.014) \\
0.17 \\
\end{array}$ & $\begin{array}{c}-0.035 \\
(0.014) \\
0.50 \\
\end{array}$ & 106632 \\
\hline Ever smoke & 0.71 & $\begin{array}{l}-0.040 \\
(0.003)\end{array}$ & $\begin{array}{c}-0.004 \\
(0.017) \\
0.00 \\
\end{array}$ & $\begin{array}{c}-0.007 \\
(0.017) \\
0.00 \\
\end{array}$ & $\begin{array}{c}-0.041 \\
(0.016) \\
0.51 \\
\end{array}$ & 106632 \\
\hline Currently drink & 0.87 & $\begin{array}{c}0.042 \\
(0.002)\end{array}$ & $\begin{array}{c}0.003 \\
(0.012) \\
0.53 \\
\end{array}$ & $\begin{array}{c}0.003 \\
(0.011) \\
0.53 \\
\end{array}$ & $\begin{array}{c}0.006 \\
(0.011) \\
0.9 \\
\end{array}$ & 106618 \\
\hline Eat fruit daily & 0.58 & $\begin{array}{c}0.056 \\
(0.004)\end{array}$ & $\begin{array}{c}0.066 \\
(0.019) \\
0.20\end{array}$ & $\begin{array}{c}0.054 \\
(0.019) \\
0.12\end{array}$ & $\begin{array}{c}0.037 \\
(0.019) \\
0.65\end{array}$ & 69094 \\
\hline Each veg daily & 0.61 & $\begin{array}{c}0.043 \\
(0.004)\end{array}$ & $\begin{array}{c}0.053 \\
(0.019) \\
0.61\end{array}$ & $\begin{array}{c}0.039 \\
(0.018) \\
0.43\end{array}$ & $\begin{array}{c}0.025 \\
(0.019) \\
0.44\end{array}$ & 69045 \\
\hline Take vitamins & 0.29 & $\begin{array}{c}0.035 \\
(0.003)\end{array}$ & $\begin{array}{c}0.005 \\
(0.019) \\
0.01 \\
\end{array}$ & $\begin{array}{c}0.004 \\
(0.018) \\
0.01 \\
\end{array}$ & $\begin{array}{c}-0.014 \\
(0.019) \\
0.65 \\
\end{array}$ & 84411 \\
\hline Active & 0.44 & $\begin{array}{c}0.055 \\
(0.004)\end{array}$ & $\begin{array}{c}-0.025 \\
(0.019) \\
0.01\end{array}$ & $\begin{array}{c}-0.025 \\
(0.019) \\
0.01\end{array}$ & $\begin{array}{c}-0.001 \\
(0.019) \\
0.86\end{array}$ & 63064 \\
\hline
\end{tabular}

Notes: This table presents estimates of the effects of years of education on various outcomes using data from the Health Survey of England (pooled waves 1991-2004). The instruments are 1) a dummy variable equal to 1 if subject to the 1947 ROSLA and equal to 0 otherwise and 2) a dummy variable equal to 1 if subject to the 1972 ROSLA and equal to 0 otherwise. Over-identification test statistics ( $\mathrm{p}$-values) are presented in the third row of each panel. Estimates in the IV-2 column are based on a second-order polynomial in age, estimates in the IV-3 and IV-4 columns are based on third- and fourth-order polynomials in age respectively. The models also regression adjust for sex, calendar month-of-birth dummies and year- and month-of-survey dummies. The IV estimates also adjust for a polynomial in month of birth. Robust standard errors are clustered by month of birth. Mean (sd) refers to the mean (standard deviation for continuous outcomes) of the entire sample. 


\section{Appendix Table C1: Earnings impact of 1947 change to compulsory schooling}

\begin{tabular}{|c|c|c|c|c|c|c|c|c|c|c|c|c|}
\hline & \multicolumn{6}{|c|}{ Panel A: Men } & \multicolumn{6}{|c|}{ Panel B: Women } \\
\hline & \multicolumn{2}{|c|}{ Log Weekly Earnings } & \multicolumn{2}{|c|}{ Log Hourly Earnings } & \multicolumn{2}{|c|}{ Observed Working } & \multicolumn{2}{|c|}{ Log Weekly Earnings } & \multicolumn{2}{|c|}{ Log Hourly Earnings } & \multicolumn{2}{|c|}{ Observed Working } \\
\hline & $(1)$ & $(2)$ & $(1)$ & $(2)$ & $(1)$ & $(2)$ & $(1)$ & $(2)$ & $(1)$ & $(2)$ & $(1)$ & $(2)$ \\
\hline \multirow[t]{2}{*}{ Hours: $1-84$} & 0.079 & 0.078 & 0.045 & 0.048 & 0.017 & -0.006 & -0.069 & -0.078 & -0.042 & -0.030 & 0.017 & 0.015 \\
\hline & $(0.028)$ & $(0.038)$ & $(0.023)$ & $(0.031)$ & $(0.017)$ & $(0.023)$ & $(0.044)$ & $(0.053)$ & $(0.025)$ & $(0.032)$ & $(0.016)$ & $(0.021)$ \\
\hline $\mathrm{N}$ & 11964 & 3462 & 11964 & 3462 & 22553 & 7181 & 11133 & 3075 & 11133 & 3075 & 24364 & 7792 \\
\hline \multirow[t]{2}{*}{ Normal hours } & 0.053 & 0.043 & 0.040 & 0.027 & 0.028 & 0.005 & -0.065 & -0.057 & -0.050 & -0.023 & 0.005 & 0.004 \\
\hline & $(0.022)$ & $(0.030)$ & $(0.022)$ & $(0.030)$ & $(0.015)$ & $(0.019)$ & $(0.043)$ & $(0.050)$ & $(0.025)$ & $(0.030)$ & $(0.015)$ & $(0.021)$ \\
\hline $\mathrm{N}$ & 11022 & 3156 & 11022 & 3156 & 22553 & 7181 & 10152 & 2787 & 10152 & 2787 & 24364 & 7792 \\
\hline
\end{tabular}

Notes: In column (1) we report reduced-form estimates from a global polynomial regression specification similar to that used by Devereux and Hart (2008), the main

difference being that the column (1) estimates are generated using a month-of-birth discontinuity design, as opposed to the year-of-birth discontinuity design of Devereux and Hart (2008). In column (2) we report reduced-form estimates from local linear regression models of outcomes on calendar birth month, a dummy for birth month after April 1933, and an interaction of birth month and this dummy. The bandwidth is 40 months on either side of April 1933. The observed working outcomes refer to the probability of being observed to work 1-84 hours (in the top panel) and working normal hours in the bottom panel. These are not conditional on working at all, hence can be interpreted as the probability of being in the samples used in the earnings analysis. Normal hours, determined from the data, are defined as 35-60 for males and 10-50 for females.

\section{Appendix Table C2: Earnings impact of 1972 change to compulsory schooling laws}

\begin{tabular}{|c|c|c|c|c|c|c|}
\hline & \multicolumn{3}{|c|}{ Panel A: Men } & \multicolumn{3}{|c|}{ Panel B: Women } \\
\hline & Log Weekly Earnings & Log Hourly Earnings & Observed Working & Log Weekly Earnings & Log Hourly Earnings & Observed Working \\
\hline \multirow[t]{2}{*}{ Hours: $1-84$} & -0.0004 & 0.003 & 0.008 & -0.014 & 0.015 & -0.029 \\
\hline & $(0.025)$ & $(0.022)$ & $(0.016)$ & $(0.044)$ & $(0.027)$ & $(0.018)$ \\
\hline $\mathrm{N}$ & 6545 & 6545 & 9327 & 5964 & 5964 & 10462 \\
\hline \multirow[t]{2}{*}{ Normal hours } & 0.004 & 0.007 & 0.014 & 0.034 & 0.013 & -0.050 \\
\hline & $(0.022)$ & $(0.021)$ & $(0.016)$ & $(0.044)$ & $(0.030)$ & $(0.019)$ \\
\hline $\mathrm{N}$ & 6168 & 6168 & 9327 & 5359 & 5359 & 10462 \\
\hline
\end{tabular}

Notes: We report reduced-form estimates from local linear regression models using the month-of-birth discontinuity design of outcomes on calendar birth month, a dummy for birth month after September 1957, and an interaction of birth month and this dummy. The bandwidth is 40 months on either side of September 1957 . Normal hours, determined from the data, are defined as 35-60 for males and 10-50 for females. 


\section{Appendix Table D1: Effect of 1947 change to compulsory schooling laws on migration to US}

Reduced-Form Estimate

Percent in US for 1933Q1

Bandwidth

Dataset

Observations

Reduced-Form Estimate

Percent in US for 1933Q1

Bandwidth

Dataset

Observations

Reduced-Form Estimate

Percent in US for 1933Q1

Bandwidth

Dataset

Observations

\begin{tabular}{cccccc}
\hline \hline \multicolumn{7}{c}{ Panel A: Men } \\
\hline 0.928 & 0.940 & 0.008 & 0.225 & 0.743 & 0.316 \\
$(0.342)$ & $(0.380)$ & $(0.137)$ & $(0.256)$ & $(0.236)$ & $(0.217)$
\end{tabular}

1.92

2.41

2.45

2.57

2.23

2.59

26

26

44

44

42

1960 Census

1970 Census

1980 Census

51

69

51

2005 ACS

2006 ACS

2007 ACS

87

87

83

\begin{tabular}{cccccc}
\hline \hline \multicolumn{7}{c}{ Panel B: Women } \\
\hline-0.028 & 0.039 & 0.007 & 0.250 & 0.257 & -0.085 \\
$(0.123)$ & $(0.294)$ & $(0.117)$ & $(0.182)$ & $(0.206)$ & $(0.197)$
\end{tabular}

\begin{tabular}{cccccc}
1.05 & 1.32 & 1.00 & 0.91 & 1.92 & 1.98 \\
40 & 39 & 27 & 35 & 43 & 34 \\
1960 Census & 1970 Census & 1980 Census & 2005 ACS & 2006 ACS & 2007 ACS \\
79 & 77 & 53 & 69 & 85 & 67 \\
& \multicolumn{7}{c}{ Panel C: Overall } \\
\hline \hline 0.131 & 0.619 & 0.023 & 0.172 & 0.492 & 0.092 \\
$(0.137)$ & $(0.230)$ & $(0.070)$ & $(0.152)$ & $(0.173)$ & $(0.137)$ \\
1.47 & 1.85 & 1.71 & 1.72 & 2.07 & 2.27 \\
49 & 40 & 27 & 47 & 44 & 37 \\
1960 Census & 1970 Census & 1980 Census & 2005 ACS & 2006 ACS & 2007 ACS \\
97 & 79 & 53 & 93 & 87 & 73
\end{tabular}

Notes: This table presents regression discontinuity estimates of the effect of the 1947 reform on immigration to the United States from Britain. The bandwidth is chosen using the cross-validation procedure discussed in the text. These regressions include a fullyinteracted linear polynomial in quarter-of-birth cohort relative to April 1947. The migration rate equals the number of persons appearing in the US dataset divided by the size of the quarterly birth cohort at birth multiplied by 100 . All of these regressions use data by quarter-of-birth birth cohort from the Office of National Statistics. Reported bandwidths are in quarters. Robust standard errors are presented in parentheses. 